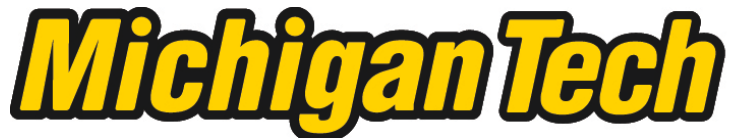 \\ Michigan Technological University Create the Future Digital Commons @ Michigan Tech
}

\section{Exploration of Ground Penetrating Radar and Time Domain Reflectometry Methods for the Determination of Pavement Dielectric Constant}

\author{
Baron W. Colbert \\ Michigan Technological University
}

Follow this and additional works at: https://digitalcommons.mtu.edu/etds

Part of the Geophysics and Seismology Commons

Copyright 2006 Baron W. Colbert

\section{Recommended Citation}

Colbert, Baron W., "Exploration of Ground Penetrating Radar and Time Domain Reflectometry Methods for the Determination of Pavement Dielectric Constant", Master's Thesis, Michigan Technological University, 2006.

https://doi.org/10.37099/mtu.dc.etds/735

Follow this and additional works at: https://digitalcommons.mtu.edu/etds

Part of the Geophysics and Seismology Commons 
Exploration of Ground Penetrating Radar and Time Domain Reflectometry Methods for the Determination of Pavement Dielectric Constant

By

Baron W. Colbert

A THESIS

Submitted in partial fulfillment of the requirements

For the degree of

MASTER OF SCIENCE IN GEOPHYSICS

MICHIGAN TECHNOLOGICAL UNIVERSITY

2006

Copyright (C) Baron W. Colbert 2006 
This thesis, "Exploration of Ground Penetrating Radar and Time Domain

Reflectometry Methods for the Determination of Pavement Dielectric Constant," is hereby approved in partial fulfillment of the requirements for the Degree of MASTER OF SCIENCE IN APPLIED GEOPHYSICS

DEPARTMENT:

Geological and Mining Engineering and Sciences

Signatures:

Thesis Advisor:

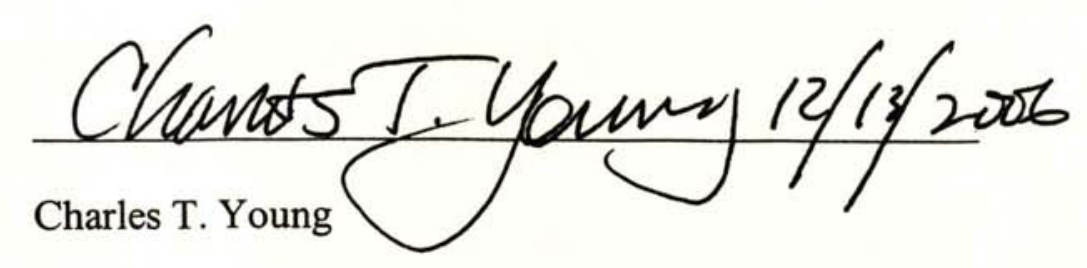

Department Chair:

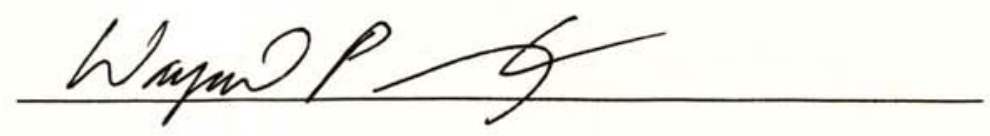

Wayne D. Pennington

Date: 13 December 2006 


\section{ABSTRACT}

Traditionally, densities of newly built roadways are checked by direct sampling (cores) or by nuclear density gauge measurements. For roadway engineers, density of asphalt pavement surfaces is essential to determine pavement quality. Unfortunately, field measurements of density by direct sampling or by nuclear measurement are slow processes. Therefore, I have explored the use of rapidlydeployed ground penetrating radar (GPR) as an alternative means of determining pavement quality. The dielectric constant of pavement surface may be a substructure parameter that correlates with pavement density, and can be used as a proxy when density of asphalt is not known from nuclear or destructive methods. The dielectric constant of the asphalt can be determined using ground penetrating radar (GPR).In order to use GPR for evaluation of road surface quality, the relationship between dielectric constants of asphalt and their densities must be established. Field measurements of GPR were taken at four highway sites in Houghton and Keweenaw Counties, Michigan, where density values were also obtained using nuclear methods in the field. Laboratory studies involved asphalt samples taken from the field sites and samples created in the laboratory. These were tested in various ways, including density, thickness, and time domain reflectometry (TDR).

In the field, GPR data was acquired using a $1000 \mathrm{MHz}$ air-launched unit and a ground-coupled unit at 200 and $400 \mathrm{MHz}$. The equipment used was owned and operated by the Michigan Department of Transportation (MDOT) and available for this study for a total of four days during summer 2005 and spring 2006. The analysis of the reflected waveforms included "routine" processing for velocity using 
commercial software and direct evaluation of reflection coefficients to determine a dielectric constant. The dielectric constants computed from velocities do not agree well with those obtained from reflection coefficients. Perhaps due to the limited range of asphalt types studied, no correlation between density and dielectric constant was evident.

Laboratory measurements were taken with samples removed from the field and samples created for this study. Samples from the field were studied using TDR, in order to obtain dielectric constant directly, and these correlated well with the estimates made from reflection coefficients. Samples created in the laboratory were measured using $1000 \mathrm{MHz}$ air-launched GPR, and $400 \mathrm{MHz}$ ground-coupled GPR, each under both wet and dry conditions.

On the basis of these observations, I conclude that dielectric constant of asphalt can be reliably measured from waveform amplitude analysis of GJPR data, based on the consistent agreement with that obtained in the laboratory using TDR. Because of the uniformity of asphalts studied here, any correlation between dielectric constant and density is not yet apparent. 


\section{Table of Contents}



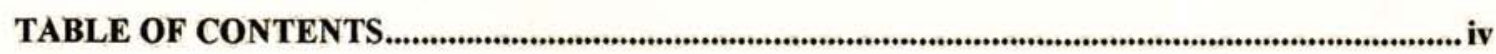

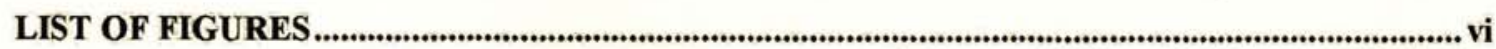

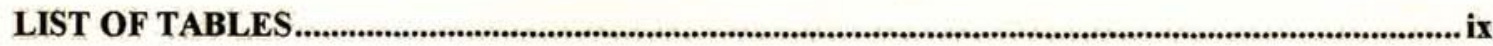

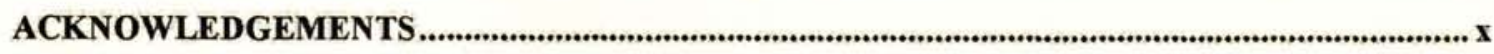

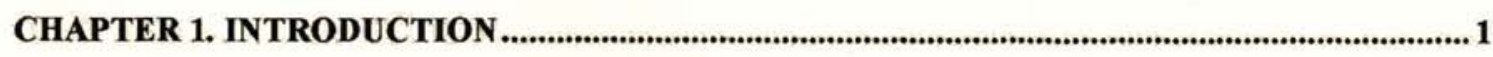

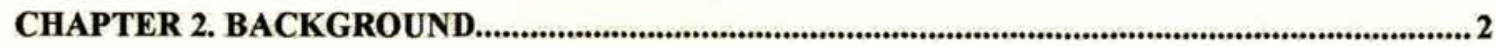

CHAPTER 3. GROUND PENETRATING RADAR ROAD SURVEYS ..............................................4

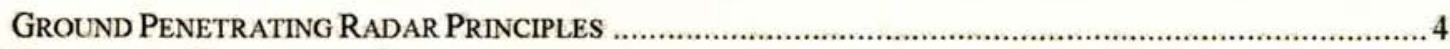

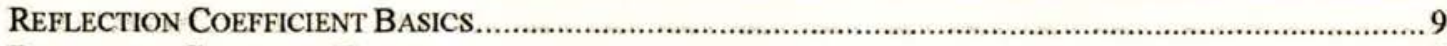

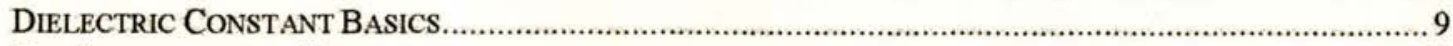

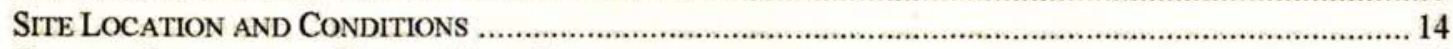

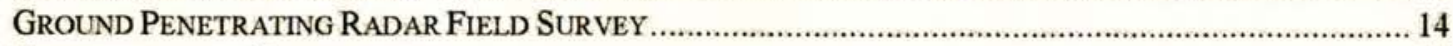

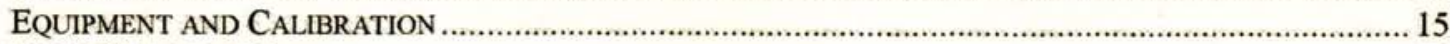

DATA COLLECTION

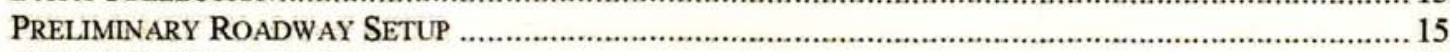

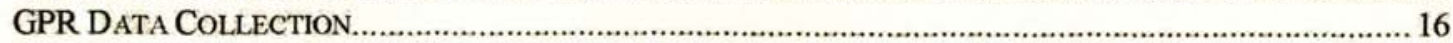

COMPARISON OF MATLAB WAVELET RESULTS VS. PAVEMENT DENSITY ……................................... 16

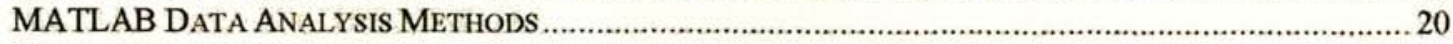

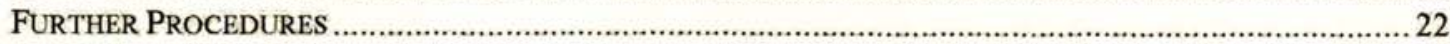

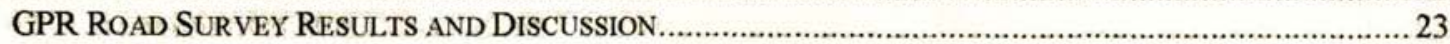

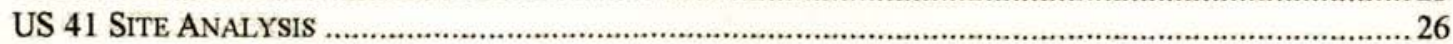

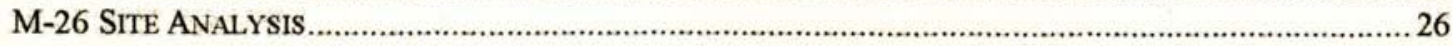

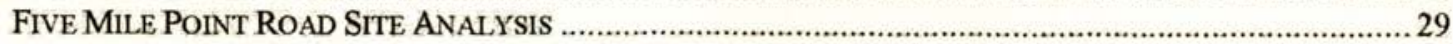

LAC LA BELLE ROAD SITE ANALYSIS FROM SURFACE REFLECTIONS …….......................................... 29

COMPARISON OF MATLAB RESULTS VS. RADAN ROADWAY SOFTWARE ................................................ 30

CHAPTER 4. GROUND PENETRATING RADAR LABORATORY MEASUREMENTS.................32

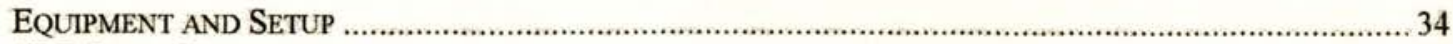



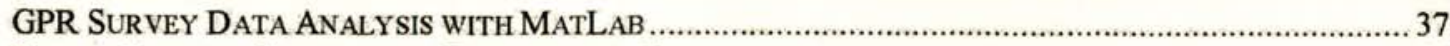

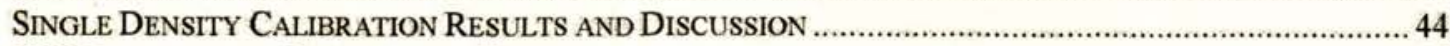

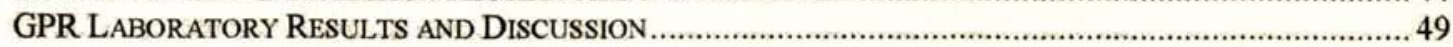

CHAPTER 5. TIME DOMAIN REFLECTOMETRY EXPERIMENTS........................................55

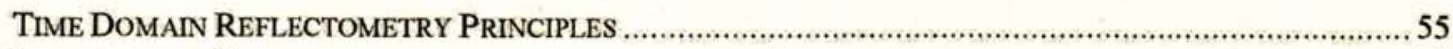

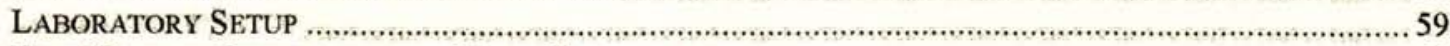

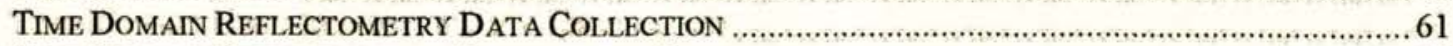

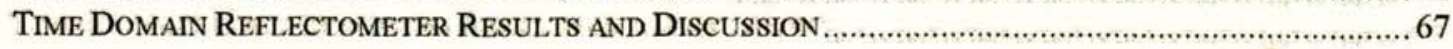



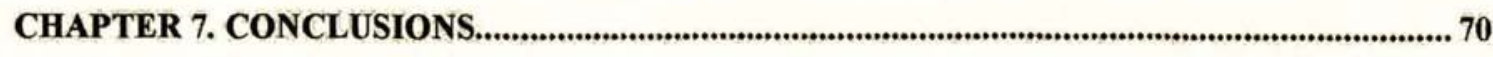

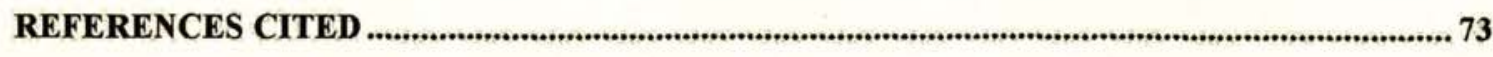

APPENDIX A: Physical Properties for Pavement Cores........................................................................75 
APPENDIX B: Continuous dielectric constant values from Radan Road software

APPENDIX C: Matlab Programs for GPR Analysis ............................................................................. 100



APPENDIX E: Thin Bed Problem for GPR Road Surveys .......................................................... 119 


\section{List of Figures}

Figure 3.1: GPR wavelet example showing wavelet reflection returns .........................5

Figure 3.2: Air Launched Antenna (left) transmitter and receiver........................... 7

Figure 3.3: Dielectric Constant Mixing Conceptual Model ....................................12

Figure 3.4: Lac La Belle Waveform Amplitude vs. Core Density(a) and Amplitude vs. Nuclear Density Graphs (b)

Figure 3.5: Core Density vs. Nuclear Density for (a)Lac La Belle and (b) M-26

Figure 3.6: M-26 Waveform Amplitude vs. Core Density(a) and Amplitude vs.

Nuclear Density Graphs (b)

Figure 3.7: US 41 Waveform and Amplitude vs. Core Density(a) and Amplitude vs.

Nuclear Density Graphs (b)

Figure 3.8: 5 Mile Point Road Waveform Amplitude vs. Core Density(a) and Amplitude vs. Nuclear Density Graphs (b)

Figure 3.9: Core Density vs. Nuclear Density for (a)US-41 and (b) Five Mile Point

Road.

Figure 3.10 GSSI3 waveform analysis of US 41 Scan 114 at core location one and pointing to the value of $A_{o}$

Figure 3.11: GPR Air Launched GPR scan of M-26 roadway site

Figure 4.1: 2006 GPR laboratory experimental setup for perpendicular direction of motion

Figure 4.2: 2006 GPR laboratory experimental setup for parallel direction of motion

Figure 4.3: Ground Coupled Antenna gliding across pavement sample.

Figure 4:4: Air-Launched GPR Scan of Saturated Samples 5 \& 6

Figure 4.5: Autopicklayers3 Composite Output Showing the GPR Scan of Sample 5 and 6

Figure 4:6: Autopicklayer3 Output Showing Upper Layer Pick

Figure 4:7: Autopicklayers3 Upper and Lower Boundary Layer Picks 
Figure 4.8: Ground Coupled GPR Wet Sample Picking Points

Figure 4.9: Sample Waveform Amplitude Vs. Density Calibration for Radar

Traverse Parallel to Long Axis of Block.

Figure 4.10: Sample Waveform Amplitude Vs. Density Calibration for Radar Traverse Perpendicular to Long Axis of Block.

Figure 5.1: Conceptual RC circuit depicting TDR response for asphalt samples. 57

Figure 5.2 Resistor Voltage Step Response 58

Figure 5.3: TDR Experimental Setup Showing Parallel Wires 59

Figure 5.4: Six inch diameter pavement samples used in TDR experiment 60

Figure 5.5: Thin rectangular pavement sample used in TDR experiment 60

Figure 5.6 TDR open end wire calibration device

Figure 5.7: TDR Graph Showing Step Response of Double Wire Device Used for TDR Time Scale Calibration...

Figure 5.8: Setup for asphalt samples for calculating air dielectric in TDR experiment.

Figure 5.9 Setup for Ideal Parallel Plate Capacitor

Figure 5.10: Original TDR Plot of US-21 Michigan Ave.

Figure 5.11 : TDR Waveform Plot of Sample US 21- Michigan Ave A Inverted and Raised by the Maximum Voltage Value 65

Figure 5.12: Reconstructed TDR Waveform Plot of US 21-Michigan A . 66

Figure 5.13 : Selected part of TDR Waveform Plot of US 21 with a linear fit applied.

Figure 1: GPR wavelet of trace 540 taken from the Lac La Belle Site.

Figure 2: GPR wavelet of trace 540 taken from the M-26 Twin Lakes site

Figure 3: GPR wavelet of trace 362 taken from the Five Mile Point Road site 122 
Figure 4: Composite Wavelet Chart showing the minimum distance where two waveforms are completely separated in time for the Lac La Belle site.

Figure 5: Composite Wavelet Chart showing the minimum distance where two waveforms are completely separated for the M-26/Twin Lakes site.

Figure 6: Composite Wavelet Chart encompassing the entire upper and lower pavement resolution at the Lac La Belle site. 


\section{List of Tables}

Table 3.1 MATLAB Calculated Dielectric Constant Values for M-26 \& Lac La

Belle Road

Table 3.2: Thickness of M-26 Cores for 2005 GPR Survey.

Table 3.3: MATLAB Vs. Radan Roadway software Dielectric Constant

Comparison of US 41 Site from the 2005 GPR Survey 30

Table 3.4: MATLAB Vs. Radan Roadway software Dielectric Constant

Comparison of M-26 Site from the 2005 GPR Survey

Table 3.5: MATLAB Vs. Radan Roadway software Dielectric Constant

Comparison of 5 Mile Point Road Site from the 2005 GPR Survey 31

Table 4.1: Physical Parameters of Manufactured Asphalt Samples.

Table 4.2: GPR Wavelet Sample Count for the Calculation of Dielectric

Constant Using Ground Coupled GPR Experiment

Table 4.3: Amplitude and Dielectric Constant Results for Wavelet Calibration

Test for Unsaturated Pavement samples 1 \& 2

Table 4.4: Amplitude and Dielectric Constant Results for Wavelet Calibration Test for Unsaturated Pavement samples 3 \& 4 Using Air Launched GPR Antenna.

Table 4.5: Amplitude and Dielectric Constant Results for Wavelet Calibration Test for Unsaturated Pavement samples 5 \& 6 Using Air Launched GPR

Antenna. 46

Table 4.6: Core Density and $\mathbf{A}_{0}$ Calibration Standard Deviation. 48

Using $A_{0}=3.28 * 10^{4}$

Table 4.7: 1GHz Air-Launched GPR Dielectric Constant Results from the 2006 GPR Laboratory Measurements.

Table 4.8: Ground Coupled GPR Dielectric Constant Results from the 2006 GPR survey 52

Table 4.9: Dielectric constant values of the air launched GPR survey using Radan Roadway Software and $\varepsilon=(c / v)^{2}$ 


\section{ACKNOWLEDGEMENTS}

First, I would like to thank the Educational Opportunity Department and Beverly Auel for providing funding for this project. This work would not have peen possible without additional financial support from the Michigan Tech University Department of Geological and Mining Engineering and Sciences.

John Belcher, from the Michigan Department of Transportation (MDOT), deserves thanks for providing the MDOT research van for GPR analysis, and the ground penetrating radar antennas. I also would like to give special thanks to Kevin Hackman of MDOT for providing nuclear density gauge readings at the various pavement site during the Summer of 2005 GPR survey. From the Michigan Tech University Civil and Environmental Engineering Department a special thanks goes to Ed Tulppo for his help with the summer of 2005 GPR survey and James Vivian for his help with the 2005 survey and manufacturing the asphalt samples for the spring of 2006 GPR survey, and Mike Chase and John Miller from the Electrical Engineering Department.

Charles Young, my thesis advisor, deserves special thanks for providing insight, guidance, and support during this project. I would also like to thank the other members of my committee for their insights in improving this manuscript.

Thanks, also to my friends, Jeremy Brown, Craig McDougal, Pastor Thomas Griffin and his family, and the saints at Lighthouse United Pentecostal Church. Who have made these past two years a memorable time of my life. Finally, thanks to my wife and daughter for helping me through the many up and downs of my life as a graduate student. I thank them for the emotional stability that they have brought to 
my like. Most of all I want to thank the Lord Jesus Christ who has been with me through everything. 


\section{CHAPTER 1. INTRODUCTION}

This thesis describes a series of three electromagnetic experiments applied to asphalt pavement to develop a process of obtaining consistent dielectric constant data. The results in principle could then be used to correlate with other physical properties of the pavement. The first experiment involved obtaining Ground Penetrating Radar (GPR) data from newly paved roadways in Houghton County, MI with groundcoupled and air-launched GPR antennas. The second experiment involved creating pavement samples manufactured at Michigan Technological University. These samples then were analyzed by ground coupled and air launched GPR antennas to determine their dielectric constant under variable moisture conditions. The final experiment involved calculating dielectric constant with a time domain reflectometer on various pavement samples provided by the Civil Engineering program at Michigan Tech. These methods were used to determine if dielectric constant can consistently be determined by GPR surveys when compared to actual roadway core information. For this study the research plan was significantly affected by the availability of ground penetrating equipment; the radar equipment and interpretation software was only available for four days since it was owned by the Michigan Department of Transportation. 


\section{CHAPTER 2. BACKGROUND}

Ground penetrating radar has emerged as a developing technology in evaluating roadway conditions. An engineer using GPR can quickly identify defects within the pavement surface nondestructively and propose the best repair strategy (Saarenketo \& Scullion, 2000). Using GPR waveforms, dielectric constant, density,

void ratio, and pavement moisture content can be determined (Saarenketo \& Scullion, 2000).

The use of ground penetrating radar for roadways started in the mid 1970's to scan for tunnels; GPR was used later to scan bridge decks (Saarenketo \& Scullion, 2000). In 1985, the Federal Highway Administration first implemented a GPR system for roadways (Morey, 1998). Today, GPR surveys are performed on roadways in order to collect information about the condition of a given pavement area (Morey, 1998). By providing the engineer a continuous profile of the pavement subsurface, more information about the roadway is known than just pavement cores alone (Morey, 1998). GPR has been successful in detecting moisture in hot mix asphalt layers, finding moisture in the base layer of pavement, and evaluation of geosynthethic material performance used within pavement layers (Lahouar et al., 2002). GPR survey crew usually includes a van driver, a radar operator/interpreter, and a drill and core operator (Morey, 1998). GPR data can be collected at a rate of $100 \mathrm{scans} /$ second and survey speeds can take place up to $100 \mathrm{~km} / \mathrm{hr}$ (Morey, 1998). Finally, GPR surveys can take place at any time except under wet or rainy surface conditions (Morey, 1998). 
Three topics of interest to experts in the roadway industry relating to GPR use are: First, developing standard specifications for pavement performance and measurements for producing consistent results (Morey, 1998). Second, understanding how electrical parameters of roadway materials correlate to moisture, strength, and deformation conditions in roadways (Saarenketo \& Scullion, 2000). And thirdly, determining dielectric constant of roadway pavements. The dielectric constant is of major importance in determining the correlation between GPR data and pavement conditions. Interest in correlating dielectric constant in pavement materials to physical properties of geological and pavement materials was led by researchers such as Maser (1992), Olhoeft (1999), Martinez \& Byrnes (2001), and Saarenketo \& Scullion (1996) in the mid 1980's through the early 2000's.

More recently, Saarenketo (2000), Scullion (2000), Rmeili (1997), and Wimsatt (1998) from the Texas Transportation Institute have conducted studies of GPR applications in the use of pavement evaluation. They focused on identifying roadway evaluation applications with air launched and ground coupled GPR antennas. For example, Maser \& Scullion (1992) detailed the continuous profiling ability of GPR to predict pavement thickness and pavement properties at strategic highway research locations in Texas (Maser \& Scullion, 1992). These studies predicted pavement thickness within .32 inches with GPR data alone and thickness to within .11 inches with a calibration core (Maser \& Scullion, 1992).

The topic of determining the velocity of radar waves in pavement with GPR was also studied at this time. Lahouar(2002) adapted the common midpoint method used in seismology to calculate an in-situ dielectric constant of pavements on 
Interstate 81 in Virginia, and concluded that the dielectric constant determined from GPR when compared to asphalt cores yielded an average error of $6.8 \%$ (Lahouar, 2002). Reppert (2000) presented a method to calculate GPR layer velocities using Brewster angles with a common midpoint survey. This study resulted in reasonable dielectric constant values using Brewster angles as compared to determining dielectric constant values from known velocities. Finally Lanbo Liu (2002) determined the dielectric constant to laboratory samples of pavement materials. He placed 30 pavement samples under various moisture conditions and then correlated the results with the sample void ratio and binder content (Liu, 2002). This study concluded that: the electromagnetic wave velocities were greatest in dry conditions and slowest in wet conditions, electromagnetic wave velocities increased slightly with an increase of void ration in dry samples, and that pavement electromagnetic wave velocity and dielectric constant can be predicted using the effective medium theory (Liu, 2002).

Currently research is focused on predicting the conditions where GPR is effective (Morey, 1998). Future research areas for GPR include establishing techniques in road analysis and rehabilitation (Saarenketo, and Scullion, 2002).

\section{CHAPTER 3. Ground Penetrating Radar Road Surveys}

\section{Ground Penetrating Radar Principles}

Ground Penetrating radar systems rely on various principles of electromagnetism which helps one to understand how GPR can scan the roadway subsurface. The GPR systems send electromagnetic pluses from the antenna onto the roadway and then records the pulse reflected from the surface and subsurface (Al- 
Qadi et al., 2005). The electromagnetic wavelet is described as the reflected pulse from the initial generation of the GPR signal with a central maximum and two local signal minima approximately one nanosecond apart (Serbin \& Or, 2004). Another definition of a wavelet is a brief wave pulse which contains many frequencies and is time limited, meaning that this wave only is in existence for a given period of time instead of oscillating forever (Liner, 2004). Figure 3.1 shows a typical GPR wavelet along with the wavelets from the surface and bottom of the first pavement layer.
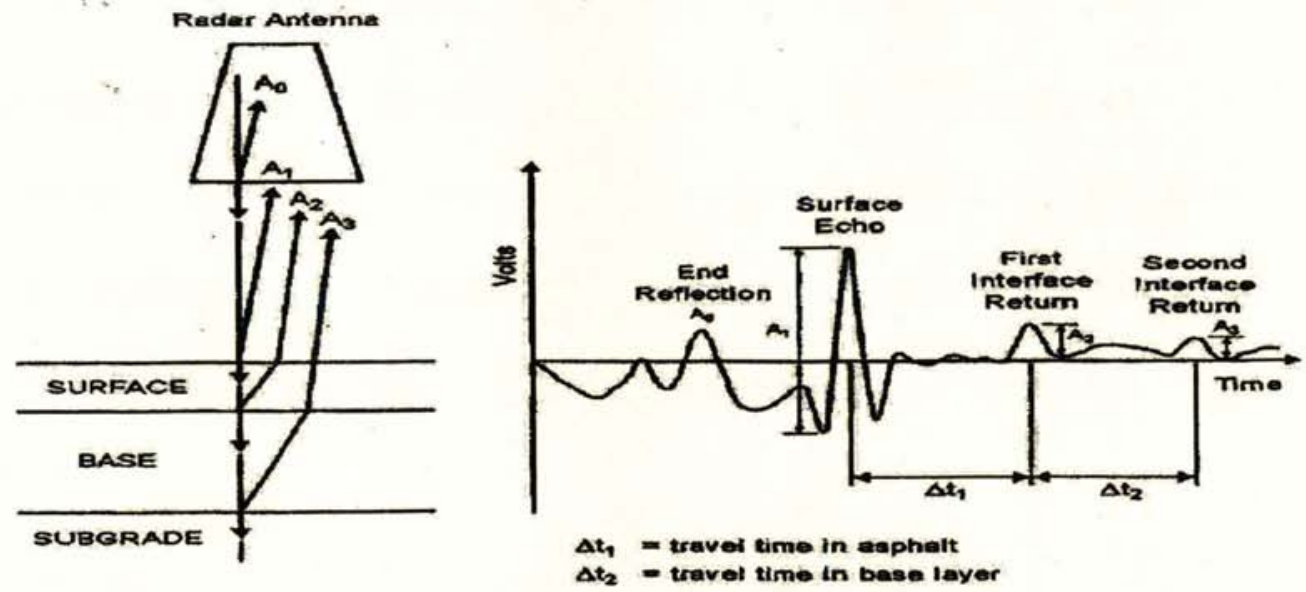

Figure 3.1: GPR wavelet example showing wavelet reflection returns depicting the principles of GPR where the incident wave is reflected at each layer interface and plotted as return voltage against time of arrival in nanoseconds

Factors which affect GPR signal propagation include the dielectric constant and electrical conductivity of a given layer (Saarenketo \& Scullion, 1996). The reflected signal of the GPR wavelets are recorded from the subsurface, and the resulting GPR signal results due to the contrasts in the dielectric properties of the subsurface pavement system (Al-Qadi et al., 2005). The amplitude of the reflected signal at each layer interface is a function of dielectric constant contrast between pavement layers (Saarenketo \& Scullion, 1994). For flexible asphalt pavement 
surfaces these contrasts rely primarily on the moisture contrast between pavement layers (Saarenketo \& Scullion, 1994).

GPR systems typically have 3 components: a pulse generator, a transmitterreceiver, and a sampler/recorder (Saarenketo \& Scullion, 2000). Common assumptions associated with GPR analysis include that the subsurface materials are homogenous, that the subsurface materials are lossless, and that the relative permeability of air is unity (Alongi et al., 1982).

Ground Penetrating Radar surveys gather vast amounts of roadway data per survey. GPR roadway surveys can generate a continuous profile of the roadway which provides more information on the roadway condition than roadway cores alone (Morey, 1998). Varying the GPR vehicle speed only affects the trace spacing of the collected data; typically, GPR is able to collect traces every 1 to $3 \mathrm{ft}$ (Maser \& Scullion, 1998)

The personnel for the roadway evaluation team include the GPR operator/interpreter and driller who take cores from the roadway (Morey, 1998). Typical techniques used within the survey include the reflection technique with an air launched horn antenna, common depth point method, and Radar Surface Arrival Detection method, and TDR and electric measurements based on capacitance measurements (Saarenketo \& Scullion, 1994). The dielectric constant is related to the velocity of radar waves in the material and the velocity of radar waves in free space by: $\varepsilon=(C / V)^{2}$ with $\mathrm{c}$ as the speed of light and $\mathrm{v}$ as layer velocity (Lahouar et al., 2002). With the common depth point method dielectric constant is determined also by the amplitudes of reflected pulses with an air launched antenna (Al-Qadi et al., 2005). 
GPR interpretations consist of detecting roadway layer interfaces and using electromagnetic wavelet traveling through the pavement subsurface (Saarenketo \& Scullion, 2000). These interpretations result in pavement subsurface profiles indicating pavement depth on a time scale (Saarenketo \& Scullion, 2000). GPR waveforms indicate two-way travel for wavelets to travel from the GPR transmitter to receiver (Saarenketo \& Scullion, 1996). In order to change from the time scale to depth scale the roadway layer dielectric constant has to be estimated. Software is provided with the GPR to allow the interpreter to acquire, process, interpret, visualize, and integrated GPR data (Saarenketo \& Scullion, 2000).

For the typical GPR survey two types of GPR antenna are used, an "airlaunched" horn antenna which is suspended about $30 \mathrm{~cm}$ about the roadway, and a ground coupled GPR antenna which is placed directly on the pavement surface shown in Figure 3.2.

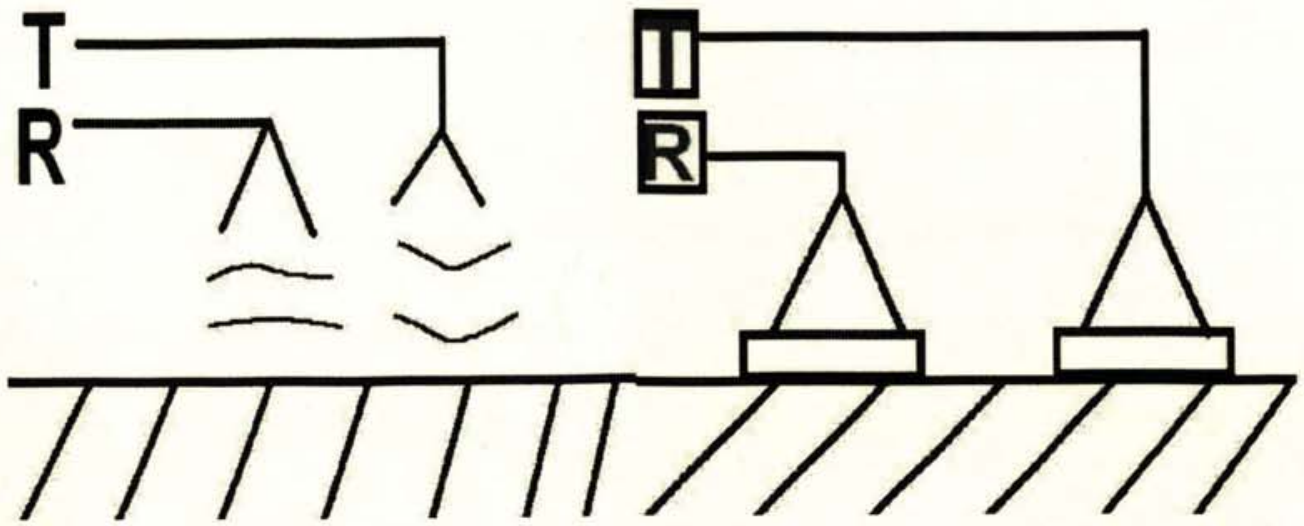

Figure 3.2: Air Launched Antenna (left) transmitter $T$ and receiver $R \&$ Ground Coupled GPR antenna transmitter $T$ and receiver $R$ (right)

The air launched horn antenna allows the radar to be used at a high speed and provides well defined directional footprint and subsurface visualization 
capabilities for the pavement engineer (Serbin and Or, 2004). Ground coupled antennae operated from $80-1500 \mathrm{MHz}$ (Saarenketo and Scullion, 2000), and provide a greater depth of penetration than air-launched antennae (Saarenketo and Scullion, 2000). The major disadvantage of using an air launched horn antenna is that its depth of penetration is only a few inches as most of the electromagnetic signal is reflected at the air/roadway interface (Al-Qadi et al., 2005). Additionally, air launched GPR antennae must be subjected to calibration procedures using a large metal plate to normalize reflected signals (Morey, 1998). One difficulty of using the ground coupled antennae is the surface coupling and ringing (Saarenketo \& Scullion, 2000). In order to overcome these difficulties, signal processing may be needed (Saarenketo \& Scullion, 2000). Another disadvantage of using ground coupled antennae is the slower rate of collecting data versus air launched antennae (Al-Qadi et al., 2005). The ground coupled antenna must move at a slower rate than the air launched antenna to avoid self destruction of the antenna on the pavement surface.

The equipment for the GPR survey in 2005 used equipment manufactured by Geophysical Survey Systems, Inc. (GSSI), which includes the GPR antennas, software, and a controller data logger. With the air launched antennas, this GPR system is capable of obtaining subsurface images of the pavement layers from a frequency range of $400 \mathrm{MHz}$ to $1 \mathrm{GHz}$, corresponding to depths of a few inches to several feet. 


\section{Reflection Coefficient Basics}

The reflection coefficient is an important concept in GPR data analysis. The definition of the reflection coefficient is the ratio of the amplitudes of the reflected wave and incident wave (Reynolds, 1997). The assumption for the reflection in GPR work is the wave is a vertically incident wave involving no spreading. The reflection coefficient is also a related to relative dielectric constant at the layer boundary (Morey, 1998). This thesis assumes that the reflection coefficient is defined to be normally incident only. Understanding the reflection coefficient behavior at pavement boundaries is important for understanding GPR images and interpretation limits (Martinez \& Byrnes, 2001). The reflection coefficient is calculated from layer to layer

by the formula

$$
R C=\frac{\sqrt{\varepsilon_{r_{1}}}-\sqrt{\varepsilon_{r_{2}}}}{\sqrt{\varepsilon}+\sqrt{\varepsilon}}
$$

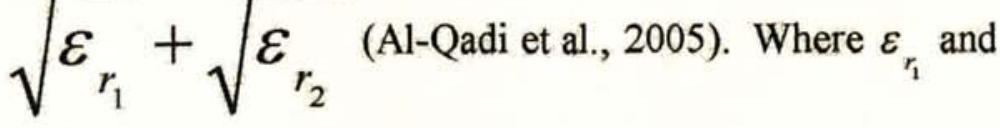

$\varepsilon_{r_{2}}$ are the dielectric constant values of the first medium and second media,

respectively. Typically, reflection coefficients range from .2 for sand and -1 for metal. Thus returning echoes for GPR depend on the material (Alongi et al., 1982). Finally reflection coefficients are valid only at vertical normal incidences but in practice, angles of incidence within 20 degrees of normal are used (Serbin \& Or, 2004).

\section{Dielectric Constant Basics}

Dielectric constant is an important parameter in GPR analysis. A simple definition of the dielectric constant is the factor $\kappa$ which increases capacitance of a capacitor when a dielectric material is inserted in place of a vacuum (Serway and Belcher, 2000). This factor helps the pavement engineer estimate various physical 
parameters of pavement, such as layer velocity, thickness, density, and moisture content. Dielectric constant is an important parameter because it is linked to the propagation velocity of GPR electromagnetic waves through a given media and the resulting reflection coefficient at the pavement layer interface (Martinez \& Byrnes, 2001). Moisture significantly affects the bulk dielectric constant value of pavement materials as it has a value of 81(Martinez \& Byrnes, 2001). The dielectric constant of water is much higher than any geologic or most roadway materials. Therefore small changes in pavement moisture content have a great effect on pavement dielectric constant or reflection coefficient values. Dielectric constant values are related to reflection amplitudes by the following formula:

$$
\varepsilon_{r_{1}}=\left(\frac{1+\frac{A_{0}}{A_{p}}}{1-\frac{A_{0}}{A_{p}}}\right) \text { where } A_{0} \text { is }
$$

the pavement surface amplitude and $A_{p}$ is the metal plate amplitude (Al-Qadi et al., 2005). The metal plate is used as a calibration reference for complete reflection when the air launched GPR is scanned over the plate.

The dielectric constant of the pavement surfaces can vary according to aggregate type and moisture conditions (Lahouar et al., 2002). Signal attenuation (due to scattering) upon the pavement surface can also create errors in dielectric constant calculations (Saarenketo, 1996). Attenuation is not a major factor affecting pavement dielectric constant in good quality pavement layers (Saarenketo, 1996). Dielectric constant values vary in value according to the pavement type as shown by Wimsatt(1998): $\varepsilon$ for pavement composed of normal aggregate $\varepsilon$ ranged from $5-6.5$. 
Pavement composed of lightweight aggregate $\varepsilon$ ranged from 3.5-4.5 in the Liu (2002) study, and for flexible base pavement dielectric constant values ranged from 7-10 (Wimsatt, 1998). In the Wimsatt (1998) study dielectric constant values lower than 3.5 indicated excessive air voids and dielectric constant values higher than 10 indicated excessive pavement moisture (Wimsatt, 1998). In the Al-Qadi(2005) study laboratory manufactured hot mix asphalt samples were tested with an air launched horn antenna and network analyzer resulted in dielectric constant values of 3.7-5.2 for dry samples and 4.1 to 5.3 for water saturated samples(Al-Qadi \& Lahouar, 2005). For pavement quality control applications Saarenketo's (2000) study showed that the pavement dielectric constant was around 5.5 in the center of the pavement slabs, and approximately 4.5 at the pavement joints.

Dielectric constant "mixing" models are used as a tool to calculate pavement dielectric constant of pavement layers from a known mixture. Mixing models express the bulk dielectric constant of a medium as a function of the dielectric constants of the constituent materials. Dielectric constant models can be used to understand recorded travel times and amplitudes obtained from GPR traces (Martinez \& Byrnes, 2001). One type of dielectric constant mixing models is based on time propagation accounting for the bulk volume fraction of the pavement material $\mathrm{V}$ and $\epsilon$ of the pavement material (Martinez \& Byrnes, 2001). This formula is:

$\varepsilon_{\text {Composite }}=\left[\sum V_{i} \sqrt{\varepsilon_{r_{i}}}\right]^{2}$ where i is the $\mathrm{i}^{\text {th }}$ component of the model and is valid at the specific frequency where $\epsilon$ is represented and for predicting the dielectric constant of low conductivity non magnetic materials (Martinez \& Byrnes, 
2001). Generally this mixing model formula can be expressed assuming asphalt is composed of air voids, aggregates, binder, and moisture is:

$$
\sqrt{\varepsilon_{H M A}}=V_{\text {air }} i \sqrt{\varepsilon_{\text {air }}}+V_{\text {agg }} i \sqrt{\varepsilon_{\text {agg }}}+V_{\text {binder }} i \sqrt{\varepsilon_{\text {binder }}}+V_{\text {water }} i \sqrt{\varepsilon_{\text {water }}}
$$

(Al-Qadi, 2005). The dielectric constants of asphalt pavement materials correlate to volumes which compose the model, which indicate discontinuities or distress in pavement (Al-Qadi, 2005). In a hot mix asphalt, the dielectric constant correlates with density, air voids, asphalt content, and moisture within the pavement layers (Al-Qadi, 2005). Figure 3.3 shows an example of a conceptual model of the dielectric constant mixing model.

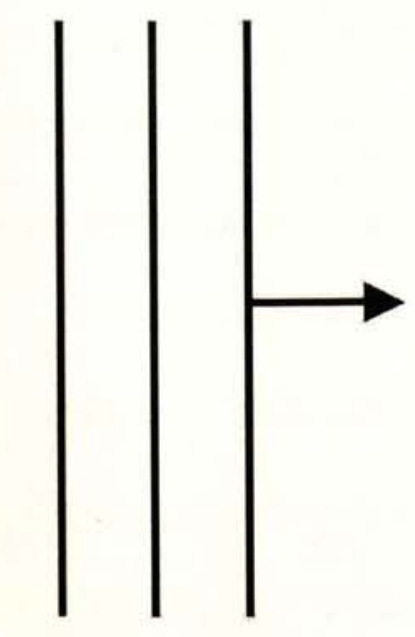

GPR Wave

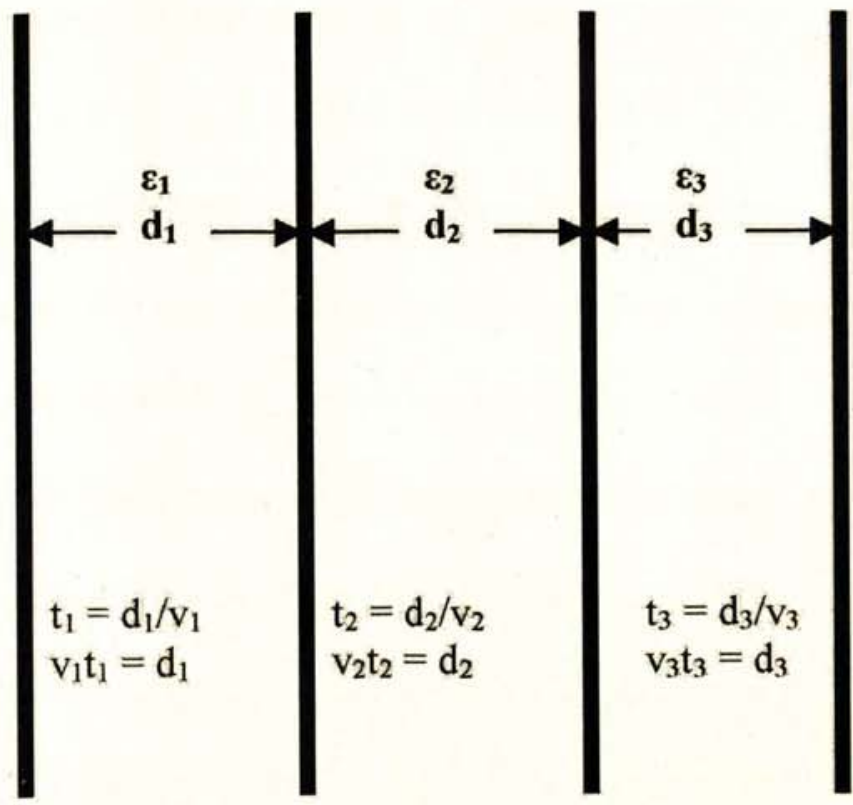

$\mathrm{d}$ is distance and volume fraction

Figure 3.3: Dielectric Constant Mixing Conceptual Model 
Total travel time for this model above is related to distance and velocity by the formula:

traveltime $=t_{1}+t_{2}+t_{3}=\frac{d_{1}}{v_{1}}+\frac{d_{2}}{v_{2}}+\frac{d_{3}}{v_{3}}=\frac{d_{1}}{c / \sqrt{\varepsilon_{1}}}+\frac{d_{2}}{c / \sqrt{\varepsilon_{2}}}+\frac{d_{3}}{c / \sqrt{\varepsilon_{3}}}=\frac{1}{c \sqrt{\varepsilon_{\text {bulk }}}}$

The dielectric constant model formulas assume that the pavement layers are homogeneous, and are composed of lossless materials (Al-Qadi, 2005). Within rocks and sediment the dielectric constant is a function of mineralogy, porosity, pore fluids, frequency, rock geometry, and electrochemical relations between rock components (Martinez \& Byrnes, 2001). In general, one should expect the dielectric constant of pavement to be frequency dependant but (Lahouar, 2002) showed that the dielectric constant variation was not significant when compared across the typical GPR operating bandwidth. The typical dielectric constant value regarding frequency is that $\varepsilon$ generally decreases with increasing frequency but the values are relatively constant over the typical GPR frequency range of $25-1500 \mathrm{MHz}$ (Martinez \& Byrnes, 2001).

If the dielectric constant is correctly estimated, then the pavement engineer can use the radar trace data to calculate: pavement layer thickness, pavement layer velocity, and pavement moisture content. To evaluate the pavement thickness from the GPR data the time difference between layer reflections and velocity between pavement layers need to be measured (Morey, 1998). This depends on strong GPR reflections at the layer interfaces which work well on flexible pavements (Morey, 1998). As for thin asphalt layers with different aggregate types small positive reflections will appear on the GPR trace at each interface (Scullion \& Rmeili, 1997). 
Pavement layer thickness can be calculated by thickness $=\frac{c^{*} \Delta t}{2 * \sqrt{\varepsilon_{r}}}$ where $\mathrm{c}$ is the speed of light and $\varepsilon_{\mathrm{r}}$ is the dielectric constant at the $\mathrm{r}^{\text {th }}$ layer (Lahouar et al., 2002). In the (Morey, 1998) study it was found that pavement thickness using GPR interpretation programs versus pavement cores were accurate to within $+-7.5 \%$ for finding asphalt thickness.

Water saturation is a variable that is important for accurate GPR interpretation (Martinez \& Byrnes, 2001). From the Martinez and Byrnes (2001) study it was shown that water exerted a first order influence on bulk dielectric constant values (Martinez \& Byrnes, 2001). High amplitudes in reflected GPR wavelets correlate to moisture filled voids (Saarenketo \& Scullion, 1994). If the pavement base layer moisture content increases then the amplitude of the reflection from the top of the base layer will also increase (Scullion \& Rmeili, 1997). The dielectric constant value of water is 81(Wimsatt, 1998).

\section{Site Location and Conditions}

\section{Ground Penetrating Radar Field Survey}

Four sites were selected for the May 2005 GPR field survey to conduct air launched and ground coupled GPR experiments:

1. US-41 in Allouez, MI M-26 in

2. Houghton County, MI near Twin Lakes State Park,

3. Five Mile Point Road in Keweenaw County, MI 
4. Lac La Belle Road in Keweenaw County, MI near the Little Betsy

River.

The weather conditions on the $11^{\text {th }}$ of May were mostly cloudy with a

temperature of $40^{\circ} \mathrm{F}$. The weather on the $12^{\text {th }}$ of May was partly sunny with a slight breeze and a temperature of $42^{\circ} \mathrm{F}$.

\section{Equipment and Calibration}

The 2005 GPR survey was carried out by using GSSI $41081000 \mathrm{MHz}$ airlaunched horn antenna, a metal sheet which provided unity reflection coefficients for the survey, with the GSSI SIR 10 data collection system.

\section{Data Collection}

For the 2005 and 2006 GPR surveys data was acquired by the GSSI Radan Roadway software and stored on a laptop computer provided by the Michigan Department of Transportation. Also GPR data was acquired on one channel for the 1 GHz air launched GPR survey in 2005 and for the ground coupled GPR data in 2005.

\section{Preliminary Roadway Setup}

Core locations and distance marks were placed at each roadway site. Core locations were marked every 30 feet beginning at the start of the roadway location and ending 300 feet from the start of the roadway site. In order to address safety concerns about collecting GPR data at each of the roadway sites it was decided that the GPR data would be collected along the shoulder of the roadway to avoid extensive lane closures. 


\section{GPR Data Collection}

After securing the roadway sites for data collection, the process of generating roadway scans from the GPR antennas begun. The steps that involve roadway GPR collection for this survey are the calibration of the air launched GPR antenna, positioning personnel for electronically marking the roadway core locations, and placing the ground coupled antenna in position for use with the GPR survey van. Data collection for the air launched antenna survey took place at a rate of approximately 39 nanoseconds/sample. This survey phase started with a bounce test. The bounce test calibrates the air launched antenna with a standard aluminum roadway construction sign. The bounce test or "rocking the van" calibrates the air launched antenna by providing the reference amplitude for a reflection coefficient of unity at various heights above the road. Afterward the van driver and helper marked the core location and were placed into position at the starting location for the survey. Finally the van driver and helper would mark core locations and scan the roadway surface with the GPR antenna.

\section{Comparison of MATLAB Wavelet Results vs. Pavement Density}

In order to explore the capabilities of GPR to determine the dielectric constant of pavement and its relationship to density, a series of calibration procedures were performed. For the 2005 GPR survey it was decided that the relationship between pavement density and waveform amplitude $A_{0}$ would be tested. $A_{0}$ is the pavement surface amplitude calculated from the GPR wavelet. The following figures 3.4 
through 3.9 show $\mathrm{A}_{0}$ plotted vs. core density and nuclear density of the pavement as well as core density versus nuclear density at each of the sites.
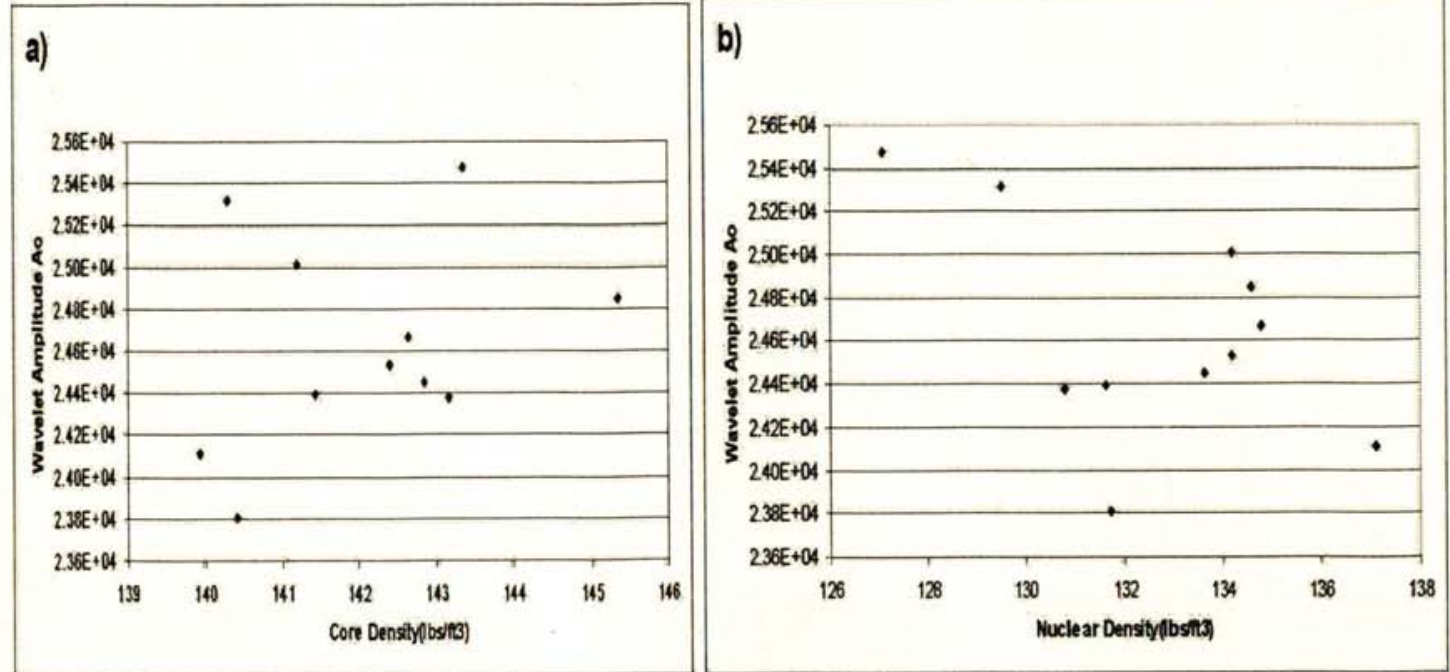

Figure 3.4: Lac La Belle Waveform Amplitude vs. Core Density(a) and Amplitude vs. Nuclear Density Graphs (b)
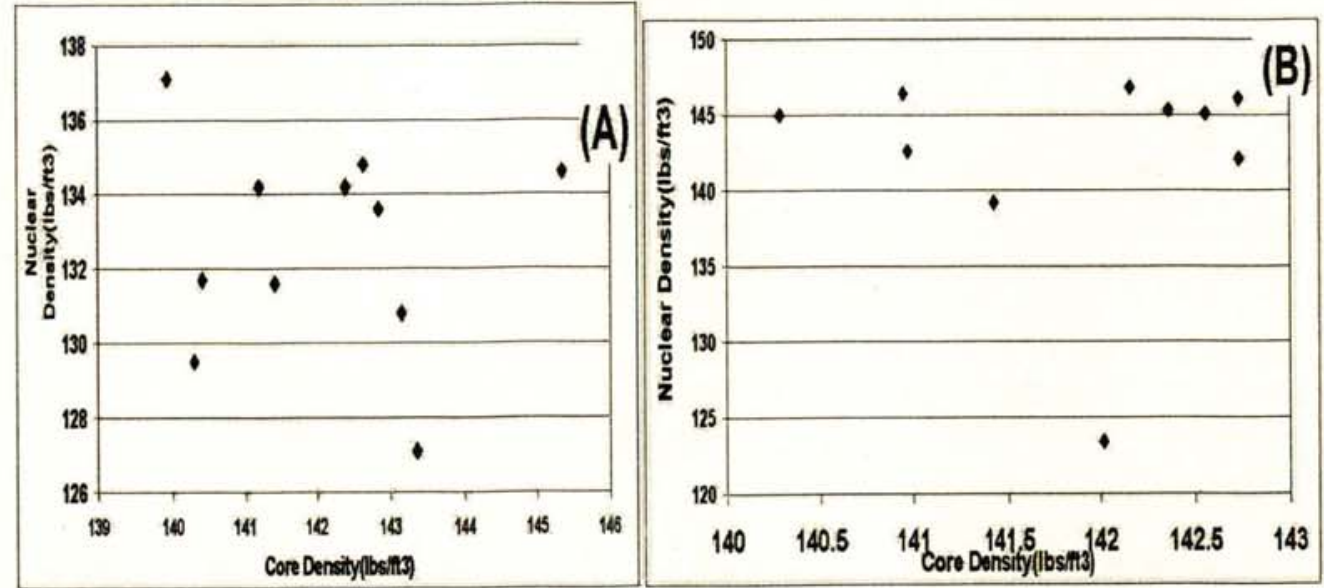

Figure 3.5: Core Density vs. Nuclear Density for (a)Lac La Belle and (b) M- 



Figure 3.6: M-26 Waveform Amplitude vs. Core Density(a) and Amplitude vs. Nuclear Density Graphs (b)
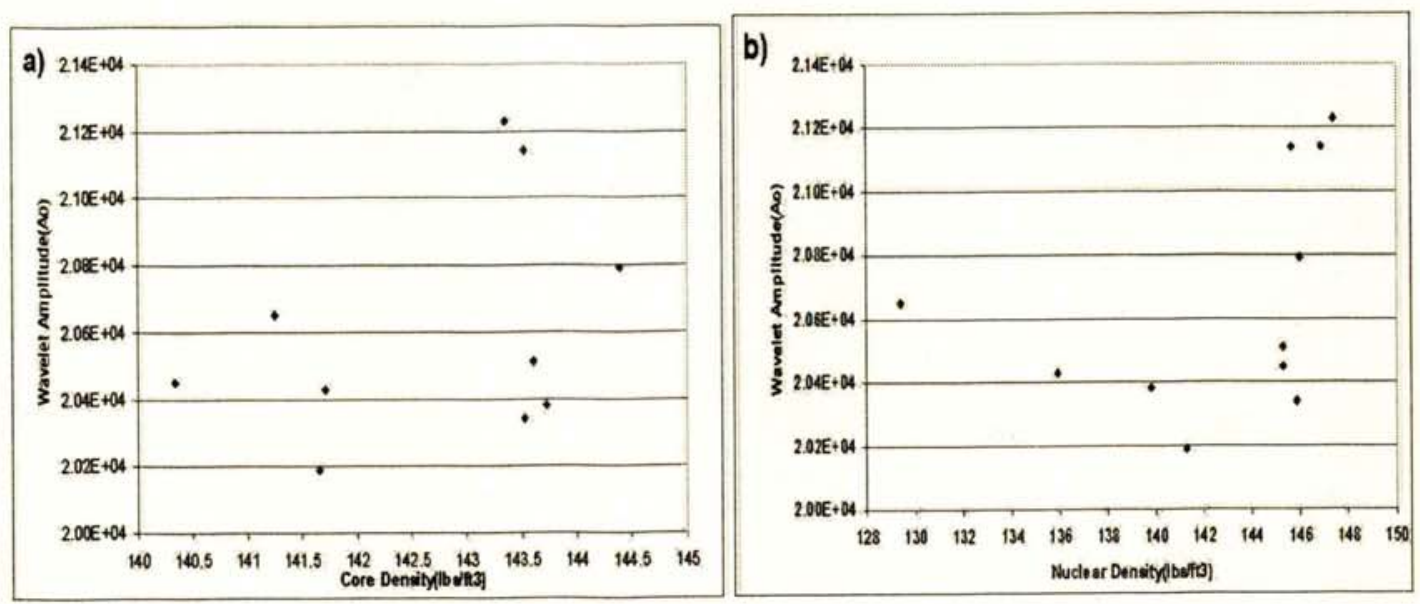

Figure 3.7: US 41 Waveform and Amplitude vs. Core Density(a) and Amplitude vs. Nuclear Density Graphs (b) 

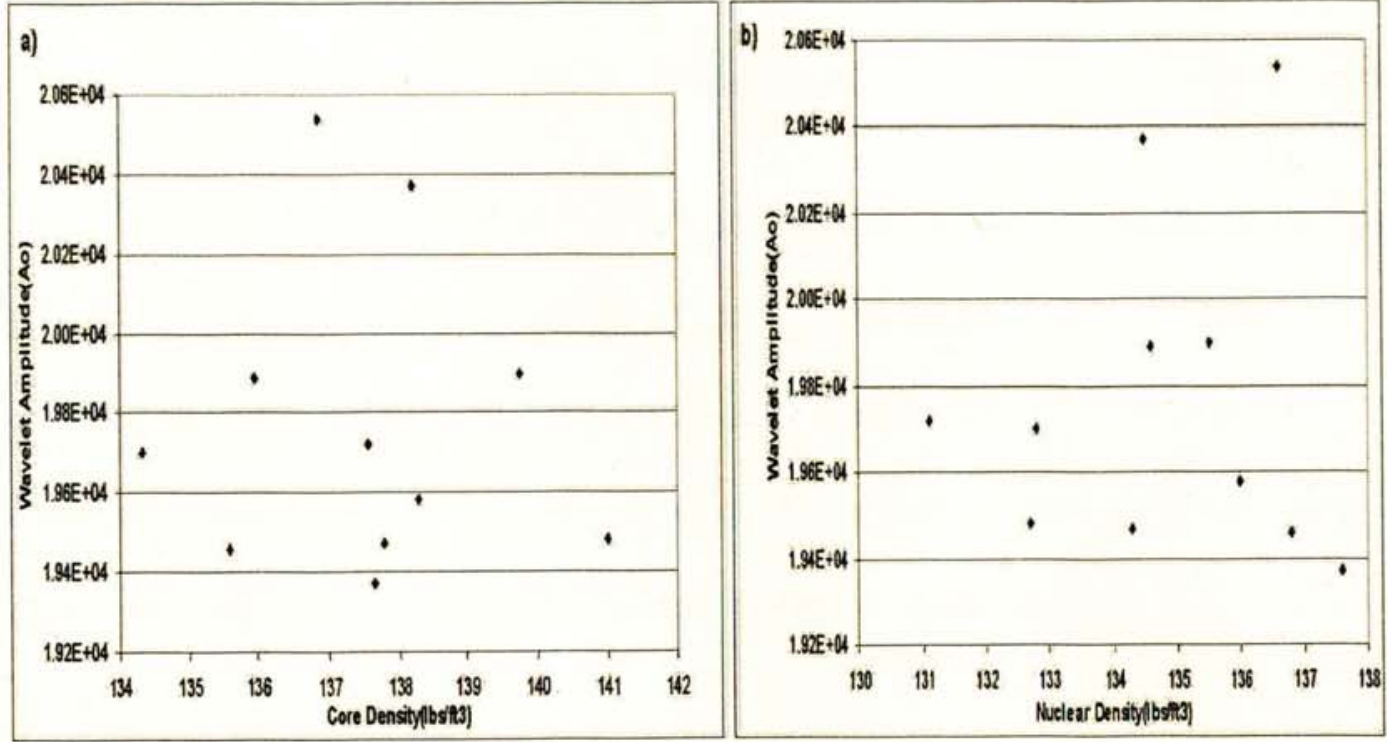

Figure 3.8: 5 Mile Point Road Waveform Amplitude vs. Core Density(a) and Amplitude vs. Nuclear Density Graphs (b)
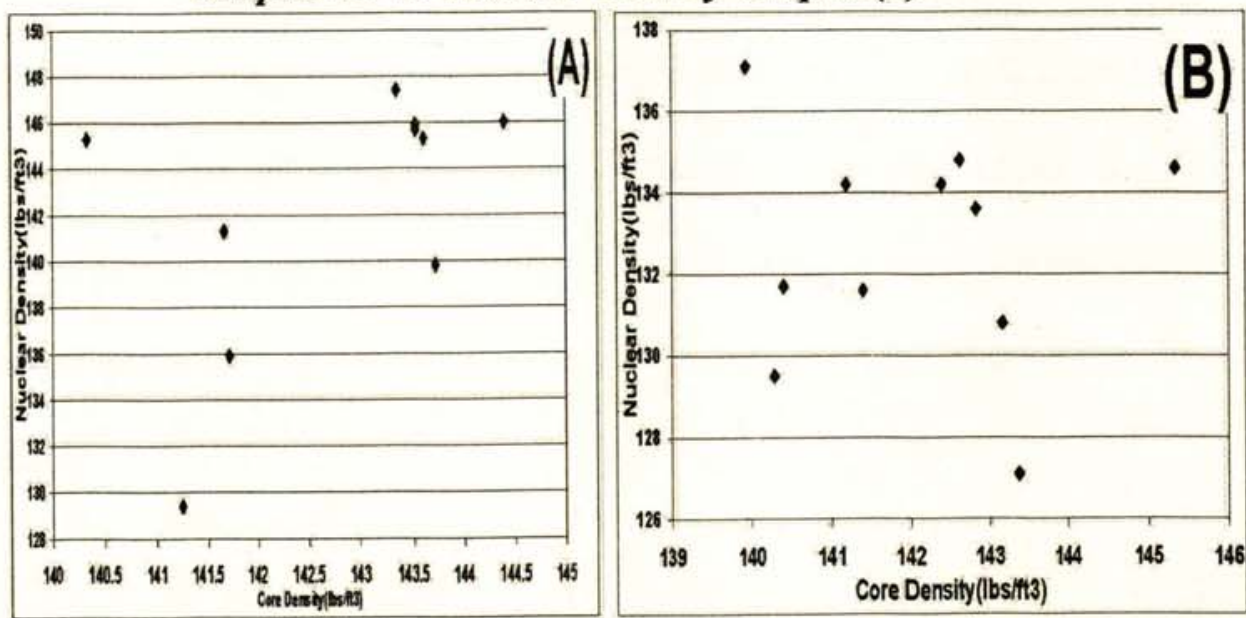

Figure 3.9: Core Density vs. Nuclear Density for (a) US-41 and (b) Five Mile Point Road

Based on the graph of waveform amplitudes vs. density there does not appear to be a direct correlation that between $\mathrm{A}_{0}$ and density. One possible explanation for this is an inadequate spread of densities to gather $A_{0}$ values from, because many of 
the charts above show a density spread of $10 \mathrm{lbs} / \mathrm{ft}^{3}$ or less are dominated by random fluctuations Thus, due to a lack of density spread, calibrations using samples of known densities were attempted to be implemented in the GPR laboratory study.

As a result, the data from the GPR study produced mixed results. From this survey the author desired a better understanding of the relationship of dielectric constant and GPR waveforms. This understanding was obtained by measuring dielectric constants with manufactured pavement samples indirectly with the radar equipment, and more directly with the time domain reflectometer.

\section{MATLAB Data Analysis Methods}

In order to gather dielectric constant and GPR waveform amplitude data, a series of MATLAB programs were used to analyze the Radan Roadway software data. The cllickerplot program is listed in Appendix C. In order to read Radan Roadway software files the MATLAB program gssi3 was used (Baradello, 2006). Gssi3 in combination with program 'cllickerplot' were used to analyze GPR wavelets at each core location. Figure 3.9 below shows a wavelet at Core Location 1 in the US41 GPR survey. 




Figure 3.10 GSSI3 waveform analysis of US 41 Scan 114 at core location one and pointing to the value of $A_{o}$

Figure 3.10 shows the location where the location where $A_{0}$ is picked on each GPR trace. It usually is the maximum positive amplitude of each wavelet; in this case it is $2.11 * 10^{4}$. The maximum plate amplitude $A_{p}$ is taken from the GSSI calibration files and it is the maximum positive amplitude value. From the GPR calibration files $A_{p}$ is $3.28 * 10^{4}$. Finally dielectric constant at the pavement surface $r 1$ is calculated by the formula: $\varepsilon_{r 1}=\left(\frac{1+\frac{A_{0}}{A_{p}}}{1-\frac{A_{0}}{A_{p}}}\right)$. Given $\mathrm{A}_{0}$ and $\mathrm{A}_{\mathrm{p}}$ the dielectric constant value for 
core location 1 at the US 41 site is $\varepsilon_{\text {core } 1}=\left(\frac{1+\frac{2.11^{*} 10^{4}}{32767}}{1-\frac{2.11^{*} 10^{4}}{32767}}\right)$ resulting in a dielectric

constant of 4.64. In order to compare the calculated dielectric constant values with the Radan Roadway software values identical GPR scan are used. For this example scan 114 was used in MATLAB to get a dielectric constant value of 4.64; scan 114 on the Radan Roadway software was used for comparison which resulted in a value of 5.44. The dielectric constant values are compared with the Radan Roadway software calculated values using the calculation procedure explained above.

\section{Further Procedures}

In order to complement the data collected by the GPR software, various techniques were used to gather more information about the pavement surface at each roadway site. First, core densities were measured at each roadway site. This data was collected by a nuclear gauge operator from the Michigan Department of Transportation. Nuclear density gauges are advantageous to use because the results can be determined non-destructively and relatively quickly at the site (Roberts et al., 1996). Nuclear density gauges determine the average density within the top several inches of the pavement; and was collected at each core location with an additional reading collected at a random adjacent location to estimate the variability of readings at each site. Also six-inch diameter pavement cores were obtained at each marked location to determine asphalt thickness measurements, and asphalt densities. Finally the asphalt core samples removed from the roadway were analyzed in the Michigan Tech University Asphalt Pavement Laboratories for thickness, moisture content, and 
density. This information was passed on to the Michigan Department of Transportation Laboratories in Lansing, Michigan. The asphalt data along with the GPR data was analyzed by John Belcher (the MDOT GPR technician) before being sent back to Michigan Technological University for final analysis. Finally, Belcher calculated GPR wavelet velocities for the US-41, M-26, and 5 Mile Point sites. With these files dielectric constant was directly calculate from these velocities using the formula: $\varepsilon=(C / V)^{2}$. For example, core location two was calculated in this fashion using Radan Roadway software velocities. At

this location a velocity of $8.63 * 10^{7}$ was calculated, $\mathrm{C}$ is $3 * 10^{8}$ therefore $\varepsilon=\left(\frac{3 * 10^{8}}{9.02 * 10^{7}}\right)^{2}=11.06$. All Radan Roadway Software values with calculated velocities were calculated in this manner.

\section{GPR Road Survey Results and Discussion}

Dielectric constant, was determined at the eleven pavement core locations at the four sites in this survey. A sample calculation for finding the dielectric constant of core location 1 for the M 26 scan in Table 3.1 is as follows. Using equation

$$
\varepsilon_{r \mathrm{l}}=\left(\frac{1+\frac{A_{0}}{A_{p}}}{1-\frac{A_{0}}{A_{p}}}\right) \text { where } \mathrm{A}_{0}=2.11 * 10^{4} \text { and } \mathrm{A}_{\mathrm{p}}=3.28 * 10^{4} \text {. Placing the }
$$


amplitudes in the dielectric constant equation $\varepsilon_{r 1}=\left(\frac{1+\frac{2.11^{*} 10^{4}}{32767}}{1-\frac{2.11^{*} 10^{4}}{32767}}\right)=4.64$. The results of the M-26, US 41, and Five Mile Point Road surveys are listed in Appendix A. The typical dielectric constant value was 5.1 with a maximum dielectric constant value of 7.99 at Core Location 3 at the Lac La Belle site. The lowest dielectric constant value occurred at Core Location 9 at the 5 Mile Point site. The results of the M-26 and Lac La Belle sites are shown in Table 3.1. When comparing these two methods the MATLAB method used surface and metal plate reflection data to calculate dielectric constants. Also the amplitude for unity reflection from the metal plate was the same for all tests, regardless of height above the plate. The exact method on how Radan Roadway software calculated velocities is proprietary, and thus not available, but it is obvious from using the program that this software makes velocity interpretations based on core thickness from the roadway samples. With thin or poor quality cores, velocity interpretation for the Radan Roadway software can lead to unrealistic dielectric constant values as is the case at the M-26 site. 
Table 3.1 MATLAB Calculated Dielectric Constant Values for M-26 \& Lac La Belle Road computed from Radan Roadway software and MATLAB Using Equation $\varepsilon_{r 1}=\left(1+\frac{A_{0}}{A_{p}} / 1-\frac{A_{0}}{A_{p}}\right)$
$\substack{\text { LacLaBelle } \\ \text { GPR Scan }}$

\begin{tabular}{|c|c|c|c|c|c|c|c|}
\hline \multirow[b]{2}{*}{$\begin{array}{l}\text { Core } \\
\text { Locaton }\end{array}$} & \multirow[b]{2}{*}{ Scan } & \multicolumn{3}{|c|}{ Wavelet Amplitude } & dielectric Constant & \multirow{2}{*}{\multicolumn{2}{|c|}{$\frac{\text { thickness }}{(\mathrm{cm})} \frac{\text { Calculation Method }}{}$}} \\
\hline & & & Ap & Ao & MATLAB RADAN & & \\
\hline 1 & & 73 & $3.28 E+04$ & $2.50 E+04$ & $7.45{ }^{*} \mathrm{NC}$ & 1.80 & Al Plate \& Amplitude \\
\hline 2 & & 132 & $3.28 E+04$ & $2.53 E+04$ & $7.80 * \mathrm{NC}$ & 1.50 & Al Plate \& Amplitude \\
\hline 3 & & 192 & $3.28 \mathrm{E}+04$ & $2.55 E+04$ & $7.99{ }^{*} \mathrm{NC}$ & 2.50 & Al Plate \& Amplitude \\
\hline 4 & & 254 & $3.28 E+04$ & $2.49 E+04$ & 7.28 *NC & 2.70 & Al Plate \& Amplitude \\
\hline 5 & & 313 & $3.28 \mathrm{E}+04$ & $2.45 E+04$ & $6.96 * \mathrm{NC}$ & 1.60 & Al Plate \& Amplitude \\
\hline 6 & & 374 & $3.28 E+04$ & $2.45 E+04$ & $6.88{ }^{*} \mathrm{NC}$ & 2.20 & Al Plate \& Amplitude \\
\hline 7 & & 434 & $3.28 E+04$ & $2.44 E+04$ & $6.81{ }^{*} \mathrm{NC}$ & 2.00 & Al Plate \& Amplitude \\
\hline 8 & & 496 & $3.28 E+04$ & $2.44 E+04$ & $6.82 * N C$ & 2.10 & Al Plate \& Amplitude \\
\hline 9 & & 555 & $3.28 E+04$ & $2.47 E+04$ & $7.09 * \mathrm{NC}$ & 2.40 & Al Plate \& Amplitude \\
\hline 10 & & 616 & $3.28 E+04$ & $2.38 E+04$ & $6.32{ }^{*} \mathrm{NC}$ & 1.90 & Al Plate \& Amplitude \\
\hline 11 & & 676 & $3.28 E+04$ & $2.41 \mathrm{E}+04$ & $6.577^{*} \mathrm{NC}$ & 1.50 & Al Plate \& Amplitude \\
\hline
\end{tabular}

${ }^{*} \mathrm{NC}=$ not calculated

M26

GPR Scan

Core

Locaton Scan
Wavelet Amplitude

$\begin{array}{lll}58 & 3.28 \mathrm{E}+04 \quad 2.11 \mathrm{E}+04\end{array}$

$2121 \quad 3.28 E+04 \quad 2.11 E+04$

$\begin{array}{llll}3 & 179 & 3.28 E+04 & 2.15 E+04\end{array}$

$\begin{array}{llll}4239 & 3.28 E+04 & 2.13 E+04\end{array}$

$\begin{array}{llll}5 & 301 & 3.28 \mathrm{E}+04 & 2.14 \mathrm{E}+04\end{array}$

$359 \quad 3.28 \mathrm{E}+04 \quad 2.12 \mathrm{E}+04$

$419 \quad 3.28 \mathrm{E}+04 \quad 2.14 \mathrm{E}+04$

$480 \quad 3.28 \mathrm{E}+04 \quad 2.17 \mathrm{E}+04$

$540 \quad 3.28 \mathrm{E}+04 \quad 2.19 \mathrm{E}+04$

$6013.28 \mathrm{E}+04 \quad 2.19 \mathrm{E}+04$

$663 \quad 3.28 \mathrm{E}+04 \quad 2.16 \mathrm{E}+04$ dielectric Constant

MATLAB RADAN
Radan Software

thickness Calculation Method (cm)

$\begin{array}{llll}4.64 & 1.28 & { }^{*} \mathrm{NC} & \text { Core Thickness } \\ 4.64 & 1.28 & 3.61 & \text { Core Thickness } \\ 4.83 & 1.39 & 3.73 & \text { Core Thickness } \\ 4.69 & 1.43 & 3.93 & \text { Core Thickness } \\ 4.74 & 1.41 & 3.50 & \text { Core Thickness } \\ 4.66 & 1.20 & 3.66 & \text { Core Thickness } \\ 4.78 & 1.12 & 3.57 & \text { Core Thickness } \\ 4.93 & 1.11 & 2.17 & \text { Core Thickness } \\ 5.05 & 1.00 & 4.19 & \text { Core Thickness } \\ 5.01 & 1.00 & 4.16 & \text { Core Thickness } \\ 4.86 & 1.21 & 3.74 & \text { Core Thickness }\end{array}$

Radan Roadway software used either core thickness data or GPR amplitude

data to calculate dielectric constant. The type of analysis performed depended on the availability of core samples data for the GPR technician to use. The availability of core sample data allowed the technician to use asphalt thickness to help interpret 
pavement velocities to calculate dielectric constants. Pavement core thickness data was used for the M-26, and Five Mile Point sites. GPR amplitude data was used for the US- 41 pavement section. Pavement cores obtained from the US-41 site were not used due to time constraints. Also pavement cores obtained from the Lac La Belle site were unreliable as they crumbled when removed from the sampling tube making their thickness determinations unreliable. Therefore, GPR amplitudes were used to interpret the Lac La Belle site within the Radan Roadway software.

\section{US 41 Site Analysis}

The average dielectric constant for the US 41 data is 4.4 with a maximum value of 4.68 at Core Location 7 and a minimum value of 4.21 at Core Location 8 . Using the Radan Roadway software calculated velocities, the average dielectric constant value is 11.39 . The maximum value of 12.28 occurred at Core Location 9 and the minimum value of 10.41 occurred and Core Location 8 . These values are consistent with the broad range of values from Wimsatt (1998), for flexible pavements. The Matlab results correspond to flexible pavements for lightweight aggregates and the Radan results correspond to flexible pavements made with course grained aggregates Wimsatt (1998). The quality of this survey was affected by the amount of moisture within the first two inches of the roadway and the lack of core thickness data that the GPR technician could use to analyze US 41 .

\section{M-26 Site Analysis}

Radan Roadway software and pavement thicknesses at the core locations were used to determine pavement velocities and dielectric constant values of the M-26 site. Radan Roadway software calculations of dielectric constant at this site were very low 
compared with typical pavement dielectric constant values, and averaged 1.22 with a maximum value of 1.443 at Core Location 4 and minimum value of 1.00 at Core Locations $9 \& 10$. These values are not realistic for pavement and thus should not be accepted. These values compared to Wimsatt (1998) are not valid for any pavement type. This discrepancy may be explained by the core sample may not have contained the entire first layer of pavement.



Figure 3.11: GPR Air Launched GPR scan of M-26 roadway site

Figure 3.11 clearly shows where the first layer throughout the scan, as shown by the light horizontal line crossing Figure 3.11 , contradicting the idea that the pavement layer was too thin to be traced by the GPR scan. The low value for dielectric constant may be due to the fact that the core samples many not have 
contained the full thickness of the top asphalt layer. The core samples used from M26 for the GPR interpretation were thin. Table 3.2 shows the average height and diameter of the M-26 core samples. Average height and diameter characteristics were calculated using three measurements on each sample.

Table 3.2: Thickness of M-26 Cores for 2005 GPR Survey

\begin{tabular}{|c|c|c|c|c|c|c|c|c|c|c|}
\hline \multicolumn{5}{|c|}{ Corelock } & & & & & & \\
\hline \multicolumn{3}{|c|}{ Project Number M 26/wwin Lake } & & & & & & & & \\
\hline Sample & 2 & 3 & 4 & 5 & 6 & 7 & 8 & 9 & 10 & 11 \\
\hline Average Height(mm) & 3.61 & 3.73 & 3.93 & 3.50 & 3.66 & 3.57 & 217 & 4.19 & 4.16 & 3.74 \\
\hline Average Diameter(mm) & 15.16 & 15.20 & 15.25 & 15.10 & 14.75 & 14.82 & 14.66 & 14.54 & 14.72 & 13.57 \\
\hline
\end{tabular}

The M-26 core samples have an average thickness of $3.63 \mathrm{~cm}$ with core location 10 being the thickest at $4.2 \mathrm{~cm}$ and core 8 being the thinnest core at $2.1 \mathrm{~cm}$. Of the four road surveys the M-26 site had on average the thinnest road cores to use for GPR interpretation. Due to the thin pavement, it's difficult to obtain realistic dielectric constant from GPR pavement amplitudes. By only observing the pavement thickness alone, the character of reflections is unidentifiable for beds less than $\lambda / 8$ thick according the Widess (1973) or about $3.75 \mathrm{~cm}$. The point of his paper is that with extremely thin bed sections destructive interference of the wavelet modifies or extinguishes the reflection making it impossible to calculate dielectric constant using the GPR wavelet (Widess, 1973). Given these conditions it wasn't possible to determine and obtain reasonable dielectric constant values because the roadway core thicknesses were too thin. 


\section{Five Mile Point Road Site Analysis}

Dielectric constant values were calculated using the Radan Roadway software velocities had an average value of 7.91 , a maximum value of 9.58 at Core Location 11, and a minimum value of 6.84 at Core Location 10. Comparing this average value to Wimsatt (1998), the results indicate this roadway is a flexible pavement. MATLAB calculated dielectric constant values had an average value of 4.05 with a maximum value at Core Location 1 of 4.36 and a minimum value at 3.89 at Core Location 9. This roadway also consistent with values for flexible pavements according to Wimsatt (1998). Generally, the difference in values fall within the range of flexible pavement but may indicate area of higher concentration of aggregate or asphalt binder used at a given core location.

\section{Lac La Belle Road Site Analysis From Surface Reflections}

For this site dielectric constant values were solely calculated and interpreted using GPR surface and subsurface wavelet amplitudes along with the MATLAB software. Because of crumbly cores, actual thickness of the pavement could not be determined and thus Radan Roadway software velocities were not calculated. Radan Roadway software determined the following dielectric constant values at the core locations shown in Table 3.1. Dielectric Constant values were determined by the following formula where $A_{0}$ is the GPR wavelet amplitude and $A_{p}$ is the aluminum plate amplitude ${ }_{\varepsilon_{\mathrm{r} 1}}=\left(\frac{1+\frac{A_{0}}{A_{p}}}{1-\frac{A_{0}}{A_{p}}}\right)$. When comparing the Lac La Belle Road dielectric constant values to Wimsatt (1998) this pavement is indicated to be a flexible pavement due to the dielectric constant values ranging from 6.5-7.8. A 
concern for interpreting this site is the very thin pavement at this site, which made it impossible to use core samples to help interpret pavement conditions in the Radan Roadway software.

\section{Comparison of MATLAB Results vs. Radan Roadway Software}

A comparison between dielectric constants calculated using the Radan Roadway software with those calculated in this study are shown in Tables 3.3, 3.4, and 3.5. Due to the instability of the roadway cores and lack of time in interpreting the roadway at the Lac La Belle site the GPR data was not analyzed by Radan Roadway software. Table 3.3 compares the MATLAB calculated dielectric constant results with the Radan Roadway software. The results that are compared are the US 41, M-26, and 5 Mile Point Sites.

Table 3.3: MATLAB Vs. Radan Roadway software Dielectric Constant Comparison of US 41 Site from the 2005 GPR Survey

\begin{tabular}{|c|c|c|c|c|c|c|c|}
\hline \multicolumn{8}{|l|}{ US41 } \\
\hline \multicolumn{2}{|l|}{ GPR Scan } & & & & & \multirow[b]{2}{*}{ thickness } & \multirow{2}{*}{$\begin{array}{l}\text { Radan Software } \\
\text { Calculation Method }\end{array}$} \\
\hline & & \multicolumn{2}{|c|}{ Wavelet Amplitude } & \multicolumn{2}{|c|}{ dielectric Constant } & & \\
\hline Core & & & & & & (cm) & \\
\hline Locaton & Scan & $A p$ & Ao & MATLAB & RADAN & & \\
\hline & & & & & & & \\
\hline 2 & 114 & $3.28 E+04$ & $2.11 E+04$ & 4.64 & 12.08 & 6.34 & 4 Al Plate \& Amplitude \\
\hline 3 & 175 & $3.28 E+04$ & $2.05 E+04$ & 4.35 & 11.06 & 7.18 & 8 Al Plate \& Amplitude \\
\hline 4 & 234 & $3.28 E+04$ & $2.03 E+04$ & 4.27 & 11.36 & 4.79 & 9 Al Plate \& Amplitude \\
\hline 5 & 295 & $3.28 E+04$ & 2.07E+04 & 4.41 & 10.66 & 4.73 & 3 Al Plate \& Amplitude \\
\hline 6 & 356 & $3.28 \mathrm{E}+04$ & $2.04 E+04$ & 4.31 & 10.94 & 4.83 & 3 Al Plate \& Amplitude \\
\hline 7 & 415 & $3.28 E+04$ & $2.12 E+04$ & 4.68 & 12.05 & 6.76 & Al Plate \& Amplitude \\
\hline 8 & 476 & $3.28 E+04$ & $2.02 E+04$ & 4.21 & 10.41 & 8.63 & 3 Al Plate \& Amplitude \\
\hline 9 & 537 & $3.28 E+04$ & $2.08 E+04$ & 4.47 & 12.28 & 7.10 & Al Plate \& Amplitude \\
\hline 10 & 598 & $3.28 E+04$ & $2.04 E+04$ & 4.29 & 11.98 & 7.25 & 5 Al Plate \& Amplitude \\
\hline 11 & 658 & $3.28 E+04$ & $2.05 E+04$ & 4.32 & 11.11 & 6.61 & Al Plate \& Amplitude \\
\hline
\end{tabular}


Table 3.4: MATLAB Vs. Radan Roadway software Dielectric Constant Comparison of M-26 Site from the 2005 GPR Survey

\begin{tabular}{|c|c|c|c|c|c|c|c|}
\hline \multicolumn{8}{|l|}{ M26 } \\
\hline \multicolumn{2}{|c|}{ GPR Scan } & & & & & & Radan Software \\
\hline & & \multicolumn{2}{|c|}{ Wavelet Amplitude } & \multicolumn{2}{|c|}{ dielectric Constant } & thickness & Calculation Method \\
\hline Core & & & & & & $(\mathrm{cm})$ & \\
\hline Locaton & Scan & Ap & Ao & MATLAB & RADAN & & \\
\hline 1 & 58 & $3.28 \mathrm{E}+04$ & $2.11 \mathrm{E}+04$ & 4.64 & 1.28 & N/A & Core Thickness \\
\hline 2 & 121 & $3.28 \mathrm{E}+04$ & $2.11 E+04$ & 4.64 & 1.28 & 3.61 & Core Thickness \\
\hline 3 & 179 & $3.28 \mathrm{E}+04$ & $2.15 E+04$ & 4.83 & 1.39 & 3.73 & Core Thickness \\
\hline 4 & 239 & $3.28 \mathrm{E}+04$ & $2.13 E+04$ & 4.69 & 1.43 & 3.93 & Core Thickness \\
\hline 5 & 301 & $3.28 \mathrm{E}+04$ & $2.14 E+04$ & 4.74 & 1.41 & 3.50 & Core Thickness \\
\hline 6 & 359 & $3.28 E+04$ & $2.12 E+04$ & 4.66 & 1.20 & 3.66 & Core Thickness \\
\hline 7 & 419 & $3.28 E+04$ & $2.14 E+04$ & 4.78 & 1.12 & 3.57 & Core Thickness \\
\hline 8 & 480 & $3.28 \mathrm{E}+04$ & $2.17 E+04$ & 4.93 & 1.11 & 2.17 & Core Thickness \\
\hline 9 & 540 & $3.28 \mathrm{E}+04$ & $2.19 E+04$ & 5.05 & 1.00 & 4.19 & Core Thickness \\
\hline 10 & 601 & $3.28 \mathrm{E}+04$ & $2.19 \mathrm{E}+04$ & 5.01 & 1.00 & 4.16 & Core Thickness \\
\hline 11 & 663 & $3.28 E+04$ & $2.16 \mathrm{E}+04$ & 4.86 & 1.21 & 3.74 & Core Thickness \\
\hline
\end{tabular}

Table 3.5: MATLAB Vs. Radan Roadway software Dielectric Constant Comparison of 5 Mile Point Road Site from the 2005 GPR Survey

\begin{tabular}{|c|c|c|c|c|c|c|c|}
\hline \multicolumn{8}{|l|}{5 Mile Pt } \\
\hline \multicolumn{2}{|l|}{ GPR Scan } & & & & & & \multirow{2}{*}{$\begin{array}{l}\text { Radan Software } \\
\text { Calculation Methoc }\end{array}$} \\
\hline & & \multicolumn{2}{|c|}{ Wavelet Amplitude } & \multicolumn{2}{|c|}{ dielectric Constant } & \multirow{2}{*}{$\frac{\text { thickness }}{\text { (cm) }}$} & \\
\hline Core & & & & & & & \\
\hline Locaton & Scan & Ap & Ao & MATLAB & RADAN & & \\
\hline 1 & 62 & $3.28 E+04$ & $2.05 E+04$ & 4.36 & 7.84 & 4.84 & Core thickness \\
\hline 2 & 121 & $3.28 E+04$ & $1.95 E+04$ & 3.93 & 7.92 & 4.61 & Core thickness \\
\hline 3 & 182 & $3.28 E+04$ & $1.99 E+04$ & 4.09 & 8.81 & 3.98 & Core thickness \\
\hline 4 & 241 & $3.28 E+04$ & $1.99 E+04$ & 4.09 & 8.27 & 4.31 & Core thickness \\
\hline 5 & 302 & $3.28 E+04$ & 1.96E+04 & 3.97 & 7.77 & 4.87 & Core thickness \\
\hline 6 & 362 & $3.28 E+04$ & $1.95 E+04$ & 3.93 & 7.63 & 4.51 & Core thickness \\
\hline 7 & 422 & $3.28 E+04$ & 1.97E+04 & 4.02 & 7.39 & 4.56 & Core thickness \\
\hline 8 & 485 & $3.28 \mathrm{E}+04$ & 1.97E+04 & 4.02 & 7.58 & 4.73 & Core thickness \\
\hline 9 & 544 & $3.28 E+04$ & $1.94 E+04$ & 3.89 & 7.35 & 4.81 & Core thickness \\
\hline 10 & 605 & $3.28 E+04$ & $1.95 E+04$ & 3.92 & 6.84 & 4.76 & Core thickness \\
\hline 11 & 663 & $3.28 E+04$ & $2.04 E+04$ & 4.29 & 9.58 & 4.01 & Core thickness \\
\hline
\end{tabular}


Table 3.6 MATLAB vs. Radan Roadway software Value Comparison

Site MATLAB $\underline{\text { Radan }}$

US 41 Realistic $\sim 2 \times$ MATLAB

M 26 Realistic Too Low

5 Mile Pt. Realistic $\sim 2 \times$ MATLAB

Tables 3.3 and 3.5 show that the dielectric constants calculated from the MATLAB and Radan Roadway software disagreed by a factor of two to three therefore the author turned to the methods of TDR and creating manufactured pavement sample to better determine values of dielectric constant. Furthermore, the Radan Roadway software is proprietary software, and it was not available for further trials at that time.

\section{Chapter 4. Ground Penetrating Radar Laboratory Measurements}

The author and his thesis advisor decided to have six pavement samples with known physical parameters manufactured to better understand the relationship between dielectric constant and pavement amplitude, $A_{0}$, the amplitude of the surface reflection. In particular, the goals of this survey included the following five goals:

1. First, creating a calibration curve using samples of known densities to relate pavement surface reflection amplitude $A_{0}$ to a single value of density. 
2. Second, designing an experiment which has a greater range of densities greater than $20 \mathrm{lbs} / \mathrm{ft}^{3}$ in order to calibrate $\mathrm{A}_{0}$ for dielectric constant and density.

3. Third, analyzing and isolating the effects of moisture using complete dry asphalt samples and calculated the velocity of and dielectric constant of GPR waves traveling within each pavement sample for wet and dry conditions.

4. Fourth, determining whether the direction of scanning the pavement samples has an effect on the dielectric constant of the sample when collecting raw data using the air-launched GPR antenna.

5. Finally, determining whether the manufactured samples produce dielectric constant values consistent with those of Wimsatt (1998) typical flexible pavement values.

In order to understand and analyze the relationship between dielectric constant and $A_{0}$, the author wrote a series of MATLAB programs specifically designed to interpret pavement surface interfaces and calculate GPR wavelet velocities within the asphalt samples. Unfortunately, for the final analysis of the raw data Belcher was not able to produce all of the raw data from this survey due to Radan Roadway software difficulties and his professional workload. The manufactured sample GPR survey was conducted at the Michigan Technological University campus. 


\section{Equipment and Setup}

The Michigan Technological University Civil Engineering Department created six asphalt pavement samples of varying densities, with physical properties shown in Table 4.1. The pavement sample dimensions were approximately 8 inches by 15 inches by 3 inches. The samples have an average thickness of 2.93 inches.

\section{Table 4.1: Physical Parameters of Manufactured Asphalt Samples}

$\begin{array}{rcrcc}\begin{array}{c}\text { Sample } \\ \text { Number }\end{array} & \begin{array}{c}\text { Density }\left(\mathbf{l b s} / \mathrm{ft}^{3} \text { ) }\right. \\ \text { Dry } \\ \text { Weight(g) }\end{array} & \begin{array}{l}\text { SSD } \\ \text { Weight(g) }\end{array} & \text { Thickness(inches) } \\ 1 & 180.90 & 13961.60 & 13977.40 & 2.84 \\ 2 & 183.60 & 13996.60 & 14023.50 & 2.91 \\ 3 & 186.20 & 14047.90 & 14087.70 & 3.00 \\ 4 & 187.00 & 13709.00 & 13792.20 & 3.02 \\ 5 & 181.50 & 13993.90 & 14042.10 & 2.87 \\ 6 & 185.00 & 13559.70 & 13645.50 & 2.95\end{array}$

The $1 \mathrm{GHz}$ air-launched antenna was used to conduct GPR scans across each pavement sample parallel and perpendicular direction to the long of the sample as shown in Figures 4.1 and 4.2. A hand held ground coupled $1 \mathrm{GHz}$ antenna from the Michigan Department of Transportation was used to provide GPR scans over each pavement sample as shown in Figure 4.3. Calibrations for unity reflection coefficient using the air-launched antenna were conducted with a two person team manually raising and lowering the antenna over a standard aluminum construction sign, to simulate the bounce test as used in a typical roadway GPR survey. Finally the raw data from the GPR was analyzed using MATLAB programs created by the author.

\section{GPR Data Collection}

The GPR antenna was held approximately 17 inches above the ground. The antenna scanned over each sample as it was placed with its long axis perpendicular or 
parallel to the direction of motion, as shown in Figure 4.1. The purpose for having the GPR antenna traverse the samples in a parallel and perpendicular manner determine if direction of traverse makes a recognizable difference in determining pavement dielectric constants values. For this experiment the finite "footprint" of the radar block was not infinitesimal in size, therefore the purpose of this experiment is to experimentally understand and reduce the effect of the edge of the pavement blocks, if possible.

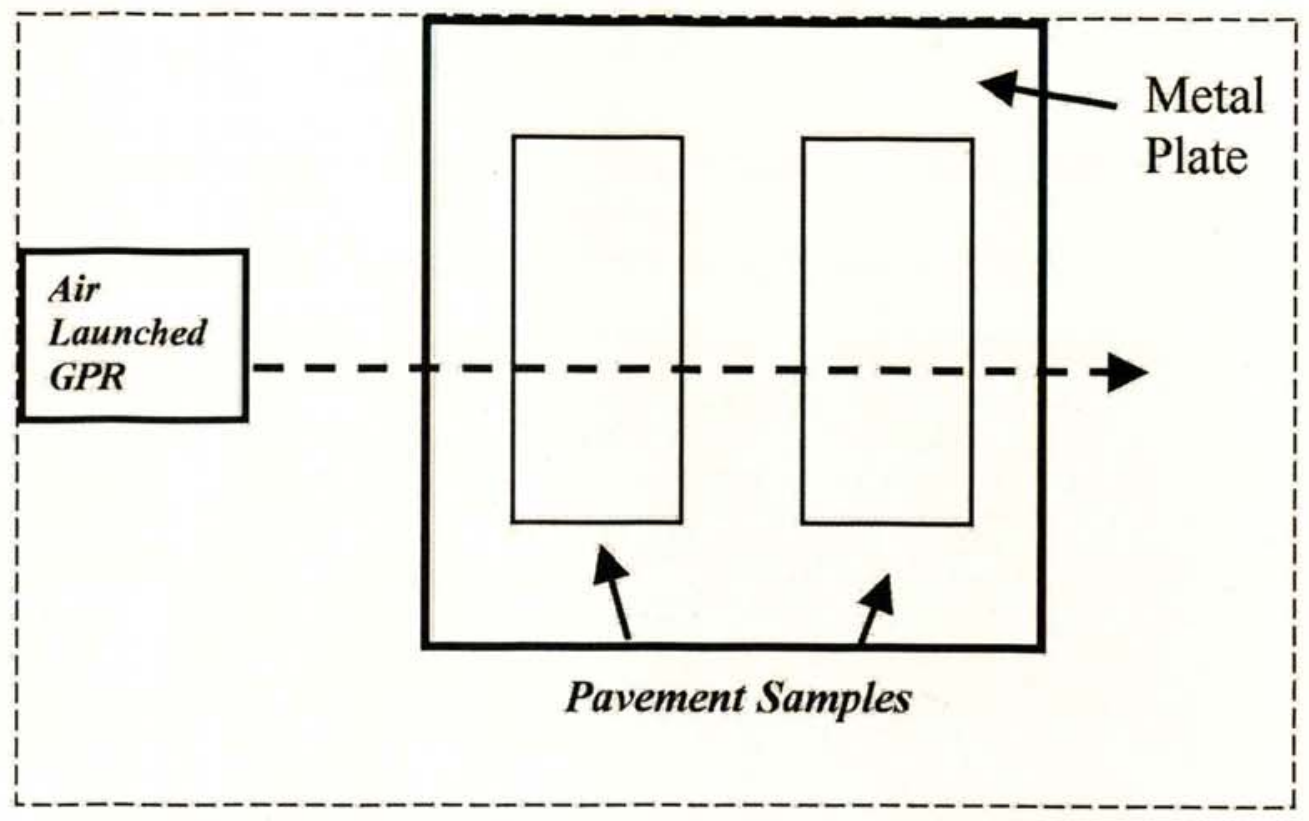

Figure 4.1: 2006 GPR laboratory experimental setup for perpendicular direction of motion 




Figure 4.2: 2006 GPR laboratory experimental setup for parallel direction of motion

The ground-coupled antenna used in this experiment is shown in Figure 4.3.

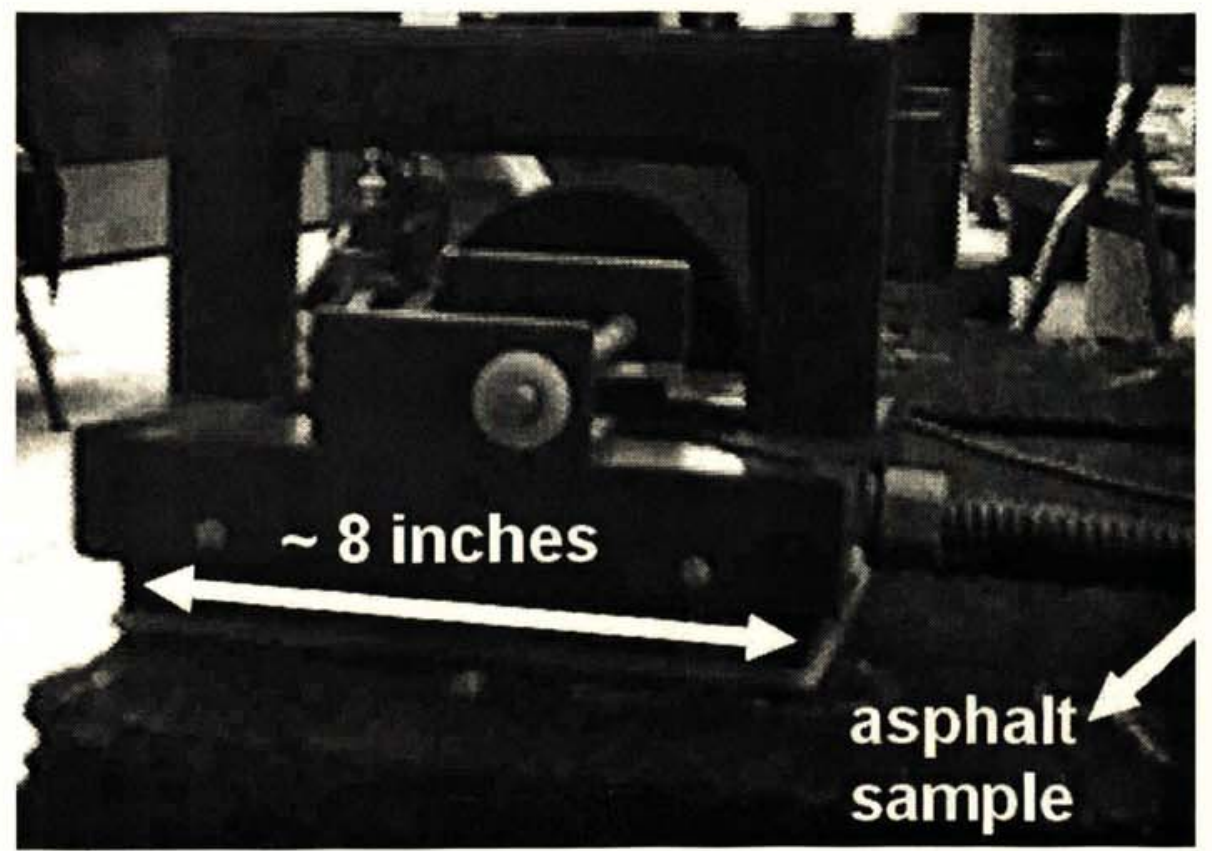

Figure 4.3: Ground Coupled Antenna gliding across pavement sample

The sample interval for the waveforms was 39 picoseconds/sample. In order to obtain GPR data of the pavement samples in a surface saturated dry condition each sample was submerged in a water bath for an hour and a half in the Michigan 
Technological University Pavement laboratory. After the samples were submerged in the water bath for nearly an hour and a half, they were weighed and then scanned by both GPR antennas according to the procedures above.

\section{GPR Survey Data Analysis with MatLab}

MATLAB was the primary program used to analyze raw data files obtained from

John Belcher from MDOT. A MATLAB program, gssi3, autopicklayers3, plus

additional programs written by Baron Colbert, were used to analyze the GPR wavelet velocities in pavement samples.

The MATLAB programs by the author were used to determine the amount of travel time that the GPR waves used to reach the top and bottom surface of each sample. Program autopicklayers3 served as a semi-automatic function selector in determining the top and bottom pavement sample interfaces based on the minimum amplitude from each GPR trace from a given raw data file scan. Given an initial time window and trace number, program "autopicklayers3" will pick the time of the most negative portion of the waveform and proceed to automatically pick the most negative points on adjacent traces. Thus, a reflection may be traced across a radar cross section. It is crucial to examine the data set carefully to obtain valid times for reflections from the metal plate, and the top of the asphalt block. This program also converted the time depth scale on a GPR trace to a specific trace number based of the raw data file's scan/second interval. This allowed the author to easily select the appropriate trace number to select pavement interfaces. The following description will explain how the pavement surface interfaces were selected for each pavement sample and how the dielectric constant values were calculated, using data from 
samples 5 and 6 from the air-launched GPR for wet samples in the experimental setup as shown in Figure 4.1.

Autopicklayers 3 asks the user to select a raw data file and input the number of traces and scans of the file. After entering the required information, the program then begins to interpret the location of the aluminum plate layer of the GPR trace. For the file including Samples 5 and 6, the author interprets the aluminum layer as the dark region within the GPR trace. For this example the aluminum layer is below scan 155 at trace 450 as shown in Figure 4.4.



Figure 4:4: Air-Launched GPR Scan of Saturated Samples 5 \& 6

After making the selection, autopicker 3 will go through every GPR trace searching for the minimum amplitude for trace number 1 through 912 with the minimum amplitude being chosen at any scan number greater than 155 as shown in Figure 4.4. The program will stop occasionally to allow for manual input of the 
location of the minimum trace in instances of multiple scan number locations having the same minimum amplitude at a particular trace number. After the program is finished, the output will be a combination plot of amplitude, first layer interpretation, and GPR image of samples $5 \& 6$ as shown in

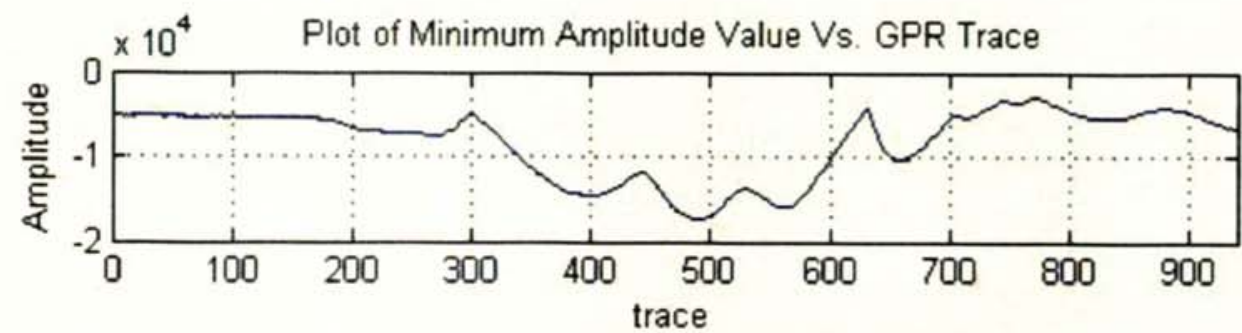

Plot of Trace Point Vs. Trace Number

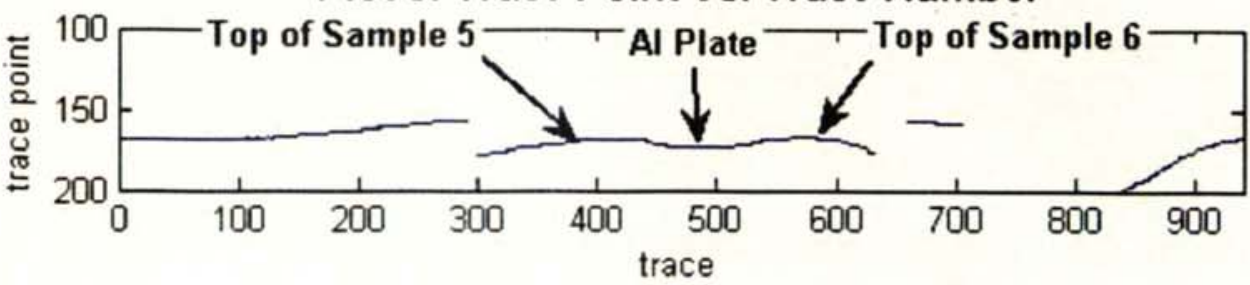

GPR Image of Pavement Samples 5 \& 6

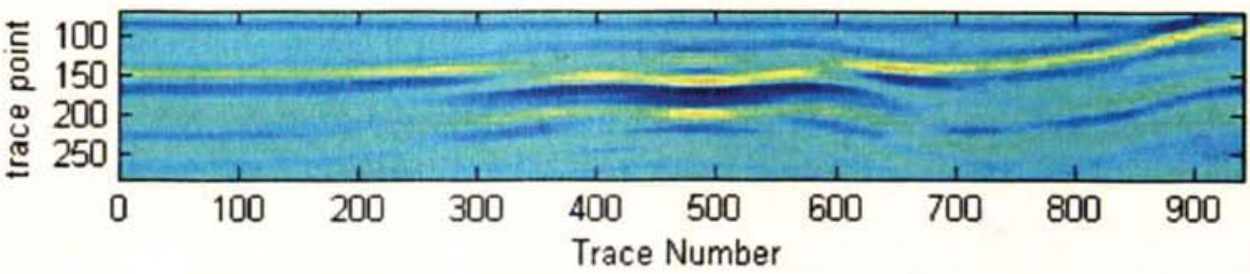

Figure 4.5: Autopicklayers3 Composite Output Showing the GPR Scan of Sample 5 and 6 Plus the Sample Surface Layer Picks and Amplitudes

Figure 4.5. Afterward, autopicklayers3 will interpret the location of the top layer of samples $5 \& 6$. Figure 4.5 displays the selection process of picking the 
surface layer for samples $5 \& 6$.



Figure 4:6: Autopicklayer3 Output Showing Upper Layer Pick Boundary Parameters for Samples 5 and 6. Proposed boundary range for upper layer boundary for samples 5 \& 6 with the solid line@ trace 120 being the upper range and the dashed line@145 being the lower range.

As shown in Figure 4.6, autopicklayers3 allows the user to select the boundary of the surface layer for samples 5 and 6 . In this case scan number 120 was the upper boundary as shown by the solid line in Figure 4.6 and scan number 145 was the lower boundary for surface layer interpretation shown by the dashed line in Figure 4.6. After autopicklayers 3 interprets the upper and lower sample interfaces it's 
displayed as shown in Figure 4.7.
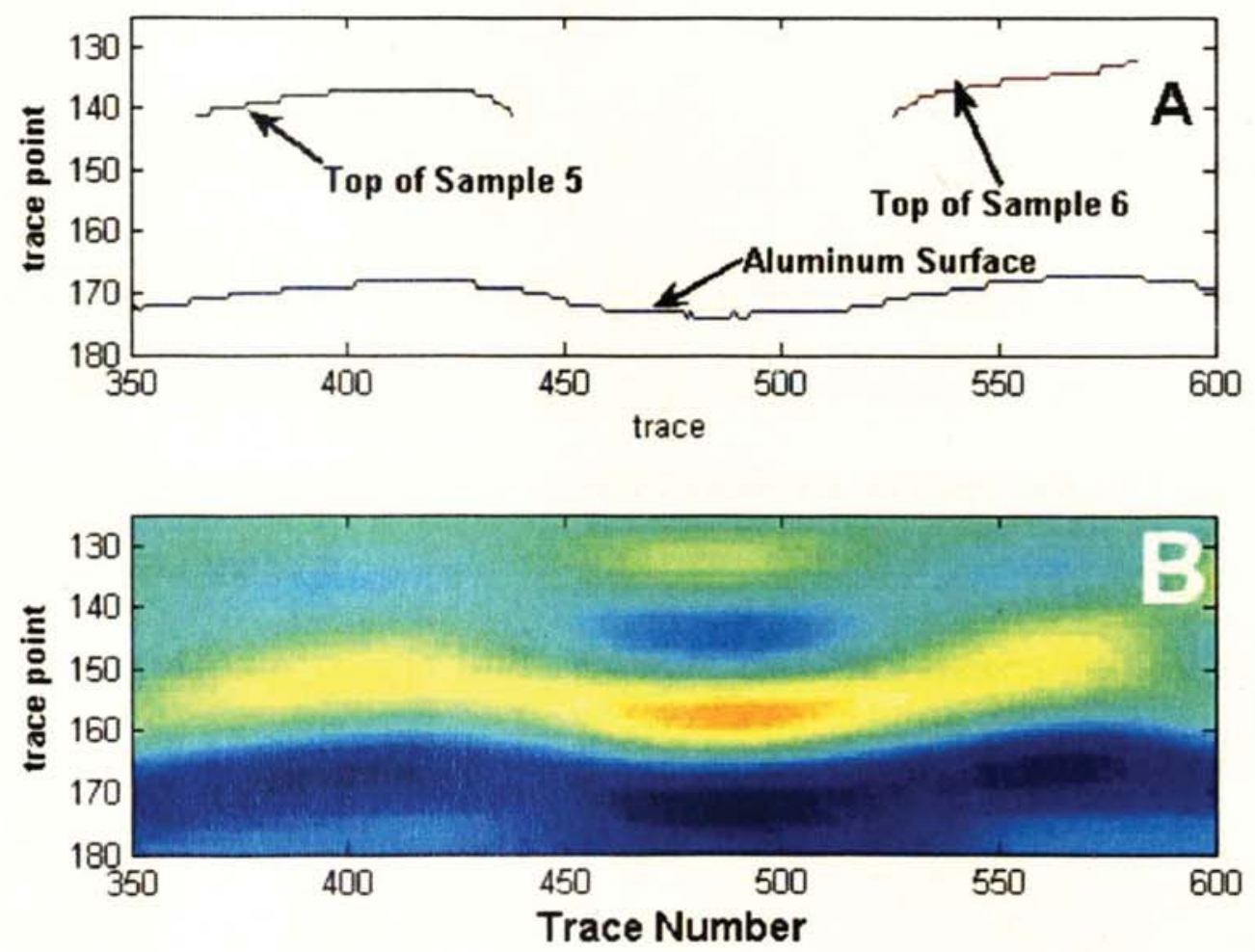

Figure 4: 7: Autopicklayers3 Upper and Lower Boundary Layer Picks A is the top surface plot of samples 5 and 6 and the aluminum plate surface and $B$ is $a$ GPR image of pavement samples 5 and 6.

At this point velocities and dielectric constants are ready to be calculated. For Sample 5 velocities were calculated by taking the difference between the bottom and top scan number from the sample and multiplying the difference by the sampling time. The top scan number for sample 5 is 169 and the bottom scan number is 137 . The sample rate is $3.91 * 10^{-11}$ seconds'. The one-way travel time for the GPR wave to travel through Sample 5 is:

$T T_{\text {oneway }}=(169-137) * 3.91 * 10^{-11} * \frac{1}{2}=6.25 * 10^{-10}$ seconds. 
With a thickness of $7.3 * 10^{-2}$ meters the velocity is:

Velocity $_{\text {samples }}=$ thickness $/$ traveltime $=\frac{7.3 * 10^{-2} \mathrm{~m}}{6.25 * 10^{-10} \mathrm{sec}}=1.17 * 10^{8} \mathrm{~m} / \mathrm{sec}$. The dielectric constant is calculated using: $\kappa=(c / v)^{2}=\left(\frac{3 * 10^{8}}{1.17 * 10^{8}}\right)^{2}=6.6$. Where $\mathrm{c}$ is the speed of light and $v$ is the velocity of the radar wave within the pavement. Thus, using the pavement thickness, and GPR travel time in pavement, and speed of light, dielectric constant measurements were calculated for the saturated and unsaturated samples for the 2006 GPR survey.

For the ground coupled GPR experiment, the GPR waveform was used to calculate the dielectric constant. Figure 4.8 below shows a sample wavelet taken from sample \#1 in the saturated phase of the ground coupled GPR experiment.



Figure 4.8: Ground Coupled GPR Wet Sample Picking Points for Top A and Bottom Pavement Surface B. The $x$ coordinates are the sample points and the $y$ coordinates are the wavelet amplitudes 
The ground coupled GPR typically has a time-depth range of 6 nanoseconds and a sampling rate of nearly 12 picoseconds/sample. For this experiment the asphalt samples are approximately 2 inches. Combined with the sampling rate of 12 picoseconds/sample, MATLAB has a reasonable resolution in determining dielectric constant values for the asphalt samples. As shown in Table 4.2., approximately 120 130 samples, are used to calculate GPR wavelet travel time within the pavement samples.

Table 4.2: GPR Wavelet Sample Count for the Calculation of Dielectric Constant Using Ground Coupled GPR Experiment

Unsaturated Sample Trace Locations

\section{Top Sample Bottom Sample Location \\ Location}

Sample 1

Sample 2

Sample 3

Sample 4

Sample 5

Sample 6
206

209

212

208

207

210
Total Sample Count Used to Determine GPR Wavelet

129

132

135

131

130

133

\section{Saturated Sample Trace Locations}

\section{Sample 1}

Sample 2

Sample 3

Sample 4

Sample 5

Sample 6

\section{Top Sample Location}

94

94

94

94

94

94
Bottom Sample

Location

215

220

222

218

215

220
Total Sample Count Used to Determine GPR

Wavelet

126

128

124

121

126 


\section{Single Density Calibration Results and Discussion}

Also as a part of the 2006 GPR survey an attempt to calibrate GPR wavelet amplitudes we according to their densities were performed. Numerical values are given in Table 4.3, 4.4, and 4.5, and the data are plotted in Figures 4.9 and 4.10.

Table 4.3: Amplitude and Dielectric Constant Results for Wavelet Calibration Test for Unsaturated Pavement samples 1 \& 2 Using Air Launched GPR Antenna Ap is metal plate reflection amplitude, Ao is pavement surface amplitude

\begin{tabular}{|c|c|c|c|c|c|c|}
\hline Core & & & & & & Motion Relative \\
\hline Locaton & Scan & Ap & Ao & dielectric Constant & Density(lbsitt $\left.{ }^{3}\right)$ & to sample \\
\hline 1 & 430 & $3.28 E+04$ & $1.89 E+04$ & 3.72 & 180.90 & parallel \\
\hline 1 & 450 & $3.28 \mathrm{E}+04$ & $1.98 E+04$ & 4.06 & 180.90 & parallel \\
\hline 1 & 470 & $3.28 E+04$ & $2.08 E+04$ & 4.46 & 180.90 & parallel \\
\hline 1 & 490 & $3.28 E+04$ & $2.05 E+04$ & 4.32 & 180.90 & parallel \\
\hline 2 & 640 & $3.28 E+04$ & $1.95 E+04$ & 3.93 & 183.60 & parallel \\
\hline 2 & 660 & $3.28 \mathrm{E}+04$ & $2.11 E+04$ & 4.63 & 183.60 & parallel \\
\hline 2 & 680 & $3.28 \mathrm{E}+04$ & $2.19 E+04$ & 5.01 & 183.60 & parallel \\
\hline 2 & 700 & $3.28 \mathrm{E}+04$ & $2.11 \mathrm{E}+04$ & 4.59 & 183.60 & parallel \\
\hline & & & & & & Motion Relative \\
\hline Core & & & & & Density(lbsitt') & to sample \\
\hline Locaton & Scan & $\underline{A p}$ & Ao & & & \\
\hline 1 & 460 & $3.28 E+04$ & $1.57 E+04$ & 2.83 & 180.90 & perpendicular \\
\hline 1 & 500 & $3.28 E+04$ & $2.04 E+04$ & 4.32 & 180.90 & perpendicular \\
\hline 1 & 540 & $3.28 E+04$ & $2.09 E+04$ & 4.50 & 180.90 & perpendicular \\
\hline 1 & 580 & $3.28 E+04$ & $1.59 E+04$ & 2.89 & 180.90 & perpendicular \\
\hline 2 & 780 & $3.28 E+04$ & $1.34 E+04$ & 2.39 & 183.60 & perpendicular \\
\hline 2 & 800 & $3.28 E+04$ & $1.91 E+04$ & 3.79 & 183.60 & perpendicular \\
\hline 2 & 820 & $3.28 E+04$ & $2.03 E+04$ & 4.25 & 183.60 & perpendicular \\
\hline 2 & 840 & $3.28 E+04$ & $1.92 E+04$ & 3.84 & 183.60 & perpendicular \\
\hline
\end{tabular}


Table 4.4: Amplitude and Dielectric Constant Results for Wavelet Calibration Test for Unsaturated Pavement samples 3 \& 4 Using Air Launched GPR Antenna

\begin{tabular}{|c|c|c|c|c|c|c|}
\hline Core & & & & & & Motion Relative \\
\hline Locaton & Scan & Ap & Ao & dielectric Constant & Density $\left(\mathrm{lbs} / \mathrm{ft}^{3}\right)$ & to sample \\
\hline 3 & 460 & $3.28 E+04$ & $1.74 E+04$ & 3.27 & 186.20 & parallel \\
\hline 3 & 480 & $3.28 \mathrm{E}+04$ & $1.82 E+04$ & 3.49 & 186.20 & parallel \\
\hline 3 & 500 & $3.28 \mathrm{E}+04$ & $1.85 E+04$ & 3.60 & 186.20 & parallel \\
\hline 3 & 520 & $3.28 E+04$ & $1.85 E+04$ & 3.59 & 186.20 & parallel \\
\hline 4 & 660 & $3.28 E+04$ & $1.76 E+04$ & 3.32 & 187.00 & parallel \\
\hline 4 & 680 & $3.28 E+04$ & $1.81 E+04$ & 3.46 & 187.00 & parallel \\
\hline 4 & 700 & $3.28 E+04$ & $1.90 E+04$ & 3.77 & 187.00 & parallel \\
\hline 4 & 720 & $3.28 \mathrm{E}+04$ & $1.77 E+04$ & 3.35 & 187.00 & parallel \\
\hline & & & & & & \\
\hline Core & & & & & & Motion Relative \\
\hline Locaton & Scan & Ap & Ao & dielectric Constant & Density(lbs/ft $\left.{ }^{3}\right)$ & to sample \\
\hline 3 & 370 & $3.28 E+04$ & 1.24E+04 & 2.22 & 186.20 & perpendicular \\
\hline 3 & 390 & $3.28 E+04$ & $1.64 E+04$ & 3.00 & 186.20 & perpendicular \\
\hline 3 & 410 & $3.28 \mathrm{E}+04$ & 1.74E+04 & 3.28 & 186.20 & perpendicular \\
\hline 3 & 430 & $3.28 \mathrm{E}+04$ & $1.41 \mathrm{E}+04$ & 2.51 & 186.20 & perpendicular \\
\hline 4 & 590 & $3.28 E+04$ & 1.44E+04 & 2.57 & 187.00 & perpendicular \\
\hline 4 & 610 & $3.28 E+04$ & $1.83 E+04$ & 3.51 & 187.00 & perpendicular \\
\hline 4 & 630 & $3.28 E+04$ & 1.85E+04 & 3.60 & 187.00 & perpendicular \\
\hline 4 & 650 & $3.28 E+04$ & $1.48 E+04$ & 2.65 & 187.00 & perpendicular \\
\hline
\end{tabular}


Table 4.5: Amplitude and Dielectric Constant Results for Wavelet Calibration Test for Unsaturated Pavement samples 5 \& 6 Using Air Launched GPR Antenna

\begin{tabular}{|c|c|c|c|c|c|c|c|}
\hline Core & & & & & & & Motion Relative \\
\hline Locaton & Scan & & Ap & Ao & dielectric Constant & Density(lbsift') & to sample \\
\hline 5 & & 500 & $3.28 E+04$ & $1.86 E+04$ & 3.61 & 181.50 & parallel \\
\hline 5 & & 520 & $3.28 \mathrm{E}+04$ & $2.06 E+04$ & 4.39 & 181.50 & parallel \\
\hline 5 & & 540 & $3.28 E+04$ & $2.13 E+04$ & 4.73 & 181.50 & parallel \\
\hline 5 & & 560 & $3.28 \mathrm{E}+04$ & $2.02 E+04$ & 4.20 & 181.50 & parallel \\
\hline & & & & & & & \\
\hline 6 & & 700 & $3.28 E+04$ & $1.92 E+04$ & 3.82 & 185.00 & parallel \\
\hline 6 & & 720 & $3.28 \mathrm{E}+04$ & $2.11 E+04$ & 4.61 & 185.00 & parallel \\
\hline 6 & & 740 & $3.28 \mathrm{E}+04$ & $2.02 E+04$ & 4.21 & 185.00 & parallel \\
\hline 6 & & 760 & $3.28 \mathrm{E}+04$ & $1.77 \mathrm{E}+04$ & 3.34 & 185.00 & parallel \\
\hline & & & & & & & \\
\hline Core & & & & & & & Motion Relative \\
\hline Locaton & Scan & & Ap & Ao & dielectric Constant & Density(lbsit $\left.{ }^{3}\right)$ & to sample \\
\hline 5 & & 480 & $3.28 \mathrm{E}+04$ & 1.39E+04 & 2.47 & 181.50 & perpendicular \\
\hline 5 & & 500 & $3.28 E+04$ & 1.69E+04 & 3.12 & 181.50 & perpendicular \\
\hline 5 & & 520 & $3.28 \mathrm{E}+04$ & 1.70E+04 & 3.17 & 181.50 & perpendicular \\
\hline 5 & & 540 & $3.28 \mathrm{E}+04$ & 1.40E+04 & 2.50 & 181.50 & perpendicular \\
\hline & & & & & & & \\
\hline 6 & & 680 & $3.28 E+04$ & 1.47E+04 & 2.63 & 185.00 & perpendicular \\
\hline 6 & & 700 & $3.28 \mathrm{E}+04$ & $1.68 \mathrm{E}+04$ & 3.10 & 185.00 & perpendicular \\
\hline 6 & & 720 & $3.28 E+04$ & $1.58 E+04$ & 2.86 & 185.00 & perpendicular \\
\hline 6 & & 740 & $3.28 E+04$ & $1.29 \mathrm{E}+04$ & 2.31 & 185.00 & perpendicular \\
\hline
\end{tabular}

In tables $4.3-4.5$ the dielectric constant was calculated using $A_{p}, A_{o}$,

and $\varepsilon_{r 1}=\left(\frac{1+\frac{A_{0}}{A_{p}}}{1-\frac{A_{0}}{A_{p}}}\right)$. The single calibration phase of this study consisted of taking $\mathrm{A}_{\mathrm{o}}$

from each of the core scans and comparing it with the sample density. Surface wave 
amplitudes were plotted vs. densities to visualize the statistical behavior. Figures 4.9

and 4.10 below show the calibration for the single density for sample waveform amplitude vs. density.



Figure 4.9: Sample Waveform Amplitude Vs. Density Calibration for Radar Traverse Parallel to Long Axis of Block.



Figure 4.10: Sample Waveform Amplitude Vs. Density Calibration for Radar Traverse Perpendicular to Long Axis of Block.

In order to determine the error of the calibrations for the parallel and perpendicular motions, a standard deviation was calculated for each sample in both directions of motion. The results for the standard deviation are shown in Table 4.6. 
Table 4.6: Core Density and $\mathbf{A}_{\mathbf{0}}$ Calibration Standard Deviation

Using $\mathrm{A}_{0}=3.28 * 10^{4}$

\begin{tabular}{|c|c|c|c|c|}
\hline $\begin{array}{l}\text { Core } \\
\text { Locaton }\end{array}$ & Density(Ibs/ft3) & $\begin{array}{l}\text { Motion Relative } \\
\text { to sample }\end{array}$ & $\begin{array}{l}\text { Standard Deviation } \\
\text { of } A_{0}\end{array}$ & $\begin{array}{l}\text { Percent } \\
\text { Error }\end{array}$ \\
\hline 1 & 180.90 & parallel & 828.39 & 2.5 \\
\hline 1 & 180.90 & perpendicular & 2813.48 & 8.6 \\
\hline Core & Density(Ibs/ft3) & $\begin{array}{l}\text { Motion Relative } \\
\text { to sample }\end{array}$ & $\begin{array}{l}\text { Standard Deviation } \\
\text { of } A_{0}\end{array}$ & $\begin{array}{l}\text { Percent } \\
\text { Error }\end{array}$ \\
\hline 2 & 183.60 & parallel & 1009.07 & 3.1 \\
\hline 2 & 183.60 & perpendicular & 3103.59 & 9.5 \\
\hline $\begin{array}{l}\text { Core } \\
\text { Locaton }\end{array}$ & Density(Ibs/ft3) & $\begin{array}{l}\text { Motion Relative } \\
\text { to sample }\end{array}$ & & \\
\hline 3 & 186.20 & parallel & 504.54 & 1.5 \\
\hline 3 & 186.20 & perpendicular & 2257.44 & 6.9 \\
\hline$\underline{\text { Core }}$ & & Motion Relative & Standard Deviation & Percent \\
\hline Locaton & Density(Ibs/ft3) & to sample & of $A_{0}$ & Error \\
\hline 4 & 187.00 & parallel & 651.84 & 2.0 \\
\hline 4 & 187.00 & perpendicular & 2190.96 & 6.7 \\
\hline Core & & Motion Relative & Standard Deviation & Percent \\
\hline Locaton & Density(lbs/ft3) & to sample & of $A_{0}$ & Error \\
\hline 5 & 181.50 & parallel & 1174.77 & 3.6 \\
\hline 5 & 181.50 & perpendicular & 1734.25 & 5.3 \\
\hline $\begin{array}{l}\text { Core } \\
\text { Locaton }\end{array}$ & ensity/lhe/ft3) & Motion Relative & Standard Deviation & $\begin{array}{l}\text { Percent } \\
\text { Error }\end{array}$ \\
\hline & 185.00 & & & 5.0 \\
\hline
\end{tabular}

Table 4.6 shows that when the air launched GPR antenna is run in a parallel direction along the pavement sample there is significantly less deviation from the mean of $A_{0}$ as shown for cores 1-4. As for cores 5 and 6 running the GPR in a parallel direction across the samples produces slightly less deviation in surface amplitude 
values. As a result of this study the calibration of pavement amplitude $A_{0}$ vs. density provided better results that the dielectric constant vs. density results of the 2005 survey. These results indicate a small linear dependence of $A_{0}$ with density.

Although the $A_{0}$ vs. density provided a trend that was linear, the result contradicted in theory that as pavement amplitude increased density or dielectric constant would increase. The calibration results from this experiment showed that as density increased $\mathrm{A}_{0}$ slightly decreased. This result indicates that again an increase in the range of densities still will be needed in order to validate this result. Despite attempts to increase the density range of asphalt samples, a density range of greater than 20 $\mathrm{lbs} / \mathrm{ft}^{3}$ could not be obtained.

\section{GPR LABORATORY RESULTS AND DISCUSSION}

Wavelet amplitude data was collected with the air-launched antenna data and used to calculate dielectric constant by using MATLAB along with sample thickness data. The thickness information of each sample was used to analyze each sample except for samples five and six. Due to faulty software, these samples could not be analyzed with their thickness data using Radan Roadway software. Pavement layer interface data determined from the ground coupled GPR antenna was used to calculate dielectric constant using $\varepsilon=(\mathrm{C} / \mathrm{V})^{2}$, where $\mathrm{C}$ is the speed of light, and $\mathrm{V}$ is the GPR wave velocity within the sample.

The results for the air-launched GPR data for the saturated and unsaturated manufactured asphalt samples are displayed in Table 4.7. The results of the ground coupled GPR data for dry and wet samples are shown in Table 4.8 . 
Table 4.7: 1GHz Air-Launched GPR Dielectric Constant Results from the GPR Laboratory Measurements

\begin{tabular}{|c|c|c|c|c|c|c|c|}
\hline \multicolumn{8}{|c|}{ Unsaturated Samples } \\
\hline & & & & & Thickness & \multirow{3}{*}{$\begin{array}{l}\text { sample bottom } \\
\text { Velocity }\end{array}$} & \\
\hline \multirow[t]{2}{*}{ Files } & \multicolumn{2}{|c|}{ Trace Locations } & \multicolumn{2}{|r|}{ (Surface to } & \multirow[t]{2}{*}{ meters } & & \multirow{2}{*}{$\frac{\varepsilon}{\text { Dielectric Const. }}$} \\
\hline & Top & Bottom & Sample & Sample Bottom) & & & \\
\hline 182Perp.dzt & 167 & 196 & 1 & $5.66 \mathrm{E}-10$ & $7.21 E-02$ & $1.27 E+08$ & 5.6 \\
\hline & 166 & 197 & 1 & $6.05 E-10$ & $7.21 \mathrm{E}-02$ & 1. $19 E+08$ & 6.4 \\
\hline & 167 & 196 & 1 & $5.66 \mathrm{E}-10$ & $7.21 E-02$ & 1.27E+08 & 5.6 \\
\hline & & & & & & & \\
\hline & 165 & 196 & 2 & $6.05 E-10$ & 7.39E-02 & $1.22 E+08$ & 6.0 \\
\hline & 166 & 195 & 2 & $5.66 \mathrm{E}-10$ & 7.39E-02 & 1. $30 E+08$ & 5.3 \\
\hline & 167 & 196 & 2 & $5.66 \mathrm{E}-10$ & 7.39E- 02 & 1. $30 E+08$ & 5.3 \\
\hline & & & & & & & \\
\hline 182PARAL.DZT & Top & Bottom & & & & & \\
\hline & 171 & 203 & 1 & $6.25 E-10$ & 7.21E-02 & 1.15E+08 & 6.8 \\
\hline & 170 & 204 & 1 & $6.64 E-10$ & $7.21 \mathrm{E}-02$ & $1.09 E+08$ & 7.6 \\
\hline & 171 & 205 & 1 & $6.64 E-10$ & 7.21E-02 & $1.09 E+08$ & 7.6 \\
\hline & & & & & & & \\
\hline & 170 & 204 & 2 & $6.64 E-10$ & 7.39E-02 & $1.11 E+08$ & 7.3 \\
\hline & 169 & 203 & 2 & $6.64 E-10$ & $7.39 E-02$ & 1.11E+08 & 7.3 \\
\hline & 168 & 202 & 2 & $6.64 E-10$ & 7.39E-02 & 1.11E+08 & 7.3 \\
\hline & & & & & & & \\
\hline & & & & & & & \\
\hline 3\&APARAL.DZT & 173 & 206 & 3 & $6.45 E-10$ & 7.61E-02 & 1. $18 E+08$ & 6.4 \\
\hline & 173 & 206 & 3 & $6.45 E-10$ & $7.61 E-02$ & 1. $18 E+08$ & 6.4 \\
\hline & 174 & 206 & 3 & 6.25E-10 & 7.61E-02 & $1.22 E+08$ & 6.1 \\
\hline & & & & & & & \\
\hline & 171 & 206 & 4 & $6.84 E-10$ & 7.67E-02 & 1.12E+08 & 7.1 \\
\hline & 171 & 206 & 4 & $6.84 E-10$ & 7.67E-02 & $1.12 E+08$ & 7.1 \\
\hline & 172 & 206 & 4 & $6.64 \mathrm{E}-10$ & $7.67 E-02$ & 1.16E+08 & 6.7 \\
\hline & & & & & & & \\
\hline 3\&4PERP,DZT & 171 & 201 & 3 & $5.86 \mathrm{E}-10$ & $7.61 \mathrm{E}-02$ & $1.30 E+08$ & 5.3 \\
\hline & 171 & 201 & 3 & $5.86 \mathrm{E}-10$ & 7.61E-02 & 1. $30 E+08$ & 5.3 \\
\hline & 171 & 201 & 3 & $5.86 \mathrm{E}-10$ & $7.61 \mathrm{E}-02$ & 1.30E+08 & 5.3 \\
\hline & & & & & & & \\
\hline & 171 & 201 & 4 & $5.86 \mathrm{E}-10$ & 7.67E-02 & $1.31 E+08$ & 5.3 \\
\hline & 171 & 201 & 4 & $5.86 \mathrm{E}-10$ & 7.67E-02 & 1.31E+08 & 5.3 \\
\hline & 173 & 201 & 4 & $5.47 \mathrm{E}-10$ & 7.67E-02 & $1.40 E+08$ & 4.6 \\
\hline 5\&6PARAL.DZT & 170 & 203 & 5 & $6.45 E-10$ & 7.30E-02 & 1.13E+08 & 7.0 \\
\hline & 170 & 204 & 5 & $6.64 E-10$ & $7.30 E-02$ & 1.10E+08 & 7.4 \\
\hline & 169 & 203 & 5 & $6.64 \mathrm{E}-10$ & 7.30E-02 & $1.10 E+08$ & 7.4 \\
\hline & & & & & & & \\
\hline & 170 & 202 & 6 & $6.25 \mathrm{E}-10$ & $7.50 E-02$ & $1.20 E+08$ & 6.2 \\
\hline & 170 & 203 & 6 & $6.45 E-10$ & 7.50E-02 & 1.16E+08 & 6.6 \\
\hline & 169 & 204 & 6 & $6.84 E-10$ & $7.50 E-02$ & 1. $10 \mathrm{E}+08$ & 7.5 \\
\hline \multirow{7}{*}{ 5\&6PE } & & 203 & 5 & $5.86 \mathrm{E}-10$ & $7.30 \mathrm{E}-02$ & 1.25E+08 & 58 \\
\hline & $\begin{array}{l}173 \\
173\end{array}$ & $\begin{array}{l}203 \\
202\end{array}$ & 5 & $5.66 \mathrm{E}-10$ & 7.30E-02 & $1.29 E+08$ & 5.4 \\
\hline & 172 & 202 & 5 & $5.86 \mathrm{E}-10$ & 7.30E-02 & $1.25 E+08$ & 5.8 \\
\hline & & & & & & & \\
\hline & 169 & 199 & 6 & $5.86 \mathrm{E}-10$ & $7.50 \mathrm{E}-02$ & $1.28 E+08$ & 5.5 \\
\hline & 170 & 200 & 6 & $5.86 \mathrm{E}-10$ & $7.50 \mathrm{E}-02$ & $1.28 E+08$ & 5.5 \\
\hline & 171 & 201 & 6 & $5.86 \mathrm{E}-10$ & $7.50 \mathrm{E}-02$ & 1.28E+08 & 5.5 \\
\hline
\end{tabular}




\begin{tabular}{|c|c|c|c|c|c|c|c|}
\hline \multicolumn{8}{|c|}{ Saturated Samples } \\
\hline & & & & Time(seconds) & Thickness & Velocity (m/s) & \\
\hline \multirow[t]{2}{*}{ Files } & \multicolumn{3}{|c|}{ Trace Locations } & (Surface to & meters & sample bottom & $\varepsilon$ \\
\hline & Top & Bottom & Sample & Sample Bottom) & & Velocity & Dielectric Const. \\
\hline \multirow[t]{7}{*}{ 1\&2Perp2.dzt } & 147 & 178 & 1 & $6.05 E-10$ & $7.21 E-02$ & 1.19E+08 & 6.4 \\
\hline & 147 & 178 & 1 & $6.05 E-10$ & 7.21E-02 & 1.19E+08 & 6.4 \\
\hline & 148 & 177 & 1 & $5.66 \mathrm{E}-10$ & 7.21E-02 & $1.27 E+08$ & 5.6 \\
\hline & & & & & & & \\
\hline & 141 & 174 & 2 & $6.45 \mathrm{E}-10$ & 7.39E-02 & 1.15E+08 & 6.8 \\
\hline & 141 & 174 & 2 & $6.45 \mathrm{E}-10$ & 7.39E-02 & 1.15E+08 & 6.8 \\
\hline & 141 & 175 & 2 & $6.64 E-10$ & 7.39E-02 & $1.11 E+08$ & 7.3 \\
\hline & & & & & & & \\
\hline \multirow{9}{*}{ 182PARA2.DZT } & Top & Bottom & & & & & \\
\hline & 126 & 158 & 1 & $6.25 \mathrm{E}-10$ & $7.21 \mathrm{E}-02$ & 1.15E+08 & 6.8 \\
\hline & 126 & 158 & 1 & $6.25 \mathrm{E}-10$ & 7.21E-02 & $1.15 E+08$ & 6.8 \\
\hline & 126 & 158 & 1 & $6.25 \mathrm{E}-10$ & $7.21 E-02$ & 1.15E+08 & 6.8 \\
\hline & 127 & 159 & 2 & $625 \mathrm{E}-10$ & & & \\
\hline & 127 & 159 & 2 & $\begin{array}{l}6.25 \mathrm{E}-10 \\
6.25 \mathrm{E}-10\end{array}$ & $\begin{array}{l}7.39 \mathrm{E}-02 \\
7.39 \mathrm{E}-02\end{array}$ & $\begin{array}{l}1.18 E+08 \\
1.18 E+08\end{array}$ & $\begin{array}{l}6.4 \\
6.4\end{array}$ \\
\hline & 127 & 159 & 2 & $6.25 E-10$ & 7.39E-02 & $\begin{array}{l}1.18 E+08 \\
1.18 E+08\end{array}$ & $\begin{array}{l}6.4 \\
6.4\end{array}$ \\
\hline & & & & & & & \\
\hline & & & & & & & \\
\hline \multirow[t]{6}{*}{ 3\&4PARA2.DZT } & 129 & 163 & 3 & $6.64 E-10$ & 7.61E-02 & 1.15E+08 & 6.8 \\
\hline & 130 & 163 & 3 & $6.45 \mathrm{E}-10$ & $7.61 \mathrm{E}-02$ & $1.18 E+08$ & 6.4 \\
\hline & 131 & 163 & 3 & $6.25 \mathrm{E}-10$ & $7.61 E-02$ & $1.22 E+08$ & 6.1 \\
\hline & & & & & & & \\
\hline & $\begin{array}{l}127 \\
125\end{array}$ & $\begin{array}{l}158 \\
157\end{array}$ & $\begin{array}{l}4 \\
4\end{array}$ & $6.05 E-10$ & $7.67 \mathrm{E}-02$ & $1.27 E+08$ & 5.6 \\
\hline & $\begin{array}{l}125 \\
124\end{array}$ & $\begin{array}{l}15 / \\
157\end{array}$ & $\begin{array}{l}4 \\
4\end{array}$ & $\begin{array}{l}6.25 \mathrm{E}-10 \\
6.45 \mathrm{E}-10\end{array}$ & 7.67E-02 & $1.23 E+08$ & 6.0 \\
\hline & 124 & & 4 & $6.45 E-10$ & 7.67E-02 & 1.19E+08 & 6.4 \\
\hline \multirow[t]{7}{*}{ 3\&4PERP2.DZT } & 141 & 172 & 3 & $6.05 E-10$ & $7.61 E-02$ & $1.26 E+08$ & 5.7 \\
\hline & 141 & 173 & 3 & $6.25 \mathrm{E}-10$ & 7.61E-02 & $1.22 E+08$ & 6.1 \\
\hline & 140 & 173 & 3 & $6.45 E-10$ & 7.61E-02 & $1.18 E+08$ & 6.4 \\
\hline & & & & & & & \\
\hline & 141 & 173 & 4 & $6.25 \mathrm{E}-10$ & 7.67E-02 & $1.23 E+08$ & 6.0 \\
\hline & 141 & 173 & 4 & $6.25 \mathrm{E}-10$ & 7.67E-02 & 1.23E+08 & 6.0 \\
\hline & 141 & 173 & 4 & $6.25 \mathrm{E}-10$ & 7.67E-02 & 1.23E+08 & 6.0 \\
\hline \multirow[t]{7}{*}{ 5\&6PARA2.DZT } & 140 & 173 & 5 & $6.45 E-10$ & $7.30 \mathrm{E}-02$ & $1.13 E+08$ & 7.0 \\
\hline & 141 & 174 & 5 & $6.45 E-10$ & 7.30E-02 & $1.13 E+08$ & 7.0 \\
\hline & 141 & 174 & 5 & $6.45 \mathrm{E}-10$ & 7.30E-02 & $1.13 E+08$ & 7.0 \\
\hline & & & & & & & \\
\hline & 138 & 170 & 6 & $6.25 E-10$ & $7.50 \mathrm{E}-02$ & $1.20 E+08$ & 6.2 \\
\hline & 139 & 172 & 6 & $6.45 \mathrm{E}-10$ & $7.50 \mathrm{E}-02$ & $1.16 E+08$ & 6.6 \\
\hline & 140 & 173 & 6 & $6.45 E-10$ & $7.50 \mathrm{E}-02$ & 1.16E+08 & 6.6 \\
\hline \multirow[t]{6}{*}{ 5\&6PERP2.DZT } & 137 & 168 & 5 & $6.05 \mathrm{E}-10$ & 7.30E-02 & $1.21 E+08$ & 6.2 \\
\hline & 137 & 169 & 5 & $6.25 \mathrm{E}-10$ & 7.30E-02 & $1.17 E+08$ & 6.6 \\
\hline & 138 & 169 & 5 & $6.05 \mathrm{E}-10$ & $7.30 \mathrm{E}-02$ & $1.21 E+08$ & 6.2 \\
\hline & 135 & 168 & 6 & $6.45 \mathrm{E}-10$ & 7.50 E-02 & $1.16 E+08$ & 6.6 \\
\hline & 136 & 169 & 6 & $6.45 E-10$ & $7.50 \mathrm{E}-02$ & $1.16 E+08$ & 6.6 \\
\hline & 134 & 167 & 6 & $6.45 E-10$ & $7.50 \mathrm{E}-02$ & 1.16E+08 & 6.6 \\
\hline
\end{tabular}


Table 4.8: Ground Coupled GPR Dielectric Constant Results from the laboratory GPR survey

\begin{tabular}{|c|c|c|c|c|c|}
\hline Files & Sample & Time(seconds) & Thickness & Velocity $(\mathrm{m} / \mathrm{s})$ & \\
\hline \multirow[t]{3}{*}{ DRY } & & one way travel time & & & \\
\hline & & & meters & sample bottom & Dielectric \\
\hline & & & & Velocity & Constant \\
\hline & & & & & \\
\hline & & & & & \\
\hline 01.dzt & 1 & $7.559 \mathrm{E}-10$ & 0.07 & $9.54 \mathrm{E}+07$ & 9.90 \\
\hline \multirow{2}{*}{ 02.dzt } & 2 & & & & \\
\hline & & $7.734 \mathrm{E}-10$ & 0.07 & $9.56 \mathrm{E}+07$ & 9.85 \\
\hline \multirow[t]{2}{*}{ 03.dzt } & 3 & $7.910 \mathrm{E}-10$ & 0.08 & $9.63 E+07$ & 9.71 \\
\hline & & & & & \\
\hline \multirow[t]{2}{*}{ 04. dzt } & 4 & 7.676E-10 & 0.08 & $9.99 \mathrm{E}+07$ & 9.01 \\
\hline & & & & & \\
\hline \multirow[t]{2}{*}{ 05. dzt } & 5 & 7.617E-10 & 0.07 & $9.58 \mathrm{E}+07$ & 9.80 \\
\hline & & & & & \\
\hline \multirow[t]{2}{*}{ 06. dzt } & 6 & $7.793 \mathrm{E}-10$ & 0.08 & $9.63 \mathrm{E}+07$ & 9.71 \\
\hline & & & & & \\
\hline & & & & & \\
\hline \multicolumn{2}{|l|}{ Files } & Time(seconds) & Thickness & Velocity $(\mathrm{m} / \mathrm{s})$ & \\
\hline \multirow[t]{3}{*}{ WET } & & one way travel time & & & \\
\hline & & & meters & sample bottom & Dielectric \\
\hline & & & & Velocity & Constant \\
\hline & & & & & \\
\hline 012.dzt & 1 & $7.09 \mathrm{E}-10$ & 0.07 & $1.02 E+08$ & 8.71 \\
\hline \multirow[t]{2}{*}{$022 \mathrm{dzt}$} & 2 & $7.38 \mathrm{E}-10$ & 0.07 & $1.00 E+08$ & 8.98 \\
\hline & & $7.50 \mathrm{E}-10$ & 0.08 & $102 F+08$ & 873 \\
\hline 032.dzt & 3 & & & & 8.73 \\
\hline \multirow[t]{2}{*}{ 042.dzt } & 4 & $7.27 \mathrm{E}-10$ & 0.08 & $1.06 \mathrm{E}+08$ & 8.07 \\
\hline & 5 & $7.09 \mathrm{E}-10$ & 0.07 & $1.03 E+08$ & 8.49 \\
\hline 052.dzt & & & & & \\
\hline 062.dzt & 6 & $7.38 \mathrm{E}-10$ & 0.08 & $1.02 E+08$ & 8.72 \\
\hline
\end{tabular}

From the results of the GPR survey in Table 4.8 the dielectric constant values for the saturated samples are generally lower then their unsaturated sample counterparts using the ground-coupled GPR antenna. Explanations for this discrepancy may be that the samples weren't fully saturated or due to human error in 
determining where the upper and lower pavement surface interfaces are located using Autopicklayers3. As for the air-launched GPR antenna, the dielectric constant ranges for the unsaturated samples are from 4.6-7.6 and for saturated samples dielectric constant ranges from 5.6-7.0 as shown in Figure 4.3. Looking at the results of Table 4.9, the author's MATLAB program calculated GPR wave velocities using the autopicklayers3 program using processed raw data files provided by John Belcher using Radan Roadway software. The dielectric constant measurements determined from the saturated samples using the ground-coupled GPR antenna as shown in Table 4.8 were generally greater than the results from the unsaturated samples. Therefore, the results from the saturated/wet samples should be discarded and only the velocity values from the unsaturated samples should be used. Table 4.9 shows that the dielectric constant values ranged from 10.78-12.76 as shown below using the GPR wave velocities obtained from Belcher's processed raw data files and sample thickness (core data). 
Table 4.9: Dielectric constant values of the air launched GPR survey using Radan Roadway Software and $\varepsilon=(c / v)^{2}$

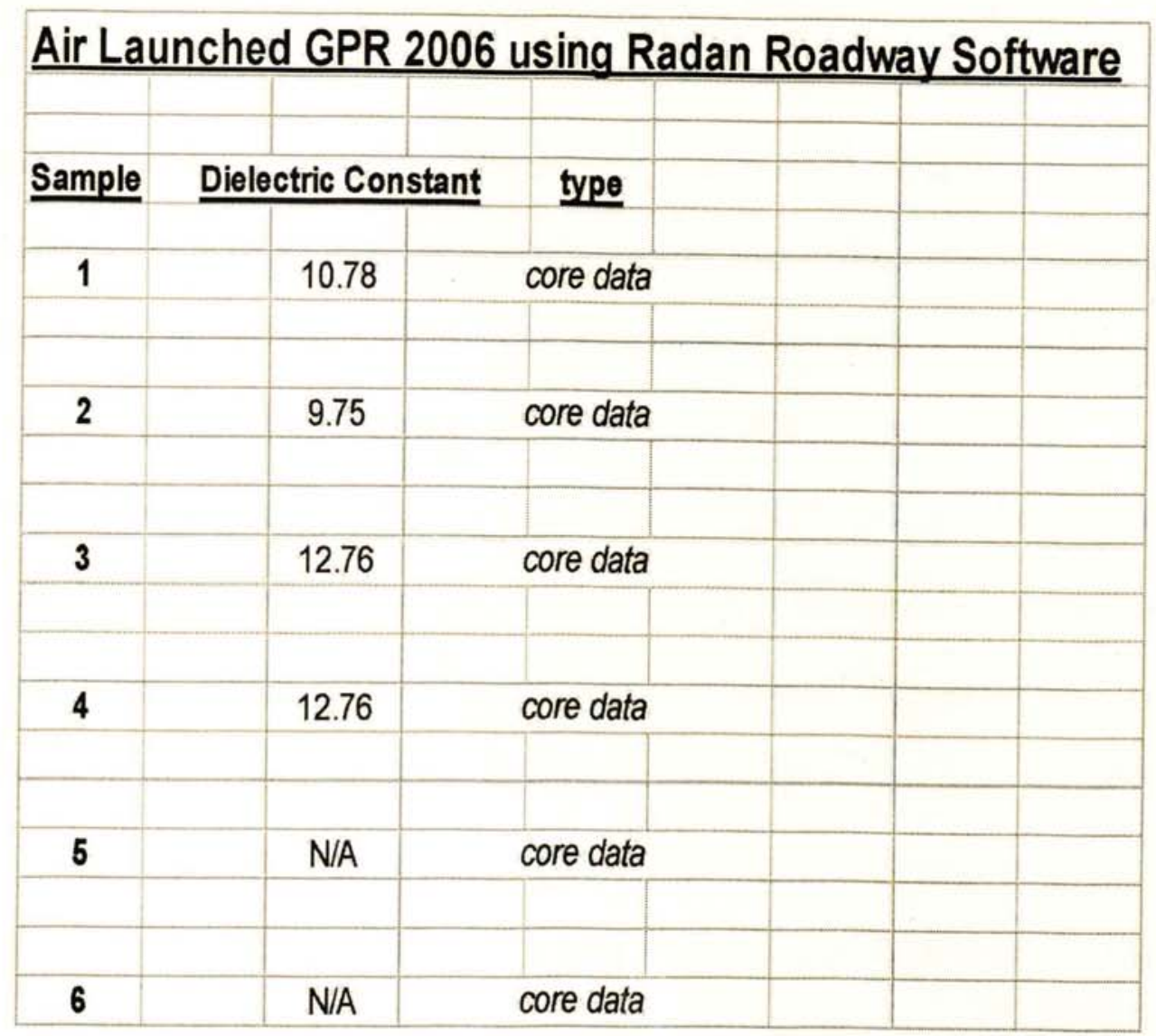

When comparing all values to Wimsatt(1998), the results generally indicate that the samples consistent with his flexible pavement values and are similar to the results for the 2005 GPR study results for flexible pavements. Also with all the samples thicker than seven centimeters there doesn't appear to be any problem with GPR analysis in terms of thin pavement sections. Some problems that were raised from the 2006 GPR analysis was the faulty Radan Roadway software, resulting not 
obtaining process raw data for each sample from the GPR technician. Other results from this survey include that using the air-launched GPR antenna on the wet sample indicated an increase in the average value of the dielectric constant in general when compared to the dry samples. Using the results from Lanbo Liu's 2002 study the results indicated that little moisture absorbed into the pavement samples and testing the samples with a ground coupled antenna. Due to the limited amount of time to conduct this survey the sample were only put into a water bath for only an hour and a half. This time may not have been sufficient enough to fully saturate the samples properly and therefore didn't yield the proper results for a ground coupled GPR study. Although with the air-launched GPR antenna reasonable results were obtained that were consistent with flexible pavements and resulted in $\varepsilon$ values increasing with increasing moisture conditions. This problem (Liu \& Guo 2002) was also discovered in the Lanbo Liu study resulting in their pavement samples not being fully saturated for their experiment. Finally, the dielectric constant measurement are sensitive to survey direction, where dielectric constant values are generally greater when the GPR antenna scans the samples along the length of the samples as shown in Figure 4.3. For instance, the pavement samples in the parallel motion setup had dielectric constant values greater than the samples in a perpendicular motion setup to within a factor of two.

\section{Chapter 5. Time Domain Reflectometry Experiments}

\section{Time Domain Reflectometry Principles}

Time domain reflectometry(TDR) is another electromagnetic technique which can complement results obtained from GPR data. The TDR operates on principles 
similar to radar, where the TDR transmits a pulse through a cable and at the end of the cable or at a break in the wire the pulse is reflected back to the TDR unit(Granite Island Group, 2002). The TDR then measures the time the pulse was transmitted and reflected before converting that time into the two way travel distance of the pulse (Granite Island Group, 2002). The result is then displayed as a distance reading or waveform (Granite Island Group, 2002). GPR measures reflections from voltage pulses from antennas whereas time domain reflectometry measures reflections along transmission lines (Serbin \& Or, 2004). TDR can be used to find the capacitance of a foil-asphalt-foil sandwich, and thus allow for estimation of the dielectric constant of the asphalt or concrete sample. The value of using the TDR is that it replaces a more expensive and unavailable network analyzer for finding dielectric constant of a pavement sample. This application for the TDR is appropriate for the time resolution when compared to a $1 \mathrm{GHz}$ air-launched antenna. In contrast, a network analyzer would sweep through frequencies commonly used in GPR applications. This use of the time domain reflectometer is novel.

Time domain reflectometry (TDR) was utilized in order to directly calculate dielectric constant of asphalt pavement samples. TDR applies a step signal to the asphalt sample, and the step response is recorded. The response is identical to that of a RC series circuit suddenly connected to a battery, as shown in Figure 5.1. To the author's knowledge this technique has never been used on pavement samples before. Samples were prepared by cutting an asphalt sample into a thin slice, and gluing aluminum foil to the slice, forming a parallel plate capacitor. The capacitance of the asphalt slice is then measured by time domain reflectometry, and assuming a parallel 
plate capacitor is used, dielectric constant is determined by using the formula for a parallel plate capacitor. A conceptual RC circuit analog to a parallel plate capacitor is shown in Figure 5.1.



Figure 5.1: Conceptual RC circuit depicting TDR response for asphalt samples

The voltage response of this equivalent circuit is $V_{o}=V_{o}\left(1-e^{-\frac{t}{R C}}\right)$ where $V_{o}$, which is battery voltage and the resistor, is ( $\left.50 \mathrm{ohms}\right)$ the internal resistance of the TDR instrument. The MATLAB program created to analyze the step response from the pavement samples appears in the form similar to an ideal resistor voltage step response as shown in Figure 5.2. 


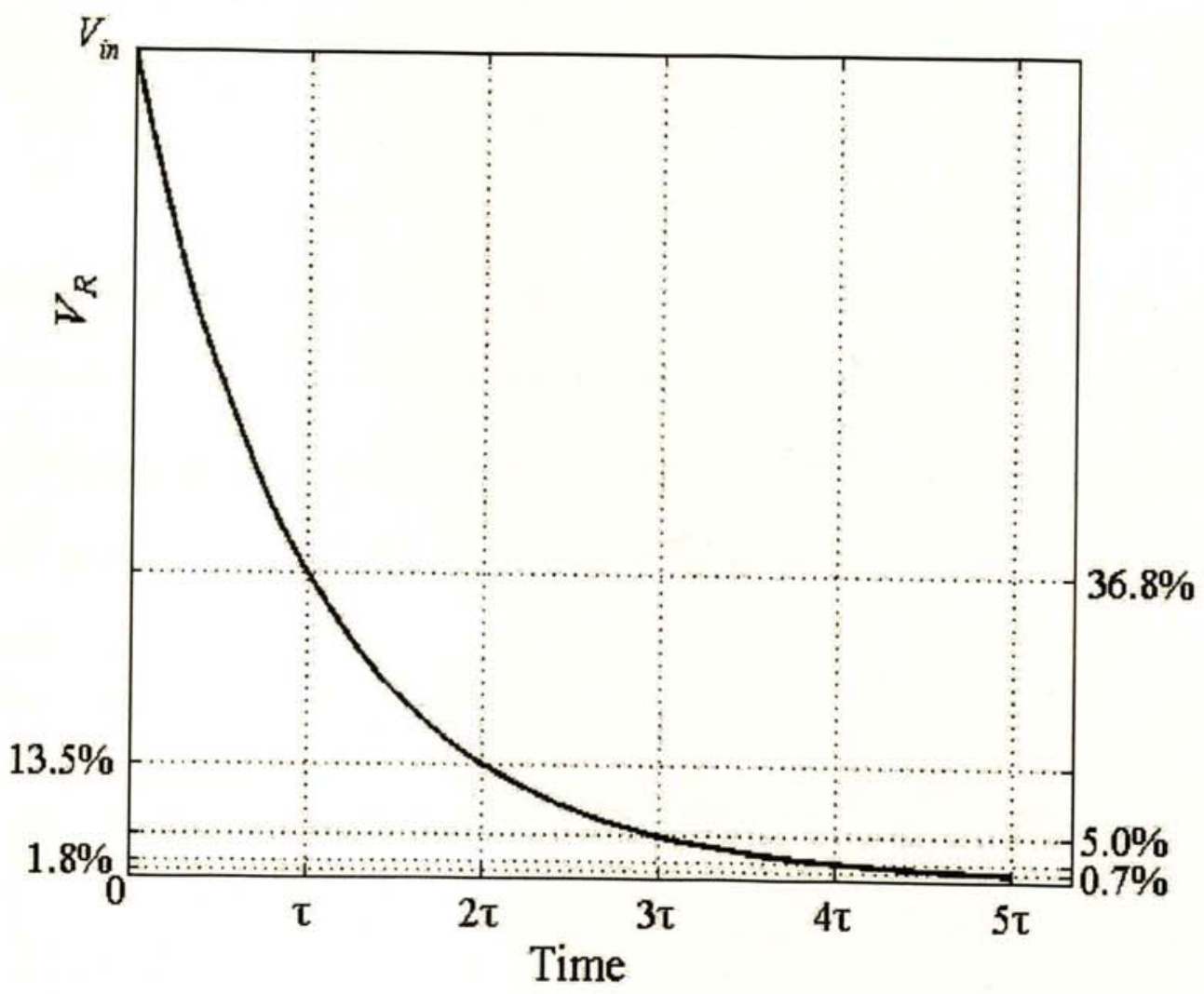

Figure 5.2 Resistor Voltage Step Response

Reference data is obtained from the TDR using an air dielectric capacitor of the same dimensions as the pavement sample. The time domain reflectometer records and displays the voltage/capacitor step response of each pavement sample. The assumptions for these experiments are that asphalt pavement samples acts as a dielectric within a parallel plate capacitor. A limitation is that the parallel plate capacitor is finite because the length of the plates are not infinite, but we assume that the discontinuous parallel plate capacitor the electric field at the edges of the capacitor plates are negated by the stronger electric field within the center of the parallel plate setup. The formula used to calculate and the theoretical air capacitance of the pavement samples as shown in Figure 5.6 is $C_{\text {theory }}=\frac{A \varepsilon}{d}$ where $\mathrm{C}$ is capacitance, $\mathrm{A}$ is plate area, $\varepsilon$ is dielectric constant, and $\mathrm{d}$ is plate distance. 


\section{Laboratory Setup}

Aluminum foil covered the top and bottom of the core sample where this experiment was conducted at room temperature in March 2006. A Tektronix 1502 Time Domain Reflectometer which used to determine capacitance of pavement cores that are covered with aluminum foil at the top and bottom of each sample. Figure 5.3 below illustrates the actual TDR setup used to calculate pavement capacitance measurements.

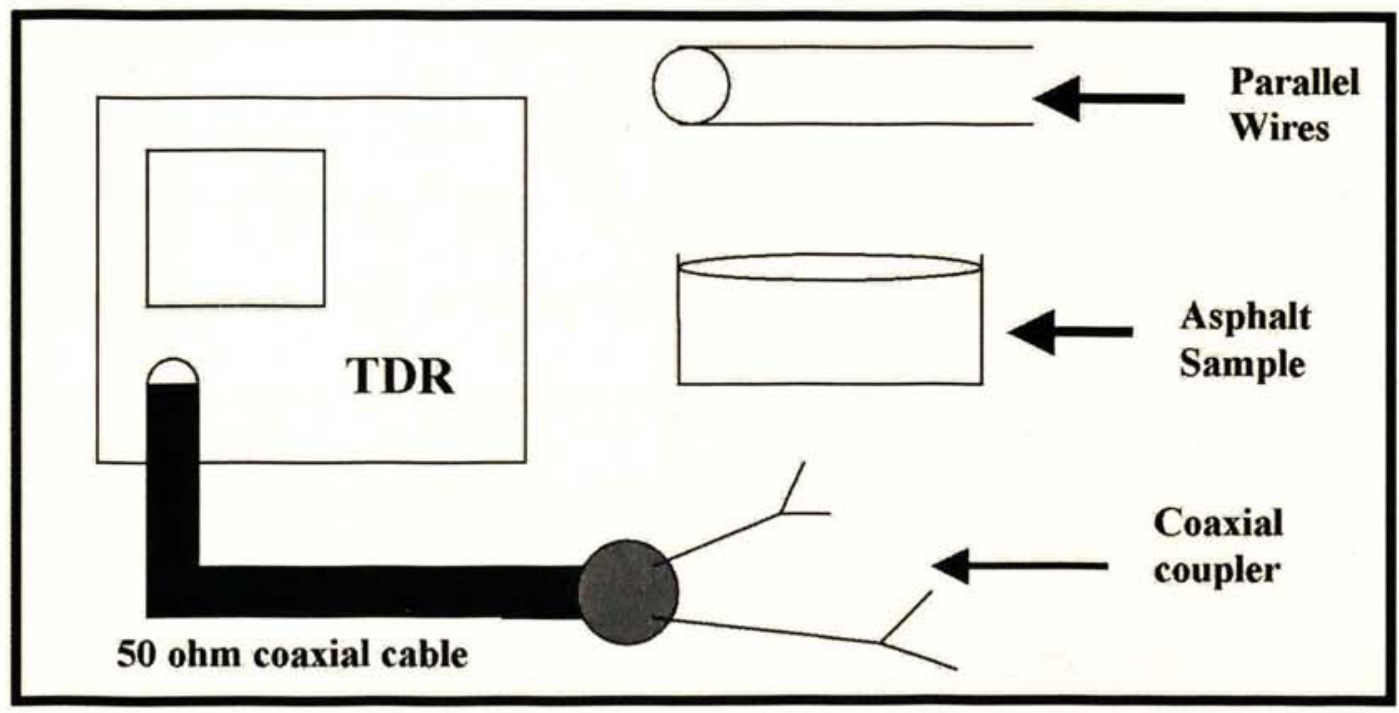

Figure 5.3: Time Domain Reflectometry Experimental Setup Showing Parallel Wires used for oscilloscope calibration the asphalt sample used as a dielectric and a coaxial coupler used to clamp to the aluminum foil plate attached to the asphalt sample

The TDR experiments used two types of pavement samples. The first type of pavement sample consisted of 6 inch diameter cores with circular shaped aluminum foil attached to the top and bottom of each (Figure 5.4), 


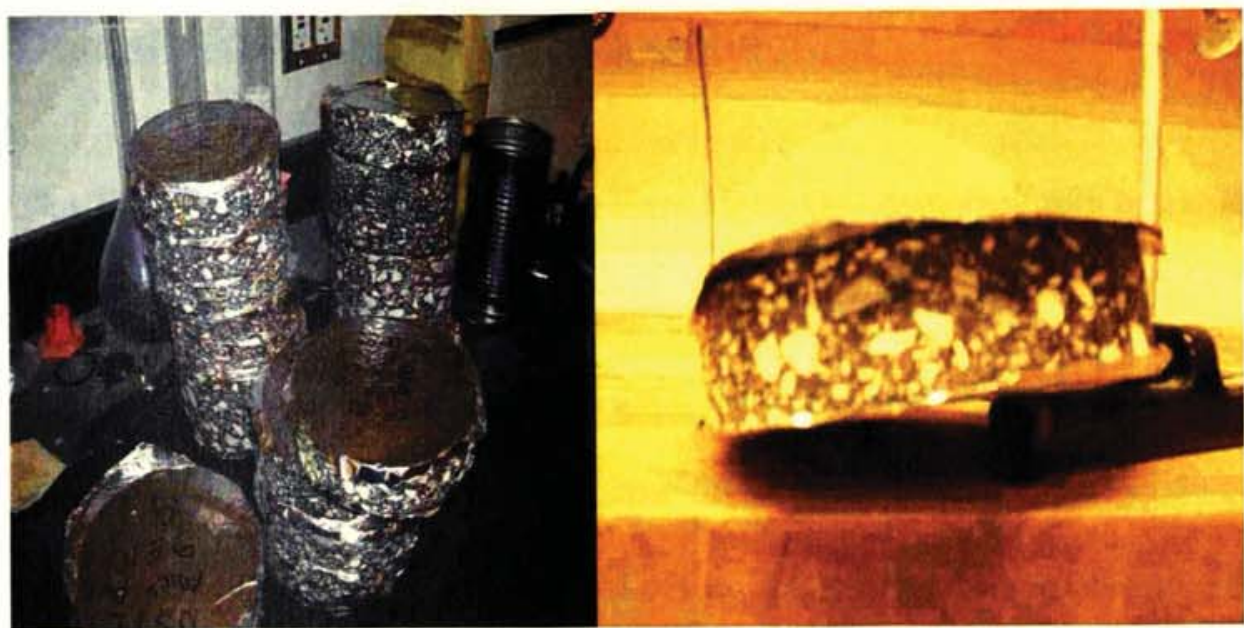

Figure 5.4: Six inch diameter pavement samples used in TDR experiment (left) and a close up of aluminum foil-asphalt-aluminum foil asphalt sandwich (right).

The second type of pavement sample used thinly cut rectangular asphalt pavement samples with aluminum foil attached to the top and bottom of each sample as shown in Figure 5.5 below. Appendix A lists the core diameter and thicknesses of each sample used in this study.

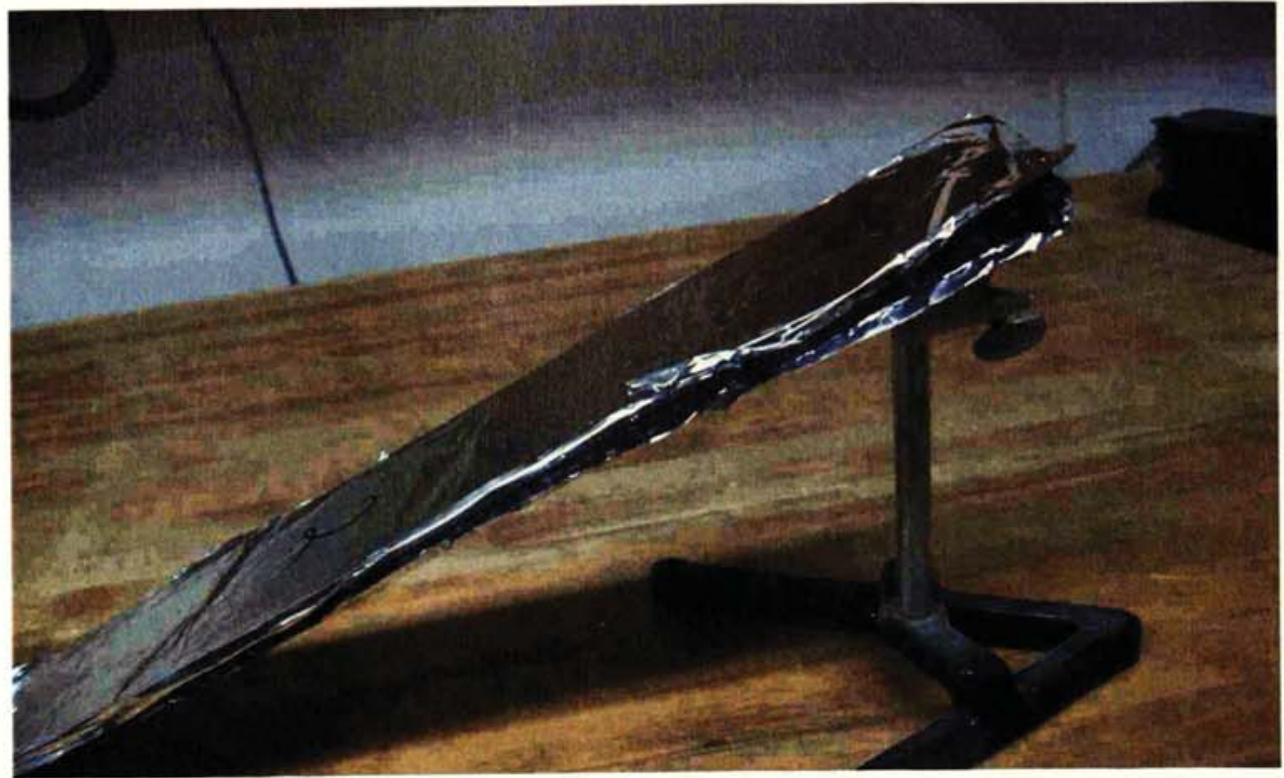

Figure 5.5: Thin rectangular pavement sample used in TDR experiment 


\section{Time Domain Reflectometry Data Collection}

The TDR was an older model (Tektronix 1502) that provided only an analog chart recorder output, no digital storage, so it was necessary to experimentally determine the time duration of the digitized data. The TDR was calibrated for horizontal time scale before recording data from the sample. The horizontal time scale was calculated from the TDR by the following steps. First the sample waveform was recorded on the TDR and the analog data was transferred by wire to the Agilent digital oscilloscope. The waveform used for time scale calibration was the TDR test using the $16.3 \mathrm{~cm}$ straight wire apparatus as shown in Figure 5.6 below. TDR data was collected by attaching voltage clips from the TDR to the top and bottom aluminum foil plate on the asphalt sample.

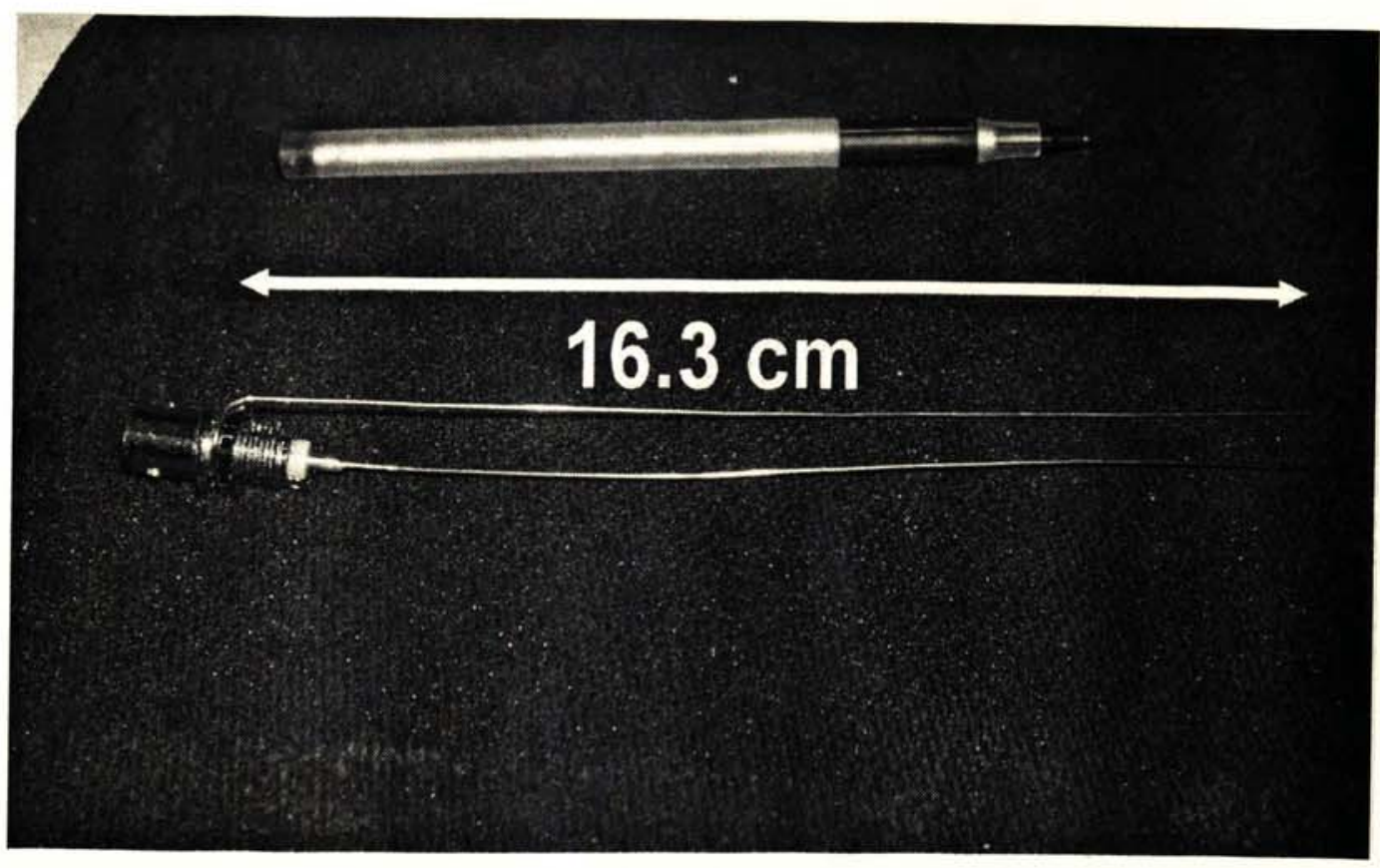

Figure 5.6 TDR open-end wire calibration device 
The TDR recorded the step response of this apparatus and the results were transferred to the oscilloscope. Figure 5.7 shows the results of the TDR step response for the double wire apparatus.



Figure 5. 7: TDR Graph Showing Step Response of Double Wire Device Used for TDR Time Scale Calibration

The arrows in Figure 5.7 show the beginning and end of the step response for the double wire. The horizontal axis is time recorder on the digital oscilloscope measured in seconds. The figure shows that the TDR will complete its step response in (1.67 - -6.99) seconds or 8.66 seconds on the oscilloscope. Now the oscilloscope time is corrected to the amount of time it takes to generate the waveform step response on the TDR. The formula used to calculated the TDR step response time is time $=\frac{2 * \text { length }}{c}$,

where the length is $.163 \mathrm{~cm}$, the length of the parallel wire apparatus in Figure 5.7. meters and $\mathrm{c}$ is the speed of light. With these values there are $92 \mathrm{TDR}$ 
nanoseconds for every 8.66 seconds of oscilloscope time. Since all of the TDR sample data is transferred to the oscilloscope the oscilloscope time must be converted to TDR time with the ratio conversion $=X_{\substack{\text { scope } \\ \text { time }}} * \frac{.92_{\text {TDR }}}{8.66_{\text {Scope }}}$. Finally to convert into oscilloscope time the conversion factor is multiplied by $1 * 10^{-9}$ seconds.

The data collection process was performed for all of the circular and rectangular asphalt pavement samples. For calibration, a capacitor with an air dielectric was also tested. This was created by stacking two aluminum-clad pavement samples on top of one another separated by a spacer, as shown in Figure 5.8 below.

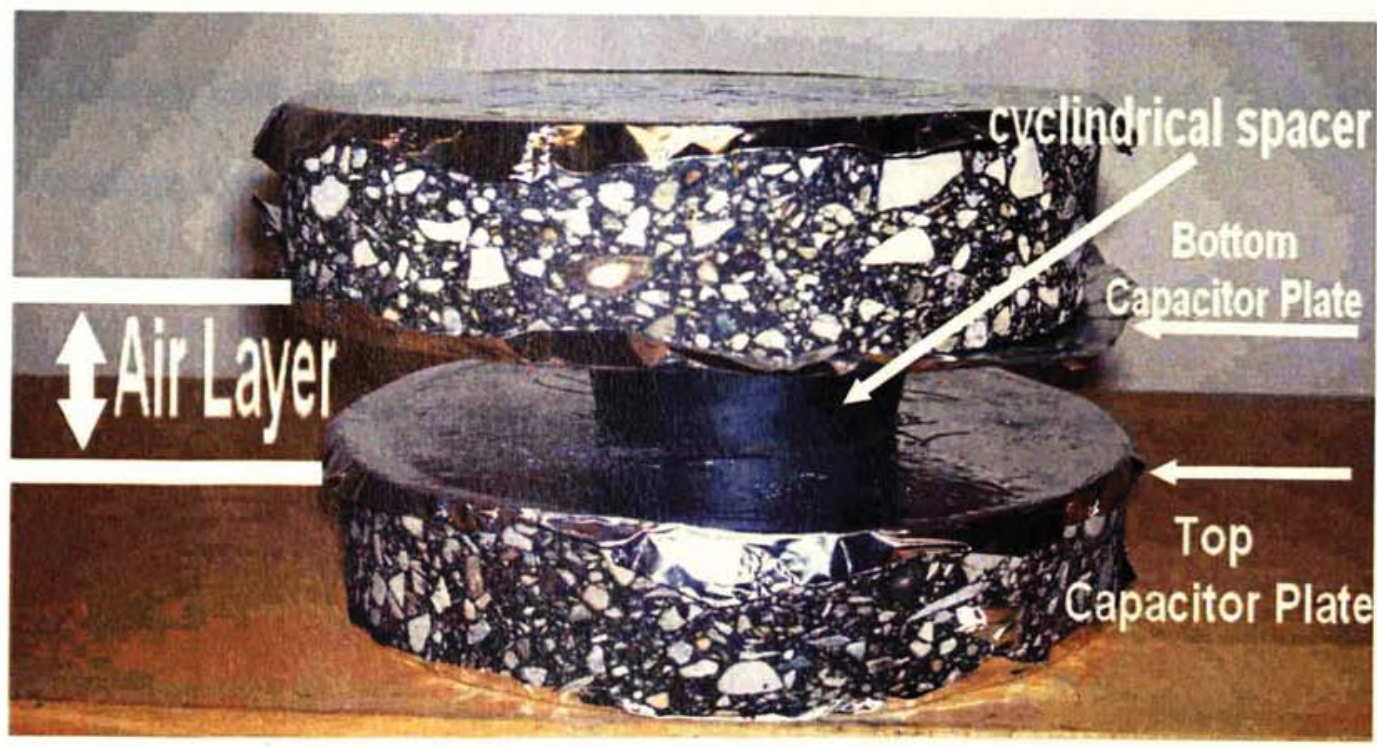

Figure 5.8: Setup for asphalt samples for calculating air dielectric in TDR experiment 


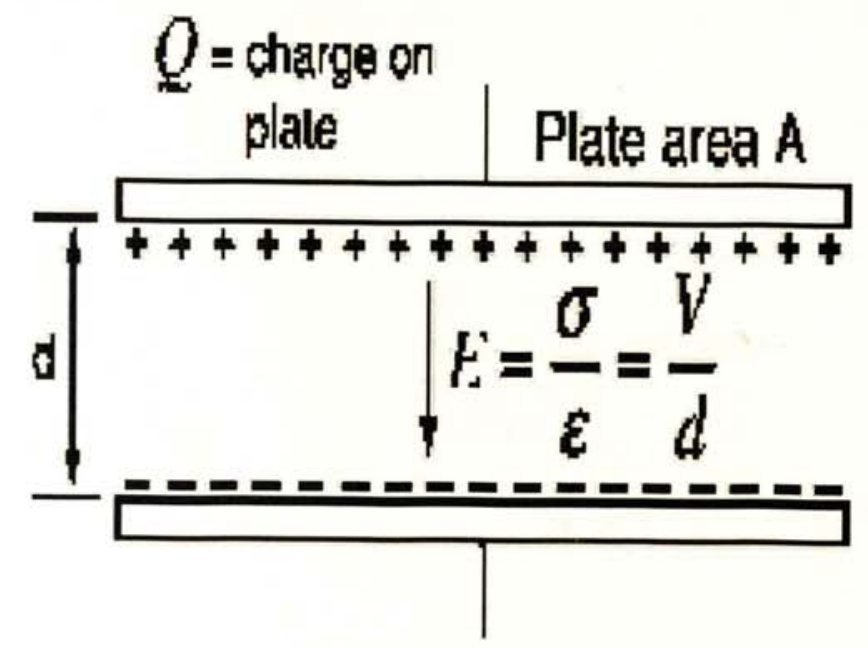

Figure 5.9 Setup for Ideal Parallel Plate Capacitor

The method used in calculating dielectric constant from the original TDR waveform as follows. First, the MATLAB program TDRDATA2 was used to load the sample waveform for manipulation as shown in Figure 5.10 below.

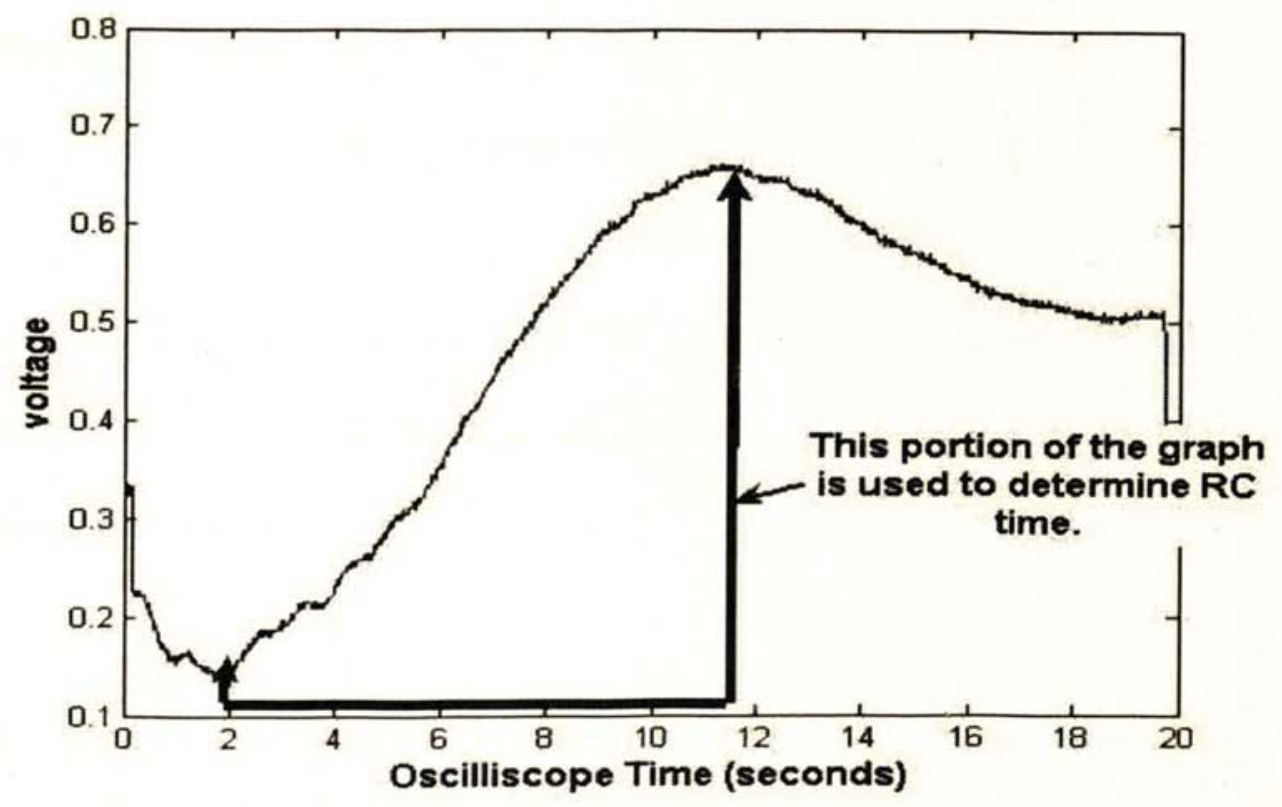

Figure 5.10: Original TDR Plot of US-21 Michigan Ave. 




Figure 5.11: TDR Waveform Plot of Sample US 21-Michigan Ave A Inverted and Raised by the Maximum Voltage Value

In Figure 5.10 shows a portion of the original waveform being used to compute RC time. In order to avoid having infinite values when the natural log of waveform is taken, the maximum voltage value of the original waveform is added to all values of the original waveform to create Figure 5.11.so that all values of the reconstructed waveform are above zero. The steepest part of the truncated TDR sample plot is selected as shown in Figure 5.12 below 


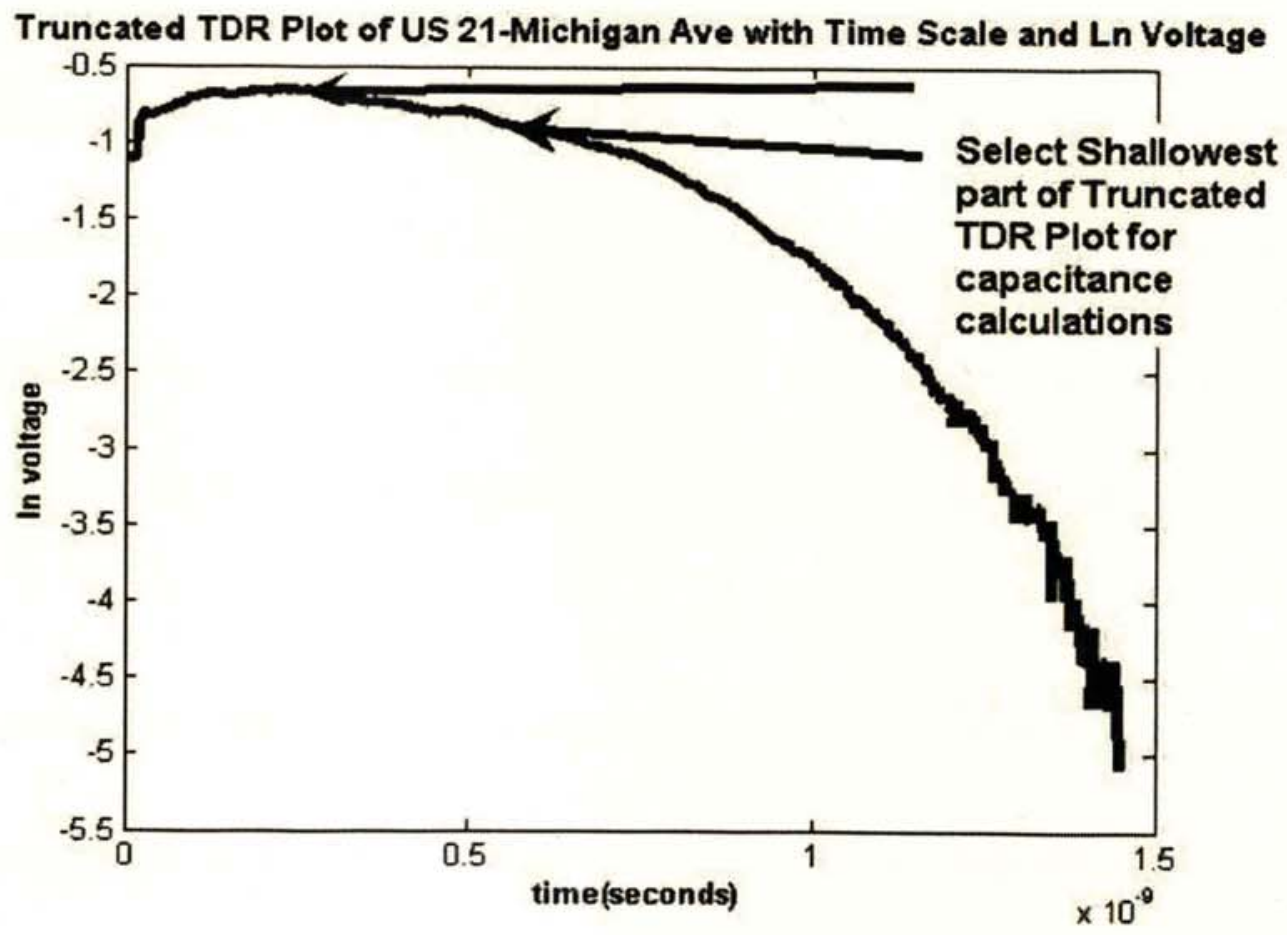

Figure 5.12 : Reconstructed TDR Waveform Plot of US 21-Michigan A

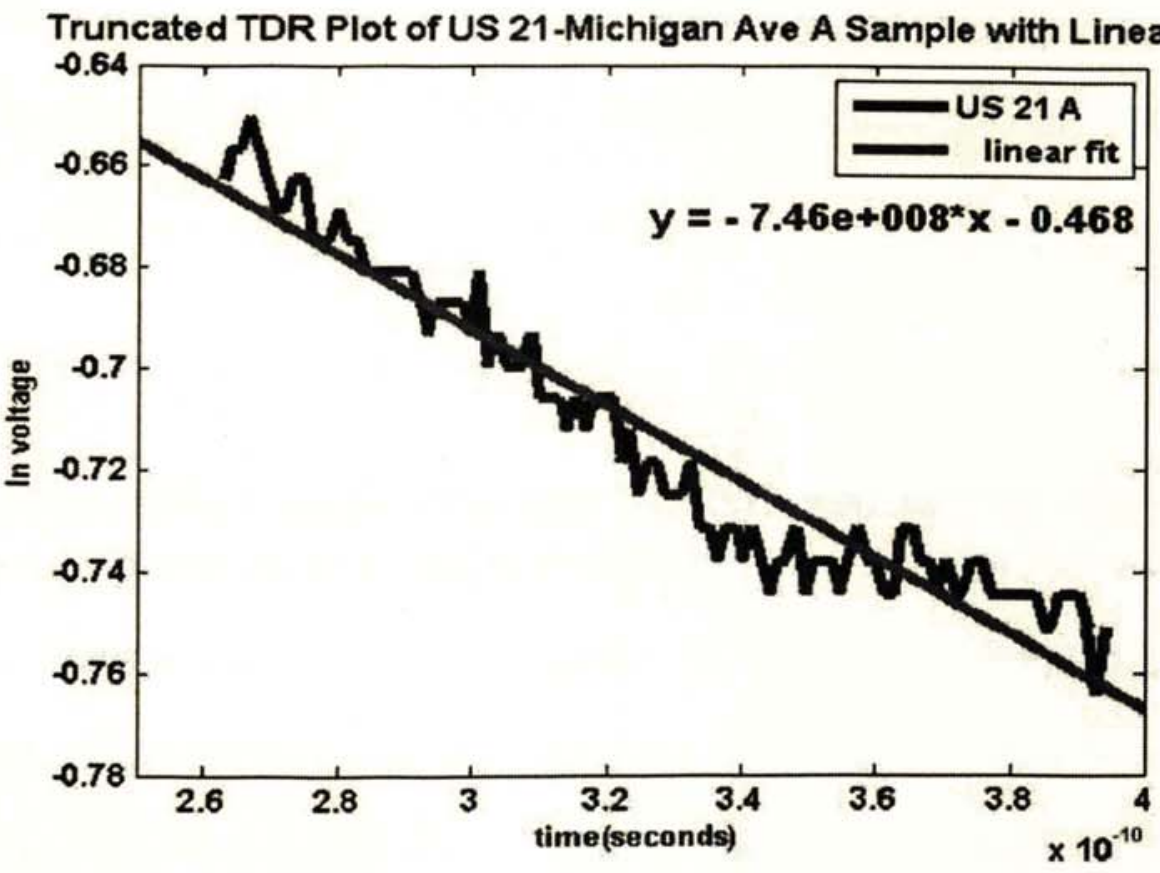

Figure 5.13 : Selected part of TDR Waveform Plot of US 21 with a linear fit applied. 
After the steepest part of the TDR wavelet is selected as shown in Figure 5.12 above. A linear fit is applied to the truncated wavelet as shown in Figure 5.13. A linear fit is used because it's assumed that the slope of the linear fit is $\frac{1}{\tau}=S l o p e_{T D R}$ where $\tau$ is the time constant. Capacitance is calculated using $\tau=\mathrm{RC}$ where $\mathrm{R}$ is 50 ohms \& $\tau=$

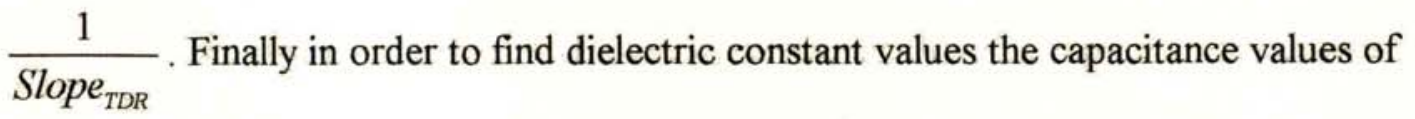
the asphalt dielectric samples are compared to TDR calculated capacitance using the air dielectric configurations of the same sample thickness as shown in Figure 5.8.

Using the formula $\kappa=\frac{C_{\text {TDRSample }}}{C_{\text {TDRair }}}$ dielectric constant for the sample is calculated where the air dielectric is assumed to have a dielectric constant value of one.

From the linear fit. the slope of the linear formula is taken and used to calculate the capacitance of sample six. For example, the absolute value of the slope given from Figure 5.14 is $\left|-7.46 * 10^{8}\right|$. Given a TDR slope value of $7.46 * 10^{8}$ the capacitance is $C=\frac{\tau}{50}$ where $\mathrm{C}=\frac{1}{50 * 7.46 * 10^{8}}=26.8 \mathrm{pf}$. All of the TDR capacitance samples are calculated in this manner.

\section{Time Domain Reflectometer Results and Discussion}

The method of calculating the dielectric constants for each of the roadway core samples involved using the shallowest part of the TDR waveform generating a linear fit to negative natural log for the TDR trace. The TDRDATA2 program created to calculate the linear equations for capacitances is shown in Appendix C. Appendix E lists the results of the dielectric constant values calculated from the TDR experiments. As seen in Appendix E there are a range of dielectric constant values 
for the pavement samples. The values ranged from a dielectric constant value of 1.61 for the $1 \mathrm{~cm}$ thick samples, to a value of 10.4 for the US-131 E pavement sample. The majority of the samples have values of 4 to 5 with most samples having values of above unity. Thus, the values are reasonable for pavement dielectric constant. Although when one compares the pavement dielectric constant values obtained with the TDR using air as a dielectric with the TDR values calculated using a pavement dielectric, the majority of dielectric constant values have a dielectric constant of 2.0 with the exception of a few asphalt pavement samples being above 3.0. As for the thin rectangular samples, their dielectric constant value averaged 2.29. From these results it is the writer's opinion that reasonable dielectric constant values can be obtained from roadway cores by calculating capacitance from the TDR and comparing it to the theoretical capacitance formula for air dielectrics for a parallel plate capacitor $\kappa=\frac{C_{T D R}}{C_{\text {theony }}}$. TDR measurements can provide reasonable results from varying pavement mixes as shown from this study in Appendix E.

Consistency for this survey is subjective in deciding where to place the linear slope at the shallowest point of the TDR log voltage vs. time graph. The selection of the slope should not include any value past one time constant or the dielectric constant results will become unreasonable for pavement samples. This problem may be overcome with also recording multiple TDR voltage scans to get an average linear slope of the capacitance function. 


\section{CHAPTER 6. SUGGESTIONS FOR FUTURE WORK}

Several refinements can be made on the methods of collecting GPR data and calculating dielectric constants for pavement sections. For the manufactured pavement sample survey one should submerge the pavement samples in a water-filled vacuum chamber to eliminate any air pockets within the samples similar to the Lanbo Liu study. Also these samples should be in the vacuum chamber for a one-day period. Also pavement samples need to be created that range in densities between $100 \mathrm{lbs} / \mathrm{ft}^{3}$ to $200 \mathrm{lbs} / \mathrm{ft}^{3}$ For the time domain reflectometer survey one should create at least 30 thin pavement cores of less than $1.5 \mathrm{~cm}$ of similar pavement mixes and density to test the stability of the TDR measurements. Also an apparatus that would accurately model an air dielectric with a dielectric constant as close to unity would need to be created for use in future tests. This study would help determine if the TDR measurements of pavement dielectric constant measurement are repeatable and if pavement thickness is a factor in this measurement.

Future studies suggestions would include collecting pavement GPR scans and dielectric constant calculations from the center of the roadway, and wheel pathway scans.

In the ideal situation, the author estimates, would be to have air and ground coupled GPR antenna traces along the edges, middle and along the wheel pathway on the roadway at each site. Also in the ideal situation 30 thin pavement samples made with the same pavement mix as the pavement tested with the GPR antenna would be made. These samples would be tested with a TDR for dielectric constant calculations. 


\section{Chapter 7. CONCLUSIONS}

Using the techniques of GPR road surveys, scanning manufactured pavement samples, and time domain reflectometry has been demonstrated here that the use of GPR wavelets can be used within a short-term comprehensive road radar plan to determine dielectric constants in a variety of asphalt pavement conditions. The procedures used to collect and calculate dielectric constant data ranged from passive methods such as field radar experiments, to more direct measurements with Time Domain Reflectometry. "Theoretical" values of dielectric constant from mixing models were also considered in this study. For the field GPR study, GPR wavelets were used to calculate dielectric constants of pavement material using both the air launched and ground coupled GPR antennas. Time domain reflectometry used in conjunction with roadway cores and GPR scans can also help to determine asphalt dielectric constants. Limitations encountered in the GPR study included the type of Radan Roadway Software interpretation, more consistent results were produced using roadway core samples, but poor quality or thin cores resulted in unrealistic dielectric constant and roadway velocity values. Using the amplitude of surface reflection resulted in fairly accurate dielectric constant data, even when the roadway is relatively thin or of poor quality. This investigation was severely limited by the small amount of time the MDOT operator were available, primarily leading to the lack of opportunity to repeat experiments and develop efficient procedures directed by experience. Therefore, this study tested initial survey design, on the basis of which refinements could be made to make measurements more reliable and accurate for GPR studies. 
Dielectric constant measurements estimated using the manufactured samples gave consistent measurements when compared to the air launched and ground coupled GPR scans. Limitations to this experiment involved determining dielectric constant data under surface saturated conditions using ground coupled antennas. This experiment required that the samples being soaked under long-term conditions possibly a day or more with a vacuum to fully saturate the samples.

The capacitance measurement of the asphalt samples using TDR provided consistent results for samples with similar thicknesses and asphalt mix type. This experiment also produced dielectric constant data consistent with actual pavement values. Limitations for this experiment are that this experiment did not work well when testing for the air dielectrics and comparing these results to the actual pavement capacitance values. This resulted in errors on the order of $2-3$ times greater than an air dielectric of 1.0. Also this experiment did not work well the comparing the TDR computed dielectric constant values of the $1.0 \mathrm{~cm}$ pavement samples with their theoretical capacitances. These values were not realistic for pavement samples.

The major conclusions that can be drawn from this study are that dielectric constant values that were obtained from these 3 experiments were in general agreement. This conclusion provides evidence that the dielectric constant values obtained in the 2005 GPR field study were accurate. The general groundwork has been laid for conducting more efficient comprehensive GPR surveys that gather the most amount of information on a short-term basis. With some extra time and expense it would be possible to develop a procedure which creates pavement conditions found 
on actual roadway and use a time domain reflectometer along with GPR to develop methods which detect defects in roadways in an efficient manner. 


\section{REFERENCES CITED}

Alongi, A.V., et al. "Concrete Evaluation by Radar Theoretical Analysis." Transportation Research Record 853 (1982): 31-37.

Al-Qadi, Imad L., and Lahouar, Samer. "Detection of Asphalt Binder Aging in Flexible Pavement by Ground Penetrating Radar." Materials Evaluation 63.9 (2005): 921-925.

Baradello, L., GPR Tips e Tricks Georadar, http://digilander.libero.it/lucabaradello/uk_tipstricks.html, 2006.

Granite Island Group, TDR Tutorial - Introduction to Time Domain Reflectometry, 2002, http://www.tscm.com/riprcop.html.

Lahouar, Samer, et al. "Approach to Determining In Situ Dielectric Constant of Pavements: Development and Implementation at Interstate 81 in Virginia." Transportation Research Record 1806 (2002): 81-87.

Liner, Christopher L. Elements of 3D Seismology $2^{\text {nd }}$ Ed, PennWell Corporation, Tulsa, Oklahoma, USA, 2004.

Liu, Lanbo, Guo, T. "Dielectric Property of Asphalt Pavement Specimens in Dry, Water-Saturated, and Frozen Conditions." Ninth International Conference on Ground Penetrating Radar (2002): 410-415.

Martinez, Alex, and Byrnes, Alan P. "Modeling Dielectric-Constant Values of Geologic Materials: An Aid to Ground-penetrating Radar Data Collection and Interpretation." Kansas Geological Survey, Current Research in Earth Sciences 247.1 (2001): http://www.kgs.ku.edu/Current/2001/martinez/martinez1.html.

Maser, Kenneth R. "Automated Interpretation for Sensing In Situ Conditions." Journal of Computing in Civil Engineering 2.3 (1998): 215-238.

Maser, Kenneth R., and Scullion, Tom. "Automated Pavement Subsurface Profiling Using Radar: Case Studies of Four Experimental Field Sites" Transportation Research Record 1344 (1992): 148-154.

Morey Rexford M. "Synthesis of Highway Practice 255, Ground Penetrating Radar for Evaluating Subsurface Conditions for Transportation Facilities." Transportation Research Board (1998).

Olhoeft, Gary R. "Maximizing the information return from ground penetrating radar." Journal of Applied Geophysics 43 (2000): 175-187. 
Reppert, Philip M., Morgan, F. Dale., and Toksöz, M. Nafi. "Dielectric constant determination using ground-penetrating radar reflection coefficients." Journal of Applied Geophysics 43 (2000): 189-197.

Reynolds, John M. An Introduction to Applied and Environmental Geophysics, John Wiley \& Sons, New York, 1997,

Roberts, Freddy L. et al., Hot Mix Asphalt Materials, Mixture Design, and Construction, NAPA Research and Education Foundation, Lanham, MD, $2^{\text {nd }}$ Ed., 1996, p. 585.

Saarenketo, T., and Scullion, T. "Road Evaluation with ground penetrating radar." Journal of Applied Geophysics 43 (2000):119-138.

Saarenketo, Timo, and Scullion, T. "Using Electrical Properties to Classify the Strength Properties of Base Course Aggregates." Texas Transportation Institute FHWA/TX-97/1341-2 (1996): p. 87.

Saarenketo, Timo, and Scullion, T. "Ground Penetrating Radar Applications on Roads and Highways." Texas Transportation Institute TX-95/1923-2F (1994): p. 52.

Scullion, T., and Saarenketo T. "Use of Ground Penetrating Radar for Site Investigation of Low-Volume Roadways and Design Recommendations." Texas Transportation Institute TX-02/4906-1 (2002): p. 58.

Scullion Tom, et al. "Applications of Ground-Coupled GPR to Pavement Evaluation." Texas Transportation Institute TX-98/2947-S (1997): p. 54.

Scullion, Tom, and Rmeili, E. "Detecting Stripping in Asphalt Concrete Layers Using Ground-Penetrating Radar." Texas Transportation Institute TX-98/2964-S (1997): p. 38.

Serbin, Guy, and Or, Dani. "Ground-Penetrating Radar Measurement of Soil Water Content Dynamics Using a Suspended Horn Antenna." IEEE Transactions on Geoscience and Remote Sensing 42.8 (2004): 1695-1705.

Serway, Raymond A., and Beichner, Robert J., Physics: For Scientists and Engineers with Modern Physics. Saunders College Publishing, Orlando, Fl, $5^{\text {th }}$ Ed. 2000.

Widess, M. B. "How Thin is a Thin Bed?" Geophysics 38.6 (1973):1176-1180.

Wimsatt, Andrew J., et al. "The Use of Ground Penetrating Radar Data In Pavement Rehabilitation Strategy Selection and Pavement Condition Assessment," SPIE proceedings series 3400 (1998):372-383. 


\section{APPENDIX A}

Appendix A contains the physical parameters for the pavement cores from the 2005 GPR survey 


\begin{tabular}{|c|c|c|c|c|c|c|c|c|c|c|}
\hline \multicolumn{11}{|c|}{ Project Number AM } \\
\hline \multicolumn{11}{|c|}{ Location US-41 } \\
\hline & & & & & & & & & & \\
\hline Sample & AM2 & AN3 & AN4 & AM5 & AMG & AM7 & AMB & AM9 & AM10 & AM11 \\
\hline Average Height & 63.42 & 71.75 & 47.89 & 47.31 & 48.31 & 67.61 & 86.30 & 70.99 & 72.47 & 66.05 \\
\hline Average Diameter & 146.42 & 146.87 & 146.59 & 146.81 & 1466.37 & 147.16 & 147.25 & 147.09 & 147.01 & 147.48 \\
\hline
\end{tabular}

\begin{tabular}{|c|c|c|c|c|c|c|c|c|c|c|}
\hline \multicolumn{5}{|c|}{ Corelock } & & & & & & \\
\hline \multicolumn{3}{|c|}{ Project Number M 26/ win Lake } & & & & & & & & \\
\hline & & & & & & & & & & \\
\hline Sample & 2 & 3 & 4 & 5 & 6 & 7 & 8 & 9 & 10 & 11 \\
\hline Average Height(mm) & 3.61 & 3.73 & 3.93 & 3.50 & 3.66 & 3.57 & 2.17 & 4.19 & 4.16 & 3.74 \\
\hline Average Diameter(mm) & 15.16 & 15.20 & 15.25 & 15.10 & 14.75 & 14.82 & 14.66 & 14.54 & 14.72 & 13.57 \\
\hline
\end{tabular}

\begin{tabular}{|c|c|c|c|c|c|c|c|c|c|c|c|}
\hline \multicolumn{5}{|c|}{ Corelock } & & & & & & & \\
\hline \multicolumn{3}{|c|}{ Location Five Mile Pt } & & & & & & & & & \\
\hline Sample & FM1 F & FM2 & FM3 & FM 4 & FM5 & FM6 & FM7 & FM 8 & FMg & FM $10 \quad F$ & FM 11 \\
\hline Average Height & 48.44 & 46.12 & 39.82 & 43.13 & 48.69 & 45.05 & 45.62 & 47.26 & 48.05 & 47.02 & 40.08 \\
\hline Alerage Diameter & 146.74 & 146.59 & 146.66 & 146.71 & 146.72 & 146.79 & 146.80 & 147,21 & 146.89 & 147.02 & 146.70 \\
\hline
\end{tabular}

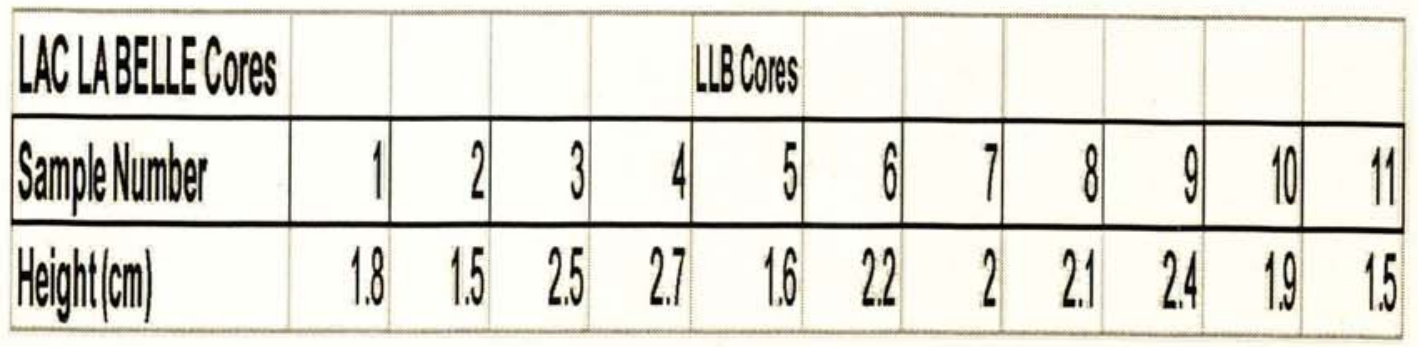




\section{APPENDIX B}

Appendix B contains the continuous dielectric constant values taken from the

Radan Road software for the 2005 and 2006 GPR surveys 
WARNING: Modification of this ASCII file outside of RADAN may cause unpredictable

Version $=5$

behavior when this file is reloaded into RADAN.

Data Filename $=$ M41 LAYER PICK.DZT

Layer threshold distance $=32.807999 \mathrm{ft}$

Number of layers $=1$

Amplitude Units $=$ Decibels with correction applied for spreading and transmission

Last Pick Settings:

Layer 1 Automatic

150

13

Calibration file $=$ C:IDATAIMTU RESEARCHIM-41 PROCESSED FILESIM41 CALIBRATION.CZT

\begin{tabular}{|c|c|c|c|c|c|c|c|}
\hline File & Ch\# & Scan\# & $y(f t)$ & Layer 1 & $z$ (in) & Amp & $\operatorname{Dev}(\mathrm{ft})$ \\
\hline M41 LAYE & 1 & 109 & 54.602 & 0 Layer 1 & 1.938 & -5.12 & 0.2 \\
\hline M41 LAYE & 1 & 110 & 55.103 & 0 Layer 1 & 2.075 & -16.79 & 0.04 \\
\hline M41 LAYE & 1 & 111 & 55.604 & 0 Layer 1 & 2.029 & -16.2 & 0.08 \\
\hline M41 LAYE & 1 & 112 & 56.105 & 0 Layer 1 & 1.908 & -4.86 & 0.16 \\
\hline M41 LAYE & 1 & 113 & 56.606 & 0 Layer 1 & 2.018 & -16.81 & 0.17 \\
\hline M41 LAYE & 1 & 114 & 57.107 & 0 Layer 1 & 2.145 & -17.39 & 0.04 \\
\hline M41 LAYE & 1 & 120 & 60.113 & 0 Layer 1 & 2.095 & -16.74 & 0.06 \\
\hline M41 LAYE & 1 & 121 & 60.614 & 0 Layer 1 & 2.003 & -4.95 & 0.15 \\
\hline M41 LAYE & 1 & 127 & 63.619 & 0 Layer 1 & 2.049 & -18.18 & 0.05 \\
\hline M41 LAYE & 1 & 128 & 64.12 & 0 Layer 1 & 2.044 & -17.11 & 0.04 \\
\hline M41 LAYE & 1 & 129 & 64.621 & 0 Layer 1 & 2.061 & -16.5 & 0.02 \\
\hline M41 LAYE & 1 & 169 & 84.659 & 0 Layer 1 & 2.21 & -5.31 & 0.29 \\
\hline M41 LAYE & 1 & 170 & 85.16 & 0 Layer 1 & 2.245 & -5.39 & 0.33 \\
\hline M41 LAYE & 1 & 172 & 86.162 & 0 Layer 1 & 2.411 & -5.46 & 0.5 \\
\hline M41 LAYE & 1 & 173 & 86.662 & 0 Layer 1 & 2.355 & -5.32 & 0.45 \\
\hline M41 LAYE & 1 & 174 & 87.163 & 0 Layer 1 & 2.286 & -5.33 & 0.38 \\
\hline M41 LAYE & 1 & 175 & 87.664 & 0 Layer 1 & 2.242 & -5.39 & 0.34 \\
\hline M41 LAYE & 1 & 176 & 88.165 & 0 Layer 1 & 2.185 & -5.24 & 0.28 \\
\hline M41 LAYE & 1 & 177 & 88.666 & 0 Layer 1 & 2.08 & -5.32 & 0.18 \\
\hline M41 LAYE & 1 & 178 & 89.167 & 0 Layer 1 & 2.107 & -5.22 & 0.21 \\
\hline M41 LAYE & 1 & 179 & 89.668 & 0 Layer 1 & 2.089 & -5.35 & 0.2 \\
\hline M41 LAYE & 1 & 180 & 90.169 & 0 Layer 1 & 2.02 & -5.35 & 0.13 \\
\hline M41 LAYE & 1 & 229 & 114.715 & 0 Layer 1 & 1.736 & -5.57 & 0.02 \\
\hline M41 LAYE & 1 & 230 & 115.216 & 0 Layer 1 & 1.646 & -5.26 & 0.07 \\
\hline M41 LAYE & 1 & 231 & 115.717 & 0 Layer 1 & 1.714 & -5.49 & 0.01 \\
\hline M41 LAYE & 1 & 232 & 116.218 & 0 Layer 1 & 1.634 & -5.22 & 0.07 \\
\hline M41 LAYE & 1 & 233 & 116.719 & 0 Layer 1 & 1.678 & -5.37 & 0.02 \\
\hline M41 LAYE & 1 & 234 & 117.22 & 0 Layer 1 & 1.663 & -5.32 & 0.03 \\
\hline M41 LAYE & 1 & 235 & 117.721 & 0 Layer 1 & 1.661 & -5.31 & 0.03 \\
\hline M41 LAYE & 1 & 236 & 118.222 & 0 Layer 1 & 1.71 & -5.47 & 0.03 \\
\hline M41 LAYE & 1 & 237 & 118.723 & 0 Layer 1 & 1.614 & -5.39 & 0.07 \\
\hline M41 LAYE & 1 & 238 & 119.224 & 0 Layer 1 & 1.589 & -5.3 & 0.09 \\
\hline M41 LAYE & 1 & 239 & 119.724 & 0 Layer 1 & 1.627 & -5.43 & 0.05 \\
\hline M41 LAYE & 1 & 240 & 120.225 & 0 Layer 1 & 1.558 & -5.43 & 0.12 \\
\hline M41 LAYE & 1 & 290 & 145.272 & 0 Layer 1 & 1.68 & -5.37 & 0.06 \\
\hline M41 LAYE & 1 & 291 & 145.773 & 0 Layer 1 & 1.71 & -5.47 & 0.09 \\
\hline M41 LAYE & 1 & 292 & 146.274 & 0 Layer 1 & 1.632 & -5.45 & 0.01 \\
\hline M41 LAYE & 1 & 293 & 146.775 & 0 Layer 1 & 1.672 & -5.59 & 0.05 \\
\hline M41 LAYE & 1 & 294 & 147.276 & 0 Layer 1 & 1.574 & -5.25 & 0.05 \\
\hline M41 LAYE & 1 & 295 & 147.777 & 0 Layer 1 & 1.646 & -5.5 & 0.03 \\
\hline M41 LAYE & 1 & 296 & 148.278 & 0 Layer 1 & 1.699 & -5.44 & 0.08 \\
\hline
\end{tabular}




\begin{tabular}{|c|c|c|c|c|c|c|c|}
\hline an\# & $x(t)$ & $\%$ Scans Vel. Type & $v($ in/ns) & $t$ (ns) & $V(\mathrm{~m} / \mathrm{s})$ & $\varepsilon$ & thickness $(\mathrm{cm})$ \\
\hline 109 & 54.602 & 100 Automatic & 3.386 & 1.141 & $8.60 E+07$ & 12.17 & 4.92 \\
\hline 110 & 55.103 & 100 Automatic & 3.504 & 1.18 & $8.90 E+07$ & 11.36 & 5.27 \\
\hline 111 & 55.604 & 100 Automatic & 3.543 & 1.141 & $9.00 E+07$ & 11.11 & 5.15 \\
\hline 112 & 56.105 & 100 Automatic & 3.224 & 1.18 & $8.19 E+07$ & 13.42 & 4.85 \\
\hline 113 & 56.606 & 90.77 Automatic & 3.299 & 1.219 & $8.38 E+07$ & 12.82 & 5.13 \\
\hline 114 & 57.107 & 90.77 Automatic & 3.398 & 1.258 & $8.63 E+07$ & 12.08 & 6.45 \\
\hline 120 & 60.113 & 90.77 Automatic & 3.319 & 1.258 & $8.43 E+07$ & 12.66 & 5.32 \\
\hline 121 & 60.614 & 90.77 Automatic & 3.276 & 1.219 & $8.32 E+07$ & 13.00 & 5.09 \\
\hline 127 & 63.619 & 93.85 Automatic & 3.461 & 1.18 & $8.79 E+07$ & 11.65 & 5.20 \\
\hline 128 & 64.12 & 93.85 Automatic & 3.343 & 1.219 & $8.49 E+07$ & 12.48 & 5.19 \\
\hline 129 & 64.621 & 93.85 Automatic & 3.48 & 1.18 & $8.84 E+07$ & 11.52 & 5.23 \\
\hline 169 & 84.659 & 98.46 Automatic & 3.5 & 1.258 & $8.89 E+07$ & 11.39 & 5.61 \\
\hline 170 & 85.16 & 100 Automatic & 3.555 & 1.258 & $9.03 E+07$ & 11.04 & 5.70 \\
\hline 172 & 86.162 & 100 Automatic & 3.594 & 1.336 & $9.13 E+07$ & 10.80 & 6.12 \\
\hline 173 & 86.662 & 100 Automatic & 3.512 & 1.336 & $8.92 E+07$ & 11.31 & 5.98 \\
\hline 174 & 87.163 & 100 Automatic & 3.512 & 1.297 & $8.92 E+07$ & 11.31 & 5.81 \\
\hline 175 & 87.664 & 100 Automatic & 3.651 & 1.258 & $9.02 E+07$ & 11.06 & 6.69 \\
\hline 176 & 88.165 & 100 Automatic & 3.461 & 1.258 & $8.79 \mathrm{E}+07$ & 11.65 & 5.55 \\
\hline 177 & 88.666 & 100 Automatic & 3.512 & 1.18 & $8.92 E+07$ & 11.31 & 5.28 \\
\hline 178 & 89.167 & 100 Automatic & 3.445 & 1.219 & $8.75 E+07$ & 11.75 & 5.35 \\
\hline 179 & 89.668 & 100 Automatic & 3.528 & 1.18 & $8.96 E+07$ & 11.21 & 5.31 \\
\hline 180 & 90.169 & 100 Automatic & 3.528 & 1.141 & $8.96 \mathrm{E}+07$ & 11.21 & 5.13 \\
\hline 229 & 114.715 & 100 Automatic & 3.657 & 0.945 & $9.29 \mathrm{E}+07$ & 10.43 & 4.41 \\
\hline 230 & 115.216 & 100 Automatic & 3.469 & 0.945 & $8.81 E+07$ & 11.59 & 4.18 \\
\hline 231 & 115.717 & 100 Automatic & 3.61 & 0.945 & $9.17 \mathrm{E}+07$ & 10.70 & 4.35 \\
\hline 232 & 116.218 & 100 Automatic & 3.445 & 0.945 & $8.75 E+07$ & 11.75 & 4.15 \\
\hline 233 & 116.719 & 100 Automatic & 3.535 & 0.945 & $8.98 E+07$ & 11.16 & 4.26 \\
\hline 234 & 117.22 & 100 Automatic & 3.604 & 0.946 & $8.90 E+07$ & 11.36 & 4.22 \\
\hline 235 & 117.721 & 100 Automatic & 3.5 & 0.945 & $8.89 E+07$ & 11.39 & 4.22 \\
\hline 236 & 118.222 & 100 Automatic & 3.602 & 0.945 & $9.15 E+07$ & 10.75 & 4.34 \\
\hline 237 & 118.723 & 100 Automatic & 3.547 & 0.906 & $9.01 \mathrm{E}+07$ & 11.09 & 4.10 \\
\hline 238 & 119.224 & 100 Automatic & 3.492 & 0.906 & $8.87 E+07$ & 11.44 & 4.04 \\
\hline 239 & 119.724 & 100 Automatic & 3.575 & 0.906 & $9.08 E+07$ & 10.91 & 4.13 \\
\hline 240 & 120.225 & 100 Automatic & 3.579 & 0.867 & $9.09 \mathrm{E}+07$ & 10.89 & 3.96 \\
\hline 290 & 145.272 & 100 Automatic & 3.539 & 0.945 & $8.99 E+07$ & 11.14 & 4.27 \\
\hline 291 & 145.773 & 100 Automatic & 3.602 & 0.945 & $9.15 E+07$ & 10.75 & 4.34 \\
\hline 292 & 146.274 & 100 Automatic & 3.587 & 0.906 & $9.11 E+07$ & 10.84 & 4.15 \\
\hline 293 & 146.775 & 100 Automatic & 3.673 & 0.906 & $9.33 E+07$ & 10.34 & 4.25 \\
\hline 294 & 147.276 & 100 Automatic & 3.461 & 0.906 & $8.79 E+07$ & 11.65 & 4.00 \\
\hline 295 & 147.777 & 100 Automatic & 3.618 & 0.906 & $9.19 E+07$ & 10.66 & 4.18 \\
\hline 296 & 148.278 & 100 Automatic & 3.579 & 0.945 & $9.09 E+07$ & 10.89 & 4.32 \\
\hline
\end{tabular}




\begin{tabular}{|c|c|c|c|c|c|c|c|}
\hline M41 LAYE & 1 & 297 & 148.779 & 0 Layer 1 & 1.596 & -5.32 & 0.02 \\
\hline M41 LAYE & 1 & 298 & 149.28 & 0 Layer 1 & 1.627 & -5.2 & 0.01 \\
\hline M41 LAYE & 1 & 299 & 149.781 & 0 Layer 1 & 1.581 & -5.52 & 0.04 \\
\hline M41 LAYE & 1 & 300 & 150.282 & 0 Layer 1 & 1.619 & -5.4 & 0 \\
\hline M41 LAYE & 1 & 301 & 150.783 & 0 Layer 1 & 1.586 & -5.53 & 0.03 \\
\hline M41 LAYE & 1 & 351 & 175.83 & 0 Layer 1 & 1.583 & -5.27 & 0.05 \\
\hline M41 LAYE & 1 & 352 & 176.331 & 0 Layer 1 & 1.506 & -5.24 & 0.13 \\
\hline M41 LAYE & 1 & 353 & 176.832 & 0 Layer 1 & 1.665 & -5.56 & 0.02 \\
\hline M41 LAYE & 1 & 354 & 177.332 & 0 Layer 1 & 1.525 & -5.31 & 0.13 \\
\hline M41 LAYE & 1 & 355 & 177.833 & 0 Layer 1 & 1.58 & -5.26 & 0.08 \\
\hline M41 LAYE & 1 & 356 & 178.334 & 0 Layer 1 & 1.555 & -5.42 & 0.1 \\
\hline M41 LAYE & 1 & 357 & 178.835 & 0 Layer 1 & 1.655 & -5.53 & 0.01 \\
\hline M41 LAYE & 1 & 358 & 179.336 & 0 Layer 1 & 1.63 & -5.44 & 0.04 \\
\hline M41 LAYE & 1 & 359 & 179.837 & 0 Layer 1 & 1.556 & -5.18 & 0.12 \\
\hline M41 LAYE & 1 & 360 & 180.338 & 0 Layer 1 & 1.581 & -5.27 & 0.1 \\
\hline M41 LAYE & 1 & 361 & 180.839 & 0 Layer 1 & 1.781 & -5.47 & 0.1 \\
\hline M41 LAYE & 1 & 406 & 203.381 & 0 Layer 1 & 2.598 & -18.87 & 0.4 \\
\hline M41 LAYE & 1 & 411 & 205.886 & 0 Layer 1 & 2.395 & -15.47 & 0.08 \\
\hline M41 LAYE & 1 & 412 & 206.387 & 0 Layer 1 & 2.434 & -15.14 & 0.1 \\
\hline M41 LAYE & 1 & 413 & 206.888 & 0 Layer 1 & 2.51 & -16.81 & 0.15 \\
\hline M41 LAYE & 1 & 414 & 207.389 & 0 Layer 1 & 2.656 & -28.69 & 0.28 \\
\hline M41 LAYE & 1 & 415 & 207.89 & 0 Layer 1 & 2.614 & -22.05 & 0.21 \\
\hline M41 LAYE & 1 & 419 & 209.894 & 0 Layer 1 & 2.595 & -17.82 & 0.11 \\
\hline M41 LAYE & 1 & 422 & 211.396 & 0 Layer 1 & 2.778 & -23.59 & 0.24 \\
\hline M41 LAYE & 1 & 423 & 211.897 & 0 Layer 1 & 2.706 & -19.76 & 0.15 \\
\hline M41 LAYE & 1 & 426 & 213.4 & 0 Layer 1 & 2.931 & -37.22 & 0.32 \\
\hline M41 LAYE & 1 & 428 & 214.402 & 0 Layer 1 & 2.651 & -18.41 & 0 \\
\hline M41 LAYE & 1 & 471 & 235.942 & 0 Layer 1 & 3.242 & -17.41 & 0.09 \\
\hline M41 LAYE & 1 & 472 & 236.443 & 0 Layer 1 & 3.163 & -15.23 & 0.01 \\
\hline M41 LAYE & 1 & 473 & 236.944 & 0 Layer 1 & 3.203 & -15.85 & 0.05 \\
\hline M41 LAYE & 1 & 474 & 237.445 & 0 Layer 1 & 3.283 & -17.36 & 0.1 \\
\hline M41 LAYE & 1 & 475 & 237.946 & 0 Layer 1 & 3.163 & -15.2 & 0.02 \\
\hline M41 LAYE & 1 & 476 & 238.447 & 0 Layer 1 & 3.163 & -15.19 & 0.03 \\
\hline M41 LAYE & 1 & 477 & 238.948 & 0 Layer 1 & 3.282 & -17.59 & 0.15 \\
\hline M41 LAYE & 1 & 478 & 239.449 & 0 Layer 1 & 3.123 & -18.28 & 0 \\
\hline M41 LAYE & 1 & 479 & 239.95 & 0 Layer 1 & 3.163 & -15.94 & 0.04 \\
\hline M41 LAYE & 1 & 481 & 240.952 & 0 Layer 1 & 3.163 & -16.14 & 0.05 \\
\hline M41 LAYE & 1 & 482 & 241.453 & 0 Layer 1 & 3.163 & -16.73 & 0.05 \\
\hline M41 LAYE & 1 & 531 & 265.999 & 0 Layer 1 & 2.32 & -14.47 & 0.01 \\
\hline M41 LAYE & 1 & 532 & 266.5 & 0 Layer 1 & 2.398 & -15.01 & 0.09 \\
\hline M41 LAYE & 1 & 533 & 267.001 & 0 Layer 1 & 2.271 & -14.25 & 0.02 \\
\hline M41 LAYE & 1 & 535 & 268.003 & 0 Layer 1 & 2.11 & -17.74 & 0.15 \\
\hline M41 LAYE & 1 & 536 & 268.503 & 0 Layer 1 & 2.117 & -16.85 & 0.12 \\
\hline M41 LAYE & 1 & 537 & 269.004 & 0 Layer 1 & 2.061 & -17.07 & 0.16 \\
\hline M41 LAYE & 1 & 538 & 269.505 & 0 Layer 1 & 2.035 & -16.54 & 0.17 \\
\hline M41 LAYE & 1 & 539 & 270.006 & 0 Layer 1 & 2.066 & -16.61 & 0.12 \\
\hline M41 LAYE & 1 & 540 & 270.507 & 0 Layer 1 & 2.099 & -15.78 & 0.08 \\
\hline M41 LAYE & 1 & 541 & 271.008 & 0 Layer 1 & 1.979 & -5.24 & 0.18 \\
\hline M41 LAYE & 1 & 542 & 271.509 & 0 Layer 1 & 2.009 & -5.32 & 0.13 \\
\hline M41 LAYE & 1 & 593 & 297.057 & 0 Layer 1 & 1.92 & -5.26 & 0.11 \\
\hline M41 LAYE & 1 & 594 & 297.558 & 0 Layer 1 & 1.885 & -5.16 & 0.16 \\
\hline
\end{tabular}




\begin{tabular}{|c|c|c|c|c|c|c|c|}
\hline 297 & 148.779 & 100 Automatic & 3.508 & 0.906 & $8.91 \mathrm{E}+07$ & 11.34 & 4.05 \\
\hline 298 & 149.28 & 100 Automatic & 3.429 & 0.945 & $8.71 E+07$ & 11.86 & 4.13 \\
\hline 299 & 149.781 & 100 Automatic & 3.63 & 0.867 & $9.22 \mathrm{E}+07$ & 10.59 & 4.02 \\
\hline 300 & 150.282 & 100 Automatic & 3.559 & 0.906 & $9.04 E+07$ & 11.01 & 4.11 \\
\hline 301 & 150.783 & 100 Automatic & 3.642 & 0.867 & $9.25 E+07$ & 10.52 & 4.03 \\
\hline 351 & 175.83 & 100 Automatic & 3.48 & 0.906 & $8.84 E+07$ & 11.52 & 4.02 \\
\hline 352 & 176.331 & 100 Automatic & 3.461 & 0.867 & $8.79 E+07$ & 11.65 & 3.83 \\
\hline 353 & 176.832 & 100 Automatic & 3.657 & 0.906 & $9.29 E+07$ & 10.43 & 4.23 \\
\hline 354 & 177.332 & 100 Automatic & 3.504 & 0.867 & $8.90 E+07$ & 11.36 & 3.87 \\
\hline 355 & 177.833 & 100 Automatic & 3.472 & 0.906 & $8.82 E+07$ & 11.57 & 4.01 \\
\hline 356 & 178.334 & 100 Automatic & 3.571 & 0.867 & $9.07 E+07$ & 10.94 & 3.96 \\
\hline 357 & 178.835 & 100 Automatic & 3.638 & 0.906 & $9.24 E+07$ & 10.54 & 4.20 \\
\hline 358 & 179.336 & 100 Automatic & 3.583 & 0.906 & $9.10 E+07$ & 10.87 & 4.14 \\
\hline 359 & 179.837 & 100 Automatic & 3.421 & 0.906 & $8.69 E+07$ & 11.92 & 3.95 \\
\hline 360 & 180.338 & 100 Automatic & 3.476 & 0.906 & $8.83 E+07$ & 11.55 & 4.02 \\
\hline 361 & 180.839 & 100 Automatic & 3.602 & 0.984 & $9.15 E+07$ & 10.75 & 4.52 \\
\hline 406 & 203.381 & 83.08 Automatic & 3.469 & 1.492 & $8.81 E+07$ & 11.59 & 6.60 \\
\hline 411 & 205.886 & 83.08 Automatic & 3.374 & 1.414 & $8.57 E+07$ & 12.25 & 6.08 \\
\hline 412 & 206.387 & 83.08 Automatic & 3.429 & 1.414 & $8.71 E+07$ & 11.86 & 6.18 \\
\hline 413 & 206.888 & 83.08 Automatic & 3.441 & 1.453 & $8.74 E+07$ & 11.78 & 6.38 \\
\hline 414 & 207.389 & 83.08 Automatic & 3.37 & 1.57 & $8.56 E+07$ & 12.28 & 6.75 \\
\hline 415 & 207.89 & 83.08 Automatic & 3.402 & 1.631 & $8.64 E+07$ & 12.06 & 6.64 \\
\hline 419 & 209.894 & 83.08 Automatic & 3.465 & 1.492 & $8.80 E+07$ & 11.62 & 6.59 \\
\hline 422 & 211.396 & 83.08 Automatic & 3.524 & 1.57 & $8.95 E+07$ & 11.23 & 7.06 \\
\hline 423 & 211.897 & 83.08 Automatic & 3.52 & 1.531 & $8.94 E+07$ & 11.26 & 6.87 \\
\hline 426 & 213.4 & 81.54 Automatic & 3.461 & 1.688 & $8.79 E+07$ & 11.65 & 7.44 \\
\hline 428 & 214.402 & 81.54 Automatic & 3.449 & 1.531 & $8.76 E+07$ & 11.73 & 6.73 \\
\hline 471 & 235.942 & 90 Automatic & 3.661 & 1.766 & $9.30 E+07$ & 10.41 & 8.23 \\
\hline 472 & 236.443 & 90 Automatic & 3.74 & 1.688 & $9.50 E+07$ & 9.97 & 8.03 \\
\hline 473 & 236.944 & 90 Automatic & 3.701 & 1.727 & $9.40 E+07$ & 10.18 & 8.14 \\
\hline 474 & 237.445 & 90 Automatic & 3.819 & 1.727 & $9.70 E+07$ & 9.56 & 8.34 \\
\hline 475 & 237.946 & 80 Automatic & 3.661 & 1.727 & $9.30 E+07$ & 10.41 & 8.03 \\
\hline 476 & 238.447 & 80 Automatic & 3.661 & 1.727 & $9.30 \mathrm{E}+07$ & 10.41 & 8.03 \\
\hline 477 & 238.948 & 80 Automatic & 3.74 & 1.766 & $9.50 \mathrm{E}+07$ & 9.97 & 8.34 \\
\hline 478 & 239.449 & 80 Automatic & 3.622 & 1.727 & $9.20 \mathrm{E}+07$ & 10.63 & 7.93 \\
\hline 479 & 239.95 & 80 Automatic & 3.74 & 1.688 & $9.50 E+07$ & 9.97 & 8.03 \\
\hline 481 & 240.952 & 80 Automatic & 3.661 & 1.727 & $9.30 E+07$ & 10.41 & 8.03 \\
\hline 482 & 241.453 & 80 Automatic & 3.661 & 1.727 & $9.30 E+07$ & 10.41 & 8.03 \\
\hline 531 & 265.999 & 96.92 Automatic & 3.461 & 1.336 & $8.79 E+07$ & 11.65 & 5.89 \\
\hline 532 & 266.5 & 96.92 Automatic & 3.575 & 1.336 & $9.08 E+07$ & 10.91 & 6.09 \\
\hline 533 & 267.001 & 96.92 Automatic & 3.488 & 1.297 & $8.86 \mathrm{E}+07$ & 11.47 & 5.77 \\
\hline 535 & 268.003 & 96.92 Automatic & 3.449 & 1.219 & $8.76 E+07$ & 11.73 & 5.36 \\
\hline 536 & 268.503 & 98.46 Automatic & 3.461 & 1.219 & $8.79 E+07$ & 11.65 & 5.38 \\
\hline 637 & 269.004 & 98.46 Automatic & 3.37 & 1.219 & $8.66 E+07$ & 12.28 & 6.23 \\
\hline 538 & 269.505 & 100 Automatic & 3.437 & 1.18 & $8.73 E+07$ & 11.81 & 5.17 \\
\hline 539 & 270.006 & 100 Automatic & 3.488 & 1.18 & $8.86 E+07$ & 11.47 & 5.25 \\
\hline 540 & 270.507 & 100 Automatic & 3.543 & 1.18 & $9.00 E+07$ & 11.11 & 5.33 \\
\hline 541 & 271.008 & 100 Automatic & 3.457 & 1.141 & $8.78 E+07$ & 11.67 & 5.03 \\
\hline 542 & 271.509 & 100 Automatic & 3.508 & 1.141 & $8.91 E+07$ & 11.34 & 5.10 \\
\hline 593 & 297.057 & 100 Automatic & 3.472 & 1.102 & $8.82 E+07$ & 11.57 & 4.88 \\
\hline 594 & 297.558 & 100 Automatic & 3.409 & 1.102 & $8.66 E+07$ & 12.00 & 4.79 \\
\hline
\end{tabular}




\begin{tabular}{llrrlrrr} 
M41 LAYE & 1 & 595 & 298.059 & O Layer 1 & 1.885 & -5.16 & 0.16 \\
M41 LAYE & 1 & 596 & 298.56 & 0 Layer 1 & 1.835 & -5.21 & 0.22 \\
M41 LAYE & 1 & 597 & 299.061 & 0 Layer 1 & 2.034 & -15.22 & 0.02 \\
M41 LAYE & 1 & 598 & 299.562 & 0 Layer 1 & 1.954 & -5.16 & 0.09 \\
M41 LAYE & 1 & 599 & 300.063 & 0 Layer 1 & 2.068 & -15.83 & 0.01 \\
M41 LAYE & 1 & 600 & 300.564 & 0 Layer 1 & 2.023 & -16.11 & 0.04 \\
M41 LAYE & 1 & 601 & 301.064 & 0 Layer 1 & 2.103 & -15.9 & 0.03 \\
M41 LAYE & 1 & 602 & 301.565 & 0 Layer 1 & 2.044 & -15.82 & 0.02 \\
M41 LAYE & 1 & 603 & 302.066 & 0 Layer 1 & 2.14 & -16.39 & 0.05 \\
M41 LAYE & 1 & 653 & 327.113 & 0 Layer 1 & 2.569 & -16.51 & 0.15 \\
M41 LAYE & 1 & 654 & 327.614 & 0 Layer 1 & 2.609 & -16.05 & 0.18 \\
M41 LAYE & 1 & 655 & 328.115 & 0 Layer 1 & 2.529 & -15.43 & 0.09 \\
M41 LAYE & 1 & 656 & 328.616 & 0 Layer 1 & 2.371 & -17.5 & 0.07 \\
M41 LAYE & 1 & 657 & 329.117 & 0 Layer 1 & 2.451 & -14.35 & 0 \\
M41 LAYE & 1 & 658 & 329.618 & O Layer 1 & $\mathbf{2 . 4 5 1}$ & -13.47 & 0.01 \\
\hline M41 LAYE & 1 & 659 & 330.119 & 0 Layer 1 & 2.332 & -17.15 & 0.14 \\
M41 LAYE & 1 & 660 & 330.62 & 0 Layer 1 & 2.45 & -13.52 & 0.03 \\
M41 LAYE & 1 & 661 & 331.121 & 0 Layer 1 & 2.371 & -16.46 & 0.12 \\
M41 LAYE & 1 & 662 & 331.622 & 0 Layer 1 & 2.648 & -17.18 & 0.17 \\
M41 LAYE & 1 & 663 & 332.123 & 0 Layer 1 & 2.57 & -14.3 & 0.33
\end{tabular}




\begin{tabular}{|c|c|c|c|c|c|c|c|}
\hline 595 & 298.059 & 100 Automatic & 3.409 & 1.102 & $8.66 \mathrm{E}+07$ & 12.00 & 4.79 \\
\hline 596 & 298.56 & 100 Automatic & 3.441 & 1.063 & $8.74 \mathrm{E}+07$ & 11.78 & 4.66 \\
\hline 597 & 299.061 & 100 Automatic & 3.551 & 1.141 & $9.02 E+07$ & 11.06 & 5.17 \\
\hline 598 & 299.562 & 100 Automatic & 3.413 & 1.141 & $8.67 E+07$ & 11.98 & 4.96 \\
\hline 599 & 300.063 & 100 Automatic & 3.61 & 1.141 & $9.17 \mathrm{E}+07$ & 10.70 & 5.25 \\
\hline 600 & 300.564 & 100 Automatic & 3.417 & 1.18 & $8.68 \mathrm{E}+07$ & 11.95 & 5.14 \\
\hline 601 & 301.064 & 100 Automatic & 3.551 & 1.18 & $9.02 E+07$ & 11.06 & 5.34 \\
\hline 602 & 301.565 & 100 Automatic & 3.453 & 1.18 & $8.77 E+07$ & 11.70 & 5.19 \\
\hline 603 & 302.066 & 100 Automatic & 3.614 & 1.18 & $9.18 \mathrm{E}+07$ & 10.68 & 5.44 \\
\hline 653 & 327.113 & 100 Automatic & 3.543 & 1.453 & $9.00 E+07$ & 11.11 & 6.53 \\
\hline 654 & 327.614 & 100 Automatic & 3.583 & 1.453 & $9.10 E+07$ & 10.87 & 6.63 \\
\hline 655 & 328.115 & 100 Automatic & 3.465 & 1.453 & $8.80 E+07$ & 11.62 & 6.42 \\
\hline 656 & 328.616 & 100 Automatic & 3.465 & 1.375 & $8.80 E+07$ & 11.62 & 6.02 \\
\hline 657 & 329.117 & 100 Automatic & 3.543 & 1.375 & $9.00 \mathrm{E}+07$ & 11.11 & 6.23 \\
\hline 658 & 329.618 & 100 Automatic & 3.543 & 1.375 & $9.00 E+07$ & 11.11 & 6.23 \\
\hline 659 & 330.119 & 100 Automatic & 3.504 & 1.336 & $8.90 E+07$ & 11.36 & 5.92 \\
\hline 660 & 330.62 & 100 Automatic & 3.465 & 1.414 & $8.80 E+07$ & 11.62 & 6.22 \\
\hline 661 & 331.121 & 100 Automatic & 3.465 & 1.375 & $8.80 E+07$ & 11.62 & 6.02 \\
\hline 662 & 331.622 & 100 Automatic & 3.543 & 1.492 & $9.00 E+07$ & 11.11 & 6.73 \\
\hline 663 & 332.123 & 95 Automatic & 3.622 & 1.414 & $9.20 \mathrm{E}+07$ & 10.63 & 6.53 \\
\hline
\end{tabular}


WARNING: Modification of this ASCII file outside of RADAN may cause

Version $=5$

Data Filename $=$ M26 ADJ SCAN LAYER.DZT

unpredictable behavior when this file is reloaded

Layer threshold distance $=32.807999 \mathrm{ft}$

Number of layers $=1$

Amplitude Units $=$ Decibels with correction applied for spreading and transmission

Last Pick Settings:

$\begin{array}{llllll}\text { Layer } 1 & \text { Core Data } & 150 & 0 & 1\end{array}$

Calibration file $=$ C:IDATAIMTU RESEARCHMM-26 PROCESSED FILESIM26 CALIB ADJ2. CZT

\begin{tabular}{|c|c|c|c|c|c|c|c|}
\hline $\mathrm{Ch} \#$ & Scan\# & & $y(f t)$ & Layer 1 & $z$ (in) & Amp & $\operatorname{Dev}(f t)$ \\
\hline M26 CORE LOCA & 1 & 53 & 26.55 & 0 Layer 1 & 3.909 & -15.32 & \\
\hline M26 CORE LOCA & 1 & 54 & 27.051 & 0 Layer 1 & 3.909 & -16.03 & \\
\hline M26 CORE LOCA & 1 & 55 & 27.552 & 0 Layer 1 & 3.706 & -14.65 & \\
\hline M26 CORE LOCA & 1 & 56 & 28.053 & 0 Layer 1 & 3.909 & -15.61 & \\
\hline M26 CORE LOCA & 1 & 57 & 28.554 & 0 Layer 1 & 3.909 & -15.67 & \\
\hline M26 CORE LOCA & 1 & 58 & 29.054 & 0 Layer 1 & 3.909 & -16.23 & \\
\hline M26 CORE LOCA & 1 & 59 & 29.555 & 0 Layer 1 & 3.909 & -16.88 & \\
\hline M26 CORE LOCA & 1 & 60 & 30.056 & 0 Layer 1 & 3.909 & -15.06 & \\
\hline M26 CORE LOCA* & 1 & 61 & 30.557 & 0 Layer 1 & 3.706 & -14.28 & \\
\hline M26 CORE LOCA & 1 & 62 & 31.058 & 0 Layer 1 & 3.706 & -14.89 & \\
\hline M26 CORE LOCA' & 1 & 63 & 31.559 & 0 Layer 1 & 3.706 & -14.64 & \\
\hline M26 CORE LOCA & 1 & 116 & 58.109 & 0 Layer 1 & 3.706 & -15.82 & \\
\hline M26 CORE LOCA & 1 & 117 & 58.61 & 0 Layer 1 & 3.909 & -16.83 & \\
\hline M26 CORE LOCA ${ }^{\circ}$ & 1 & 118 & 59.111 & 0 Layer 1 & 3.909 & -16.24 & \\
\hline M26 CORE LOCA & 1 & 119 & 59.612 & 0 Layer 1 & 3.706 & -15.51 & \\
\hline M26 CORE LOCA & 1 & 120 & 60.113 & 0 Layer 1 & 3.909 & -16.33 & \\
\hline M26 CORE LOCA' & 1 & 121 & 60.614 & 0 Layer 1 & 3.909 & -16.46 & \\
\hline M26 CORE LOCA & 1 & 122 & 61.115 & 0 Layer 1 & 3.706 & -15.78 & \\
\hline M26 CORE LOCA & 1 & 123 & 61.616 & 0 Layer 1 & 3.909 & -16.17 & \\
\hline M26 CORE LOCA & 1 & 124 & 62.116 & 0 Layer 1 & 3.909 & -15.8 & \\
\hline M26 CORE LOCA & 1 & 125 & 62.617 & 0 Layer 1 & 3.706 & -15.65 & \\
\hline M26 CORE LOCA & 1 & 126 & 63.118 & 0 Layer 1 & 3.706 & -15.39 & \\
\hline M26 CORE LOCA & 1 & 297 & 148.779 & 0 Layer 1 & 3.541 & -15.52 & \\
\hline M26 CORE LOCA* & 1 & 298 & 149.28 & 0 Layer 1 & 3.541 & -16.32 & \\
\hline M26 CORE LOCA* & 1 & 299 & 149.781 & 0 Layer 1 & 3.541 & -17.01 & \\
\hline M26 CORE LOCA* & 1 & 300 & 150.282 & 0 Layer 1 & 3.541 & -15.51 & \\
\hline M26 CORE LOCA & 1 & 301 & 150.783 & 0 Layer 1 & 3.541 & -15.5 & \\
\hline M26 CORE LOCA' & 1 & 302 & 151.284 & 0 Layer 1 & 3.541 & -15.74 & \\
\hline M26 CORE LOCA & 1 & 303 & 151.785 & 0 Layer 1 & 3.541 & -16.33 & \\
\hline M26 CORE LOCA & 1 & 304 & 152.286 & 0 Layer 1 & 3.541 & -15.67 & \\
\hline M26 CORE LOCA & 1 & 305 & 152.786 & 0 Layer 1 & 3.541 & -15.58 & \\
\hline M26 CORE LOCA & 1 & 306 & 153.287 & 0 Layer 1 & 3.541 & -16.9 & \\
\hline M26 CORE LOCA* & 1 & 307 & 153.788 & 0 Layer 1 & 3.541 & -15.47 & \\
\hline M26 CORE LOCA & 1 & 357 & 178.835 & 0 Layer 1 & 4.039 & -16.27 & \\
\hline M26 CORE LOCA & 1 & 358 & 179.336 & 0 Layer 1 & 4.039 & -15.18 & \\
\hline M26 CORE LOCA & 1 & 359 & 179.837 & 0 Layer 1 & 4.039 & -14.92 & \\
\hline M26 CORE LOCA' & 1 & 360 & 180.338 & 0 Layer 1 & 4.039 & -15.07 & \\
\hline M26 CORE LOCA & 1 & 361 & 180.839 & 0 Layer 1 & 4.039 & -15.15 & \\
\hline M26 CORE LOCA & 1 & 362 & 181.34 & 0 Layer 1 & 4.039 & -16.52 & \\
\hline M26 CORE LOCA & 1 & 363 & 181.841 & 0 Layer 1 & 4.039 & -16.62 & \\
\hline M26 CORE LOCA & 1 & 364 & 182.342 & 0 Layer 1 & 4.039 & -15.77 & \\
\hline
\end{tabular}




\begin{tabular}{|c|c|c|c|c|c|c|c|}
\hline Scan\# & (ft) & \% Scans Vel. Type & $\mathrm{v}(\mathrm{in} / \mathrm{ns})$ & $t(n s)$ & $n / s)$ & $\varepsilon$ & thickness (c \\
\hline 53 & 26.55 & 0 Core Data & 10.43 & 0.75 & $2.65 E+08$ & 1.28 & 9.93 \\
\hline 54 & 27.051 & 0 Core Data & 10.43 & 0.75 & $2.65 E+08$ & 1.28 & 9.93 \\
\hline 55 & 27.552 & 0 Core Data & 10.43 & 0.711 & $2.65 E+08$ & 1.28 & 9.41 \\
\hline 56 & 28.053 & 0 Core Data & 10.43 & 0.75 & $2.65 E+08$ & 1.28 & 9.93 \\
\hline 57 & 28.554 & 0 Core Data & 10.43 & 0.75 & $2.65 E+08$ & 1.28 & 9.93 \\
\hline 58 & 29.054 & 0 Core Data & 10.43 & 0.75 & $2.65 E+08$ & 1.28 & 9.93 \\
\hline 59 & 29.555 & 0 Core Data & 10.43 & 0.75 & $2.65 E+08$ & 1,28 & 9,93 \\
\hline 60 & 30.056 & 0 Core Data & 10.43 & 0.75 & $2.65 E+08$ & 1.28 & 9.93 \\
\hline 61 & 30.557 & 0 Core Data & 10.43 & 0.711 & $2.65 E+08$ & 1.28 & 9.41 \\
\hline 62 & 31.058 & 0 Core Data & 10.43 & 0.711 & $2.65 E+08$ & 1.28 & 9.41 \\
\hline 63 & 31.559 & 0 Core Data & 10.43 & 0.711 & $2.65 E+08$ & 1.28 & 9.41 \\
\hline 116 & 58.109 & 0 Core Data & 10.43 & 0.711 & $2.65 E+08$ & 1.28 & 9.41 \\
\hline 117 & 58.61 & 0 Core Data & 10.43 & 0.75 & $2.65 E+08$ & 1.28 & 9.93 \\
\hline 118 & 59.111 & 0 Core Data & 10.43 & 0.75 & $2.65 E+08$ & 1.28 & 9.93 \\
\hline 119 & 59.612 & 0 Core Data & 10.43 & 0.711 & $2.65 E+08$ & 1.28 & 9.41 \\
\hline 120 & 60.113 & 0 Core Data & 10.43 & 0.75 & $2.65 E+08$ & 1.28 & 9.93 \\
\hline 121 & 60.614 & 0 Core Data & 10.43 & 0.75 & $2.65 E+08$ & 1.28 & 9.93 \\
\hline 122 & 61.115 & 0 Core Data & 10.43 & 0.711 & $2.65 E+08$ & 1.28 & 9.41 \\
\hline 123 & 61.616 & 0 Core Data & 10.43 & 0.75 & $2.65 E+08$ & 1.28 & 9.93 \\
\hline 124 & 62.116 & 0 Core Data & 10.43 & 0.75 & $2.65 E+08$ & 1.28 & 9.93 \\
\hline 125 & 62.617 & 0 Core Data & 10.43 & 0.711 & $2.65 E+08$ & 1.28 & 9.41 \\
\hline 126 & 63.118 & 0 Core Data & 10.43 & 0.711 & $2.65 E+08$ & 1.28 & 9.41 \\
\hline 297 & 148.779 & 0 Core Data & 9.96 & 0.711 & $2.53 E+08$ & 1.41 & 8.99 \\
\hline 298 & 149.28 & 0 Core Data & 9.96 & 0.711 & $2.53 E+08$ & 1.41 & 8.99 \\
\hline 299 & 149.781 & 0 Core Data & 9.96 & 0.711 & $2.53 E+08$ & 1.41 & 8.99 \\
\hline 300 & 150.282 & 0 Core Data & 9.96 & 0.711 & $2.53 E+08$ & 1.41 & 8.99 \\
\hline 301 & 150.783 & 0 Core Data & 9.96 & 0.711 & $2.53 \mathrm{E}+08$ & 1.41 & 8.99 \\
\hline 302 & 151.284 & 0 Core Data & 9.96 & 0.711 & $2.63 E+08$ & 1.41 & 8.99 \\
\hline 303 & 151.785 & 0 Core Data & 9.96 & 0.711 & $2.53 E+08$ & 1.41 & 8.99 \\
\hline 304 & 152.286 & 0 Core Data & 9.96 & 0.711 & $2.53 E+08$ & 1.41 & 8.99 \\
\hline 305 & 152.786 & 0 Core Data & 9.96 & 0.711 & $2.53 E+08$ & 1.41 & 8.99 \\
\hline 306 & 153.287 & 0 Core Data & 9.96 & 0.711 & $2.53 E+08$ & 1.41 & 8.99 \\
\hline 307 & 153.788 & 0 Core Data & 9.96 & 0.711 & $2.53 E+08$ & 1.41 & 8.99 \\
\hline 357 & 178.835 & 0 Core Data & 10.77 & 0.75 & $2.74 E+08$ & 1.20 & 10.26 \\
\hline 358 & 179.336 & 0 Core Data & 10.77 & 0.75 & $2.74 E+08$ & 1.20 & 10.26 \\
\hline 359 & 179.837 & 0 Core Data & 10.77 & 0.75 & $2.74 E+08$ & 1.20 & 10.26 \\
\hline 360 & 180.338 & 0 Core Data & 10.77 & 0.75 & $2.74 E+08$ & 1.20 & 10.26 \\
\hline 361 & 180.839 & 0 Core Data & 10.77 & 0.75 & $2.74 E+08$ & 1.20 & 10.26 \\
\hline 362 & 181.34 & 0 Core Data & 10.77 & 0.75 & $2.74 E+08$ & 1.20 & 10.26 \\
\hline 363 & 181.841 & 0 Core Data & 10.77 & 0.75 & $2.74 E+08$ & 1.20 & 10.26 \\
\hline 364 & 182.342 & 0 Core Data & 10.77 & 0.75 & $2.74 E+08$ & 1.20 & 10.26 \\
\hline
\end{tabular}




\begin{tabular}{|c|c|c|c|c|c|c|}
\hline M26 CORE LOCA" & 1 & 365 & 182.843 & 0 Layer 1 & 4.039 & -14.77 \\
\hline M26 CORE LOCA & 1 & 366 & 183.344 & 0 Layer 1 & 4.039 & -15.41 \\
\hline M26 CORE LOCA & 1 & 367 & 183.845 & 0 Layer 1 & 4.039 & -16.31 \\
\hline M26 CORE LOCA" & 1 & 417 & 208.892 & 0 Layer 1 & 4.18 & -15.43 \\
\hline M26 CORE LOCA & 1 & 418 & 209.393 & 0 Layer 1 & 3.962 & -14.76 \\
\hline M26 CORE LOCA & 1 & 419 & 209.894 & 0 Layer 1 & 4.18 & -15.66 \\
\hline M26 CORE LOCA- & 1 & 420 & 210.394 & 0 Layer 1 & 4.18 & -15.86 \\
\hline M26 CORE LOCA & 1 & 421 & 210.895 & 0 Layer 1 & 4.18 & -14.75 \\
\hline M26 CORE LOCA & 1 & 422 & 211.396 & 0 Layer 1 & 4.18 & -14.74 \\
\hline M26 CORE LOCA & 1 & 423 & 211.897 & 0 Layer 1 & 4.18 & -15 \\
\hline M26 CORE LOCA & 1 & 424 & 212.398 & 0 Layer 1 & 3.962 & -14.76 \\
\hline M26 CORE LOCA & 1 & 425 & 212.899 & 0 Layer 1 & 4.18 & -15.53 \\
\hline M26 CORE LOCA & 1 & 426 & 213.4 & 0 Layer 1 & 4.18 & -15.55 \\
\hline M26 CORE LOCA & 1 & 427 & 213.901 & 0 Layer 1 & 4.18 & -15.92 \\
\hline M26 CORE LOCA & 1 & 480 & 240.451 & 0 Layer 1 & 4.202 & -15 \\
\hline M26 CORE LOCA & 1 & 481 & 240.952 & 0 Layer 1 & 4.202 & -14.95 \\
\hline M26 CORE LOCA & 1 & 482 & 241.453 & 0 Layer 1 & 4.202 & -14.39 \\
\hline M26 CORE LOCA & 1 & 483 & 241.954 & 0 Layer 1 & 4.202 & -15.14 \\
\hline M26 CORE LOCA & 1 & 484 & 242.455 & 0 Layer 1 & 4.421 & -14.92 \\
\hline M26 CORE LOCA & 1 & 485 & 242.956 & 0 Layer 1 & 4.202 & -15.63 \\
\hline M26 CORE LOCA ${ }^{-}$ & 1 & 486 & 243.456 & 0 Layer 1 & 4.202 & -14.42 \\
\hline M26 CORE LOCA & 1 & 487 & 243.957 & 0 Layer 1 & 4.202 & -13.87 \\
\hline M26 CORE LOCA“ & 1 & 488 & 244.458 & 0 Layer 1 & 4.202 & -14.41 \\
\hline M26 CORE LOCA & 1 & 489 & 244.959 & 0 Layer 1 & 4.202 & -14.11 \\
\hline M26 CORE LOCA & 1 & 490 & 245.46 & 0 Layer 1 & 4.202 & -14.57 \\
\hline M26 CORE LOCA* & 1 & 539 & 270.006 & 0 Layer 1 & 4.42 & -14.43 \\
\hline M26 CORE LOCA & 1 & 540 & 270.507 & 0 Layer 1 & 4.65 & -15.58 \\
\hline M26 CORE LOCA & 1 & 541 & 271.008 & 0 Layer 1 & 4.65 & -14.37 \\
\hline M26 CORE LOCA & 1 & 542 & 271.509 & 0 Layer 1 & 4.42 & -14.02 \\
\hline M26 CORE LOCA“ & 1 & 543 & 272.01 & 0 Layer 1 & 4.65 & -15.37 \\
\hline M26 CORE LOCA & 1 & 544 & 272.511 & 0 Layer 1 & 4.42 & -14.05 \\
\hline M26 CORE LOCA & 1 & 545 & 273.012 & 0 Layer 1 & 4.65 & -14.39 \\
\hline M26 CORE LOCA & 1 & 546 & 273.513 & 0 Layer 1 & 4.65 & -15.69 \\
\hline M26 CORE LOCA & 1 & 547 & 274.014 & 0 Layer 1 & 4.42 & -14.46 \\
\hline M26 CORE LOCA & 1 & 548 & 274.515 & 0 Layer 1 & 4.42 & -13.95 \\
\hline M26 CORE LOCA“ & 1 & 549 & 275.016 & 0 Layer 1 & 4.65 & -15.51 \\
\hline M26 CORE LOCA & 1 & 600 & 300.564 & 0 Layer 1 & 4.65 & -15.71 \\
\hline M26 CORE LOCA ${ }^{\circ}$ & 1 & 601 & 301.064 & 0 Layer 1 & 4.65 & -15.94 \\
\hline M26 CORE LOCA & 1 & 602 & 301.565 & 0 Layer 1 & 4.42 & -14.95 \\
\hline M26 CORE LOCA & 1 & 603 & 302.066 & 0 Layer 1 & 4.65 & -16.22 \\
\hline M26 CORE LOCA“ & 1 & 604 & 302.567 & 0 Layer 1 & 4.65 & -16.3 \\
\hline M26 CORE LOCA & 1 & 605 & 303.068 & 0 Layer 1 & 4.65 & -15.46 \\
\hline M26 CORE LOCA“ & 1 & 606 & 303.569 & 0 Layer 1 & 4.65 & -16.33 \\
\hline M26 CORE LOCA & 1 & 607 & 304.07 & 0 Layer 1 & 4.65 & -16.42 \\
\hline M26 CORE LOCA & 1 & 608 & 304.571 & 0 Layer 1 & 4.65 & -15.23 \\
\hline M26 CORE LOCA & 1 & 609 & 305.072 & 0 Layer 1 & 4.65 & -16.63 \\
\hline M26 CORE LOCA & 1 & 610 & 305.573 & 0 Layer 1 & 4.881 & -16.09 \\
\hline M26 CORE LOCA & 1 & 658 & 329.618 & 0 Layer 1 & 4.02 & -14.13 \\
\hline M26 CORE LOCA & 1 & 659 & 330.119 & 0 Layer 1 & 4.02 & -14.79 \\
\hline M26 CORE LOCA“ & 1 & 660 & 330.62 & 0 Layer 1 & 4.02 & -15.57 \\
\hline M26 CORE LOCA & 1 & 661 & 331.121 & 0 Layer 1 & 4.23 & -16.28 \\
\hline M26 CORE LOCA & 1 & 662 & 331.622 & 0 Layer 1 & 4.02 & -16.77 \\
\hline M26 CORE LOCA & 1 & 663 & 332.123 & 0 Layer 1 & 4.23 & -16.47 \\
\hline M26 CORE LOCA & 1 & 664 & 332.624 & 0 Layer 1 & 4.23 & -16.23 \\
\hline M26 CORE LOCA“ & 1 & 665 & 333.125 & 0 Layer 1 & 4.02 & -15.26 \\
\hline M26 CORE LOCA & 1 & 666 & 333.626 & 0 Layer 1 & 4.02 & -15.29 \\
\hline M26 CORE LOCA & 1 & 667 & 334.126 & 0 Layer 1 & 4.23 & -15.73 \\
\hline M26 CORE LOCA & 1 & 668 & 334.627 & 0 Layer 1 & 4.02 & -14.67 \\
\hline
\end{tabular}




\begin{tabular}{|c|c|c|c|c|c|c|c|}
\hline 365 & 182.843 & 0 Core Data & 10.77 & 0.75 & $2.74 \mathrm{E}+08$ & 1.20 & 10.26 \\
\hline 366 & 183.344 & 0 Core Data & 10.77 & 0.75 & $2.74 \mathrm{E}+08$ & 1.20 & 10.26 \\
\hline 367 & 183.845 & 0 Core Data & 10.77 & 0.75 & $2.74 \mathrm{E}+08$ & 1.20 & 10.26 \\
\hline 417 & 208.892 & 0 Core Data & 11.15 & 0.75 & $2.83 E+08$ & 1.12 & 10.62 \\
\hline 418 & 209.393 & 0 Core Data & 11.15 & 0.711 & $2.83 E+08$ & 1.12 & 10.06 \\
\hline 419 & 209.894 & 0 Core Data & 11.15 & 0.75 & $2.83 E+08$ & 1.12 & 10.62 \\
\hline 420 & 210.394 & 0 Core Data & 11.15 & 0.75 & $2.83 \mathrm{E}+08$ & 1.12 & 10.62 \\
\hline 421 & 210.895 & 0 Core Data & 11.15 & 0.75 & $2.83 E+08$ & 1.12 & 10.62 \\
\hline 422 & 211.396 & 0 Core Data & 11.15 & 0.75 & $2.83 E+08$ & 1.12 & 10.62 \\
\hline 423 & 211.897 & 0 Core Data & 11.15 & 0.75 & $2.83 E+08$ & 1.12 & 10.62 \\
\hline 424 & 212.398 & 0 Core Data & 11.15 & 0.711 & $2.83 E+08$ & 1.12 & 10.06 \\
\hline 425 & 212.899 & 0 Core Data & 11.15 & 0.75 & $2.83 E+08$ & 1.12 & 10.62 \\
\hline 426 & 213.4 & 0 Core Data & 11.15 & 0.75 & $2.83 E+08$ & 1.12 & 10.62 \\
\hline 427 & 213.901 & 0 Core Data & 11.15 & 0.75 & $2.83 E+08$ & 1.12 & 10.62 \\
\hline 480 & 240.451 & 0 Core Data & 11.21 & 0.75 & $2.85 \mathrm{E}+08$ & 1.11 & 10.67 \\
\hline 481 & 240.952 & 0 Core Data & 11.21 & 0.75 & $2.85 E+08$ & 1.11 & 10.67 \\
\hline 482 & 241.453 & 0 Core Data & 11.21 & 0.75 & $2.85 E+08$ & 1.11 & 10.67 \\
\hline 483 & 241.954 & 0 Core Data & 11.21 & 0.75 & $2.85 E+08$ & 1.11 & 10.67 \\
\hline 484 & 242.455 & 0 Core Data & 11.21 & 0.789 & $2.85 E+08$ & 1.11 & 11.23 \\
\hline 485 & 242.956 & O Core Data & 11.21 & 0.75 & $2.85 E+08$ & 1.11 & 10.67 \\
\hline 486 & 243.456 & 0 Core Data & 11.21 & 0.75 & $2.85 E+08$ & 1.11 & 10.67 \\
\hline 487 & 243.957 & 0 Core Data & 11.21 & 0.75 & $2.85 E+08$ & 1.11 & 10.67 \\
\hline 488 & 244.458 & 0 Core Data & 11.21 & 0.75 & $2.85 E+08$ & 1.11 & 10.67 \\
\hline 489 & 244.959 & 0 Core Data & 11.21 & 0.75 & $2.85 E+08$ & 1.11 & 10.67 \\
\hline 490 & 245.46 & 0 Core Data & 11.21 & 0.75 & $2.85 \mathrm{E}+08$ & 1.11 & 10.67 \\
\hline 539 & 270.006 & 0 Core Data & 11.79 & 0.75 & $2.99 \mathrm{E}+08$ & 1.00 & 11.23 \\
\hline 540 & 270.507 & 0 Core Data & 11.79 & 0.789 & $2.99 \mathrm{E}+08$ & 1.00 & 11.81 \\
\hline 541 & 271.008 & 0 Core Data & 11.79 & 0.789 & $2.99 \mathrm{E}+08$ & 1.00 & 11.81 \\
\hline 542 & 271.509 & 0 Core Data & 11.79 & 0.75 & $2.99 \mathrm{E}+08$ & 1.00 & 11.23 \\
\hline 543 & 272.01 & 0 Core Data & 11.79 & 0.789 & $2.99 E+08$ & 1.00 & 11.81 \\
\hline 544 & 272.511 & 0 Core Data & 11.79 & 0.75 & 2.99E+08 & 1.00 & 11.23 \\
\hline 545 & 273.012 & 0 Core Data & 11.79 & 0.789 & $2.99 \mathrm{E}+08$ & 1.00 & 11.81 \\
\hline 546 & 273.513 & 0 Core Data & 11.79 & 0.789 & $2.99 \mathrm{E}+08$ & 1.00 & 11.81 \\
\hline 547 & 274.014 & 0 Core Data & 11.79 & 0.75 & $2.99 \mathrm{E}+08$ & 1.00 & 11.23 \\
\hline 548 & 274.515 & 0 Core Data & 11.79 & 0.75 & $2.99 \mathrm{E}+08$ & 1.00 & 11.23 \\
\hline 549 & 275.016 & 0 Core Data & 11.79 & 0.789 & $2.99 \mathrm{E}+08$ & 1.00 & 11.81 \\
\hline 600 & 300.564 & 0 Core Data & 11.79 & 0.789 & $2.99 E+08$ & 1.00 & 11.81 \\
\hline 601 & 301.064 & 0 Core Data & 11.79 & 0.789 & $2.99 E+08$ & 1.00 & 11.81 \\
\hline 602 & 301.565 & 0 Core Data & 11.79 & 0.75 & $2.99 \mathrm{E}+08$ & 1.00 & 11.23 \\
\hline 603 & 302.066 & 0 Core Data & 11.79 & 0.789 & $2.99 \mathrm{E}+08$ & 1.00 & 11.81 \\
\hline 604 & 302.567 & 0 Core Data & 11.79 & 0.789 & $2.99 E+08$ & 1.00 & 11.81 \\
\hline 605 & 303.068 & 0 Core Data & 11.79 & 0.789 & $2.99 E+08$ & 1.00 & 11.81 \\
\hline 606 & 303.569 & 0 Core Data & 11.79 & 0.789 & $2.99 \mathrm{E}+08$ & 1.00 & 11.81 \\
\hline 607 & 304.07 & 0 Core Data & 11.79 & 0.789 & $2.99 E+08$ & 1.00 & 11.81 \\
\hline 608 & 304.571 & 0 Core Data & 11.79 & 0.789 & $2.99 \mathrm{E}+08$ & 1.00 & 11.81 \\
\hline 609 & 305.072 & 0 Core Data & 11.79 & 0.789 & $2.99 \mathrm{E}+08$ & 1.00 & 11.81 \\
\hline 610 & 305.573 & 0 Core Data & 11.79 & 0.828 & $2.99 \mathrm{E}+08$ & 1.00 & 12.40 \\
\hline 658 & 329.618 & 0 Core Data & 10.72 & 0.75 & $2.72 E+08$ & 1.21 & 10.21 \\
\hline 659 & 330.119 & 0 Core Data & 10.72 & 0.75 & $2.72 E+08$ & 1.21 & 10.21 \\
\hline 660 & 330.62 & 0 Core Data & 10.72 & 0.75 & $2.72 E+08$ & 1.21 & 10.21 \\
\hline 661 & 331.121 & 0 Core Data & 10.72 & 0.789 & $2.72 E+08$ & 1.21 & 10.74 \\
\hline 662 & 331.622 & 0 Core Data & 10.72 & 0.75 & $2.72 E+08$ & 1.21 & 10.21 \\
\hline 663 & 332.123 & 0 Core Data & 10.72 & 0.789 & $2.72 E+08$ & 1.21 & 10.74 \\
\hline 664 & 332.624 & 0 Core Data & 10.72 & 0.789 & $2.72 E+08$ & 1.21 & 10.74 \\
\hline 665 & 333.125 & 0 Core Data & 10.72 & 0.75 & $2.72 E+08$ & 1.21 & 10.21 \\
\hline 666 & 333.626 & 0 Core Data & 10.72 & 0.75 & $2.72 E+08$ & 1.21 & 10.21 \\
\hline 667 & 334.126 & 0 Core Data & 10.72 & 0.789 & $2.72 E+08$ & 1.21 & 10.74 \\
\hline 668 & 334.627 & 0 Core Data & 10.72 & 0.75 & $2.72 E+08$ & 1.21 & 10.21 \\
\hline
\end{tabular}


WARNING: Modification of this ASCII file outside of RADAN may cause

Version $=5$

Data Filename $=$ MTU5PT1 LAYER.DZT

unpredictable behavior when this file is reloaded into RADAN.

Layer threshold distance $=32.807999 \mathrm{ft}$

Number of layers $=1$

Amplitude Units $=$ Decibels with correction applied for spreading and transmission

Last Pick Settings:

Layer 1 Core Data

$150 \quad 0.00$ 1

Calibration file $=$ C:IDATAIMTU RESEARCHI5 MILE PT PROCESSED FILESICALIBPT.CZT

\begin{tabular}{|c|c|c|c|c|c|c|c|}
\hline File & Ch\# & Scan\# & $x(f)$ & Layer 1 & $z$ (in) & Amp & $\operatorname{Dev}(\mathrm{ft})$ \\
\hline FINAL RESULTS & 1 & 57 & 28.55 & 0 Layer 1 & 1.911 & -19.32 & \\
\hline FINAL RESULTS & 1 & 58 & 29.05 & 0 Layer 1 & 1.911 & -19.76 & 0.08 \\
\hline FINAL RESULTS & 1 & 59 & 29.56 & 0 Layer 1 & 1.911 & -20.12 & \\
\hline FINAL RESULTS & 1 & 60 & 30.06 & 0 Layer 1 & 1.911 & -19.07 & \\
\hline FINAL RESULTS & 1 & 61 & 30.56 & 0 Layer 1 & 1.911 & -18.67 & 0.04 \\
\hline FINAL RESULTS & 1 & 62 & 31.06 & 0 Layer 1 & 1.911 & -19.08 & \\
\hline FINAL RESULTS & 1 & 63 & 31.56 & 0 Layer 1 & 1.911 & -19.56 & 0.04 \\
\hline FINAL RESULTS & 1 & 64 & 32.06 & 0 Layer 1 & 1.828 & -18.85 & 0.11 \\
\hline FINAL RESULTS & 1 & 65 & 32.56 & 0 Layer 1 & 1.828 & -18.93 & 0.07 \\
\hline FINAL RESULTS & 1 & 66 & 33.06 & 0 Layer 1 & 1.911 & -19.64 & 0.01 \\
\hline FINAL RESULTS & 1 & 67 & 33.56 & 0 Layer 1 & 1.911 & -20.01 & 0.05 \\
\hline FINAL RESULTS & 1 & 177 & 88.67 & 0 Layer 1 & 1.648 & -21.87 & \\
\hline FINAL RESULTS & 1 & 178 & 89.17 & 0 Layer 1 & 1.57 & -21.94 & 0.12 \\
\hline FINAL RESULTS & 1 & 179 & 89.67 & 0 Layer 1 & 1.57 & -22.04 & 0.04 \\
\hline FINAL RESULTS & 1 & 180 & 90.17 & 0 Layer 1 & 1.57 & -22.22 & 0.08 \\
\hline FINAL RESULTS & 1 & 181 & 90.67 & 0 Layer 1 & 1.57 & -21.66 & 0.08 \\
\hline FINAL RESULTS & 1 & 182 & 91.17 & 0 Layer 1 & 1.648 & -22.2 & \\
\hline FINAL RESULTS & 1 & 183 & 91.67 & 0 Layer 1 & 1.57 & -21.85 & 0.12 \\
\hline FINAL RESULTS & 1 & 184 & 92.17 & 0 Layer 1 & 1.648 & -22.71 & \\
\hline FINAL RESULTS & 1 & 185 & 92.67 & 0 Layer 1 & 1.648 & -22.67 & 0.08 \\
\hline FINAL RESULTS & 1 & 186 & 93.18 & 0 Layer 1 & 1.648 & -22.99 & 0.04 \\
\hline FINAL RESULTS & 1 & 187 & 93.68 & 0 Layer 1 & 1.648 & -23.44 & 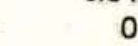 \\
\hline FINAL RESULTS & 1 & 297 & 148.78 & 0 Layer 1 & 1.92 & -21.74 & 0.01 \\
\hline FINAL RESULTS & 1 & 298 & 149.28 & 0 Layer 1 & 1.837 & -20.82 & 0.11 \\
\hline FINAL RESULTS & 1 & 299 & 149.78 & 0 Layer 1 & 1.92 & -21.36 & 0.05 \\
\hline FINAL RESULTS & 1 & 300 & 150.28 & 0 Layer 1 & 1.92 & -20.71 & 0.03 \\
\hline FINAL RESULTS & 1 & 301 & 150.78 & 0 Layer 1 & 1.92 & -21.02 & 0.05 \\
\hline FINAL RESULTS & 1 & 302 & 151.28 & 0 Layer 1 & 1.92 & -20.38 & 0.06 \\
\hline FINAL RESULTS & 1 & 303 & 151.79 & 0 Layer 1 & 1.92 & -20.27 & 0.01 \\
\hline FINAL RESULTS & 1 & 304 & 152.29 & 0 Layer 1 & 1.92 & -19.82 & 0.03 \\
\hline FINAL RESULTS & 1 & 305 & 152.79 & 0 Layer 1 & 1.92 & -20.1 & 0.01 \\
\hline FINAL RESULTS & 1 & 306 & 153.29 & 0 Layer 1 & 1.837 & -19.81 & 0.11 \\
\hline FINAL RESULTS & 1 & 307 & 153.79 & 0 Layer 1 & 1.92 & -20.01 & 0.07 \\
\hline FINAL RESULTS & 1 & 357 & 178.84 & 0 Layer 1 & 1.854 & -20.41 & 0.06 \\
\hline FINAL RESULTS & 1 & 358 & 179.34 & 0 Layer 1 & 1.854 & -20.03 & 0.02 \\
\hline FINAL RESULTS & 1 & 359 & 179.84 & 0 Layer 1 & 1.937 & -21.41 & 0.1 \\
\hline FINAL RESULTS & 1 & 360 & 180.34 & 0 Layer 1 & 1.77 & -20.5 & 0.13 \\
\hline FINAL RESULTS & 1 & 361 & 180.84 & 0 Layer 1 & 1.77 & -20.42 & 0.13 \\
\hline FINAL RESULTS & 1 & 362 & 181.34 & 0 Layer 1 & 1.77 & -20.99 & 0.13 \\
\hline FINAL RESULTS & 1 & 363 & 181.84 & 0 Layer 1 & 1.77 & -21.61 & 0.17 \\
\hline FINAL RESULTS & 1 & 364 & 182.34 & 0 Layer 1 & 1.854 & -21.74 & 0.01 \\
\hline
\end{tabular}




\begin{tabular}{|c|c|c|c|c|c|c|c|}
\hline Scan\# & $x(f t)$ & $\%$ Scans Vel. Type & $v($ in/ns) & $t(n s)$ & $V(\mathrm{~m} / \mathrm{s})$ & & ness $(\mathrm{cm})$ \\
\hline 57 & $\$ 28.55$ & 96 Core Data & 4.217 & 0.906 & 107111800 & 7.84 & 4.85 \\
\hline 58 & $\$ 29.05$ & 96 Core Data & 4.217 & 0.906 & 107111800 & 7.84 & 4.85 \\
\hline 59 & $\$ 29.56$ & 96 Core Data & 4.217 & 0.906 & 107111800 & 7.84 & 4.85 \\
\hline 60 & $\$ 30.06$ & 96 Core Data & 4.217 & 0.906 & 107111800 & 7.84 & 4.85 \\
\hline 61 & $\$ 30.56$ & 96 Core Data & 4.217 & 0.906 & 107111800 & 7.84 & 4.85 \\
\hline 62 & $\$ 31.06$ & 96 Core Data & 4.217 & 0.906 & 107111800 & 7.84 & 4.85 \\
\hline 63 & $\$ 31.56$ & 96 Core Data & 4.217 & 0.906 & 107111800 & 7.84 & 4.85 \\
\hline 64 & $\$ 32.06$ & 96 Core Data & 4.217 & 0.867 & 107111800 & 7.84 & 4.64 \\
\hline 65 & $\$ 32.56$ & 96 Core Data & 4.217 & 0.867 & 107111800 & 7.84 & 4.64 \\
\hline 66 & $\$ 33.06$ & 96 Core Data & 4.217 & 0.906 & 107111800 & 7.84 & 4.85 \\
\hline 67 & $\$ 33.56$ & 96 Core Data & 4.217 & 0.906 & 107111800 & 7.84 & 4.85 \\
\hline 177 & $\$ 88.67$ & 98 Core Data & 3.98 & 0.828 & 101092000 & 8.81 & 4.19 \\
\hline 178 & $\$ 89.17$ & 98 Core Data & 3.98 & 0.789 & 101092000 & 8.81 & 3.99 \\
\hline 179 & $\$ 89.67$ & 98 Core Data & 3.98 & 0.789 & 101092000 & 8.81 & 3.99 \\
\hline 180 & $\$ 90.17$ & 98 Core Data & 3.98 & 0.789 & 101092000 & 8.81 & 3.99 \\
\hline 181 & $\$ 90.67$ & 98 Core Data & 3.98 & 0.789 & 101092000 & 8.81 & 3.99 \\
\hline 182 & $\$ 91.17$ & 98 Core Data & 3.98 & 0.828 & 101092000 & 8.81 & 4.19 \\
\hline 183 & $\$ 91.67$ & 98 Core Data & 3.98 & 0.789 & 101092000 & 8.81 & 3.99 \\
\hline 184 & $\$ 92.17$ & 98 Core Data & 3.98 & 0.828 & 101092000 & 8.81 & 4.19 \\
\hline 185 & $\$ 92.67$ & 98 Core Data & 3.98 & 0.828 & 101092000 & 8.81 & 4.19 \\
\hline 186 & $\$ 93.18$ & 98 Core Data & 3.98 & 0.828 & 101092000 & 8.81 & 4.19 \\
\hline 187 & $\$ 93.68$ & 98 Core Data & 3.98 & 0.828 & 101092000 & 8.81 & 4.19 \\
\hline 297 & $\$ 148.78$ & 98 Core Data & 4.236 & 0.906 & 107594400 & 7.77 & 4.88 \\
\hline 298 & $\$ 149.28$ & 98 Core Data & 4.236 & 0.867 & 107594400 & 7.77 & 4.67 \\
\hline 299 & $\$ 149.78$ & 98 Core Data & 4.236 & 0.906 & 107594400 & 7.77 & 4.88 \\
\hline 300 & $\$ 150.28$ & 98 Core Data & 4.236 & 0.906 & 107594400 & 7.77 & 4.88 \\
\hline 301 & $\$ 150.78$ & 98 Core Data & 4.236 & 0.906 & 107594400 & 7.77 & 4.88 \\
\hline 302 & $\$ 161.28$ & 98 Core Data & 4.236 & 0.906 & 107694400 & 7.77 & 4.88 \\
\hline 303 & $\$ 151.79$ & 98 Core Data & 4.236 & 0.906 & 107594400 & 7.77 & 4.88 \\
\hline 304 & $\$ 152.29$ & 98 Core Data & 4.236 & 0.906 & 107594400 & 7.77 & 4.88 \\
\hline 305 & $\$ 152.79$ & 98 Core Data & 4.236 & 0.906 & 107594400 & 7.77 & 4.88 \\
\hline 306 & $\$ 153.29$ & 98 Core Data & 4.236 & 0.867 & 107594400 & 7.77 & 4.67 \\
\hline 307 & $\$ 153.79$ & 98 Core Data & 4.236 & 0.906 & 107594400 & 7.77 & 4.88 \\
\hline 357 & $\$ 178.84$ & 92 Core Data & 4.276 & 0.867 & 108610400 & 7.63 & 4.71 \\
\hline 358 & $\$ 179.34$ & 92 Core Data & 4.276 & 0.867 & 108610400 & 7.63 & 4.71 \\
\hline 359 & $\$ 179.84$ & 92 Core Data & 4.276 & 0.906 & 108610400 & 7.63 & 4.92 \\
\hline 360 & $\$ 180.34$ & 92 Core Data & 4.276 & 0.828 & 108610400 & 7.63 & 4.50 \\
\hline 361 & $\$ 180.84$ & 92 Core Data & 4.276 & 0.828 & 108610400 & 7.63 & 4.50 \\
\hline 362 & $\$ 181.34$ & 92 Core Data & 4.276 & 0.828 & 108610400 & 7.63 & 4.60 \\
\hline 363 & $\$ 181.84$ & 92 Core Data & 4.276 & 0.828 & 108610400 & 7.63 & 4.50 \\
\hline 364 & $\$ 182.34$ & 92 Core Data & 4.276 & 0.867 & 108610400 & 7.63 & 4.71 \\
\hline
\end{tabular}




\begin{tabular}{|c|c|c|c|c|c|c|c|}
\hline FINAL RESULTS & 1 & 365 & 182.84 & 0 Layer 1 & 1.77 & -20.16 & 0.09 \\
\hline FINAL RESULTS & 1 & 366 & 183.34 & 0 Layer 1 & 1.937 & -21.77 & 0.11 \\
\hline FINAL RESULTS & 1 & 367 & 183.85 & 0 Layer 1 & 1.854 & -21.38 & 0.01 \\
\hline FINAL RESULTS & 1 & 417 & 208.89 & 0 Layer 1 & 1.8 & -21.05 & 0.09 \\
\hline FINAL RESULTS & 1 & 419 & 209.89 & 0 Layer 1 & 1.8 & -21.23 & 0.04 \\
\hline FINAL RESULTS & 1 & 421 & 210.90 & 0 Layer 1 & 1.8 & -21.16 & 0.11 \\
\hline FINAL RESULTS & 1 & 422 & 211.40 & 0 Layer 1 & 1.8 & -21.69 & 0.07 \\
\hline FINAL RESULTS & 1 & 423 & 211.90 & 0 Layer 1 & 1.8 & -21.68 & 0.06 \\
\hline FINAL RESULTS & 1 & 424 & 212.40 & 0 Layer 1 & 1.8 & -20.71 & 0.07 \\
\hline FINAL RESULTS & 1 & 425 & 212.90 & 0 Layer 1 & 1.8 & -20.29 & 0.07 \\
\hline FINAL RESULTS & 1 & 426 & 213.40 & 0 Layer 1 & 1.8 & -19.95 & 0.07 \\
\hline FINAL RESULTS & 1 & 427 & 213.90 & 0 Layer 1 & 1.885 & -20.03 & 0.05 \\
\hline FINAL RESULTS & 1 & 480 & 240.45 & 0 Layer 1 & 1.861 & -20.96 & 0.1 \\
\hline FINAL RESULTS & 1 & 483 & 241.95 & 0 Layer 1 & 1.861 & -20.23 & 0.06 \\
\hline FINAL RESULTS & 1 & 484 & 242.46 & 0 Layer 1 & 1.861 & -20.7 & 0.01 \\
\hline FINAL RESULTS & 1 & 488 & 244.46 & 0 Layer 1 & 1.861 & -20.81 & 0.04 \\
\hline FINAL RESULTS & 1 & 489 & 244.96 & 0 Layer 1 & 1.861 & -20.44 & 0.08 \\
\hline FINAL RESULTS & 1 & 490 & 245.46 & 0 Layer 1 & 1.861 & -19.96 & 0.04 \\
\hline FINAL RESULTS & 1 & 491 & 245.96 & 0 Layer 1 & 1.861 & -20.61 & 0.01 \\
\hline FINAL RESULTS & 1 & 536 & 268.50 & 0 Layer 1 & 1.805 & -20.12 & 0.08 \\
\hline FINAL RESULTS & 1 & 538 & 269.51 & 0 Layer 1 & 1.89 & -20.41 & 0 \\
\hline FINAL RESULTS & 1 & 539 & 270.01 & 0 Layer 1 & 1.805 & -20.08 & 0.12 \\
\hline FINAL RESULTS & 1 & 540 & 270.51 & 0 Layer 1 & 1.89 & -20.65 & 0 \\
\hline FINAL RESULTS & 1 & 543 & 272.01 & 0 Layer 1 & 1.805 & -19.89 & 0.07 \\
\hline FINAL RESULTS & 1 & 544 & 272.51 & 0 Layer 1 & 1.89 & -20.11 & 0.06 \\
\hline FINAL RESULTS & 1 & 545 & 273.01 & 0 Layer 1 & 1.89 & -20.61 & 0.02 \\
\hline FINAL RESULTS & 1 & 546 & 273.51 & 0 Layer 1 & 1.89 & -20.89 & 0.1 \\
\hline FINAL RESULTS & 1 & 547 & 274.01 & 0 Layer 1 & 1.805 & -20.07 & 0.06 \\
\hline FINAL RESULTS & 1 & 549 & 275.02 & 0 Layer 1 & 1.89 & -20.87 & 0.07 \\
\hline FINAL RESULTS & 1 & 550 & 275.52 & 0 Layer 1 & 1.805 & -20.58 & 0.05 \\
\hline FINAL RESULTS & 1 & 600 & 300.56 & 0 Layer 1 & 1.87 & -20.56 & 0 \\
\hline FINAL RESULTS & 1 & 601 & 301.06 & 0 Layer 1 & 1.87 & -20.43 & 0.04 \\
\hline FINAL RESULTS & 1 & 602 & 301.57 & 0 Layer 1 & 1.958 & -21.47 & 0.04 \\
\hline FINAL RESULTS & 1 & 603 & 302.07 & 0 Layer 1 & 1.87 & -21.46 & 0.08 \\
\hline FINAL RESULTS & 1 & 604 & 302.57 & 0 Layer 1 & 1.87 & -20.94 & 0.04 \\
\hline FINAL RESULTS & 1 & 606 & 303.67 & 0 Layer 1 & 1.87 & -21.01 & 0.08 \\
\hline FINAL RESULTS & 1 & 607 & 304.07 & 0 Layer 1 & 1.87 & -20.99 & 0.08 \\
\hline FINAL RESULTS & 1 & 608 & 304.57 & 0 Layer 1 & 1.958 & -22.32 & 0.04 \\
\hline FINAL RESULTS & 1 & 609 & 305.07 & 0 Layer 1 & 1.958 & -21.98 & 0.04 \\
\hline FINAL RESULTS & 1 & 610 & 305.57 & 0 Layer 1 & 1.958 & -21.12 & 0.07 \\
\hline FINAL RESULTS & 1 & 611 & 306.07 & 0 Layer 1 & 1.958 & -20.91 & 0.03 \\
\hline FINAL RESULTS & 1 & 658 & 329.62 & 0 Layer 1 & 1.654 & -20.47 & 0.15 \\
\hline FINAL RESULTS & 1 & 659 & 330.12 & 0 Layer 1 & 1.58 & -19.96 & 0.01 \\
\hline FINAL RESULTS & 1 & 660 & 330.62 & 0 Layer 1 & 1.58 & -20.31 & 0.05 \\
\hline FINAL RESULTS & 1 & 661 & 331.12 & 0 Layer 1 & 1.58 & -20.41 & 0.01 \\
\hline FINAL RESULTS & 1 & 662 & 331.62 & 0 Layer 1 & 1.58 & -20.34 & 0.09 \\
\hline FINAL RESULTS & 1 & 663 & 332.12 & 0 Layer 1 & 1.68 & -20.26 & 0.01 \\
\hline FINAL RESULTS & 1 & 664 & 332.62 & 0 Layer 1 & 1.58 & -20.15 & 0.09 \\
\hline FINAL RESULTS & 1 & 665 & 333.13 & 0 Layer 1 & 1.654 & -21.37 & 0.07 \\
\hline FINAL RESULTS & 1 & 666 & 333.63 & 0 Layer 1 & 1.58 & -20.7 & 0.05 \\
\hline FINAL RESULTS & 1 & 667 & 334.13 & 0 Layer 1 & 1.58 & -19.93 & 0.01 \\
\hline FINAL RESULTS & 1 & 668 & 334.63 & 0 Layer 1 & 1.58 & -20.47 & 0.09 \\
\hline
\end{tabular}




\begin{tabular}{|c|c|c|c|c|c|c|c|}
\hline 365 & $\$ 182.84$ & 90 Core Data & 4.276 & 0.828 & 108610400 & 7.63 & 4.50 \\
\hline 366 & $\$ 183.34$ & 90 Core Data & 4.276 & 0.906 & 108610400 & 7.63 & 4.92 \\
\hline 367 & $\$ 183.85$ & 90 Core Data & 4.276 & 0.867 & 108610400 & 7.63 & 4.71 \\
\hline 417 & $\$ 208.89$ & 67 Core Data & 4.346 & 0.828 & 110388400 & 7.39 & 4.57 \\
\hline 419 & $\$ 209.89$ & 67 Core Data & 4.346 & 0.828 & 110388400 & 7.39 & 4.57 \\
\hline 421 & $\$ 210.90$ & 64 Core Data & 4.346 & 0.828 & 110388400 & 7.39 & 4.57 \\
\hline 422 & $\$ 211.40$ & 64 Core Data & 4.346 & 0.828 & 110388400 & 7.39 & 4.57 \\
\hline 423 & $\$ 211.90$ & 64 Core Data & 4.346 & 0.828 & 110388400 & 7.39 & 4.57 \\
\hline 424 & $\$ 212.40$ & 64 Core Data & 4.346 & 0.828 & 110388400 & 7.39 & 4.57 \\
\hline 425 & $\$ 212.90$ & 64 Core Data & 4.346 & 0.828 & 110388400 & 7.39 & 4.57 \\
\hline 426 & $\$ 213.40$ & 64 Core Data & 4.346 & 0.828 & 110388400 & 7.39 & 4.57 \\
\hline 427 & $\$ 213.90$ & 64 Core Data & 4.346 & 0.867 & 110388400 & 7.39 & 4.79 \\
\hline 480 & $\$ 240.45$ & 73 Core Data & 4.291 & 0.867 & 108991400 & 7.58 & 4.73 \\
\hline 483 & $\$ 241.95$ & 75 Core Data & 4.291 & 0.867 & 108991400 & 7.58 & 4.73 \\
\hline 484 & $\$ 242.46$ & 76 Core Data & 4.291 & 0.867 & 108991400 & 7.58 & 4.73 \\
\hline 488 & $\$ 244.46$ & 76 Core Data & 4.291 & 0.867 & 108991400 & 7.58 & 4.73 \\
\hline 489 & $\$ 244.96$ & 76 Core Data & 4.291 & 0.867 & 108991400 & 7.58 & 4.73 \\
\hline 490 & $\$ 245.46$ & 76 Core Data & 4.291 & 0.867 & 108991400 & 7.58 & 4.73 \\
\hline 491 & $\$ 245.96$ & 76 Core Data & 4.291 & 0.867 & 108991400 & 7.58 & 4.73 \\
\hline 536 & $\$ 268.50$ & 81 Core Data & 4.358 & 0.828 & 110693200 & 7.35 & 4.58 \\
\hline 538 & $\$ 269.51$ & 81 Core Data & 4.358 & 0.867 & 110693200 & 7.35 & 4.80 \\
\hline 539 & $\$ 270.01$ & 81 Core Data & 4.358 & 0.828 & 110693200 & 7.35 & 4.58 \\
\hline 540 & $\$ 270.51$ & 79 Core Data & 4.358 & 0.867 & 110693200 & 7.35 & 4.80 \\
\hline 543 & $\$ 272.01$ & 79 Core Data & 4.358 & 0.828 & 110693200 & 7.35 & 4.58 \\
\hline 544 & $\$ 272.61$ & 79 Core Data & 4.368 & 0.867 & 110693200 & 7.36 & 4.80 \\
\hline 545 & $\$ 273.01$ & 79 Core Data & 4.358 & 0.867 & 110693200 & 7.35 & 4.80 \\
\hline 546 & $\$ 273.51$ & 79 Core Data & 4.358 & 0.867 & 110693200 & 7.35 & 4.80 \\
\hline 547 & $\$ 274.01$ & 79 Core Data & 4.358 & 0.828 & 110693200 & 7.35 & 4.58 \\
\hline 549 & $\$ 275.02$ & 79 Core Data & 4.358 & 0.867 & 110693200 & 7.35 & 4.80 \\
\hline 550 & $\$ 275.52$ & 79 Core Data & 4.358 & 0.828 & 110693200 & 7.35 & 4.58 \\
\hline 600 & $\$ 300.56$ & 92 Core Data & 4.516 & 0.828 & 114706400 & 6.84 & 4.75 \\
\hline 601 & $\$ 301.06$ & 92 Core Data & 4.516 & 0.828 & 114706400 & 6.84 & 4.75 \\
\hline 602 & $\$ 301.57$ & 92 Core Data & 4.516 & 0.867 & 114706400 & 6.84 & 4.97 \\
\hline 603 & $\$ 302.07$ & 93 Core Data & 4.516 & 0.828 & 114706400 & 6.84 & 4.75 \\
\hline 604 & $\$ 302.57$ & 93 Core Data & 4.516 & 0.828 & 114706400 & 6.84 & 4.75 \\
\hline 606 & $\$ 303.67$ & 93 Core Data & 4.616 & 0.828 & 114706400 & 6.84 & 4.75 \\
\hline 607 & $\$ 304.07$ & 93 Core Data & 4.516 & 0.828 & 114706400 & 6.84 & 4.75 \\
\hline 608 & $\$ 304.57$ & 93 Core Data & 4.516 & 0.867 & 114706400 & 6.84 & 4.97 \\
\hline 609 & $\$ 305.07$ & 93 Core Data & 4.516 & 0.867 & 114706400 & 6.84 & 4.97 \\
\hline 610 & $\$ 305.57$ & 93 Core Data & 4.516 & 0.867 & 114706400 & 6.84 & 4.97 \\
\hline 611 & $\$ 306.07$ & 93 Core Data & 4.516 & 0.867 & 114706400 & 6.84 & 4.97 \\
\hline 658 & $\$ 329.62$ & 90 Core Data & 3.815 & 0.867 & 96901000 & 9.58 & 4.20 \\
\hline 659 & $\$ 330.12$ & 89 Core Data & 3.815 & 0.828 & 96901000 & 9.58 & 4.01 \\
\hline 660 & $\$ 330.62$ & 89 Core Data & 3.815 & 0.828 & 96901000 & 9.58 & 4.01 \\
\hline 661 & $\$ 331.12$ & 87 Core Data & 3.815 & 0.828 & 96901000 & 9.58 & 4.01 \\
\hline 662 & $\$ 331.62$ & 87 Core Data & 3.815 & 0.828 & 96901000 & 9.58 & 4.01 \\
\hline 663 & $\$ 332.12$ & 86 Core Data & 3.816 & 0.828 & 96901000 & 9.68 & 4.01 \\
\hline 664 & $\$ 332.62$ & 85 Core Data & 3.815 & 0.828 & 96901000 & 9.58 & 4.01 \\
\hline 665 & $\$ 333.13$ & 85 Core Data & 3.815 & 0.867 & 96901000 & 9.58 & 4.20 \\
\hline 666 & $\$ 333.63$ & 85 Core Data & 3.815 & 0.828 & 96901000 & 9.58 & 4.01 \\
\hline 667 & $\$ 334.13$ & 85 Core Data & 3.815 & 0.828 & 96901000 & 9.58 & 4.01 \\
\hline 668 & $\$ 334.63$ & 85 Core Data & 3.815 & 0.828 & 96901000 & 9.58 & 4.01 \\
\hline
\end{tabular}


WARNING: Modification of this ASCII file outside of RADAN may cause

Version $=5$

unpredictable behavior when this file is reloaded

Data Filename $=1$ 1\&2PERP.DZT into RADAN.

Layer threshold distance $=32.807999 \mathrm{ft}$

Number of layers $=2$

Amplitude Units $=$ Data Units

Last Pick Settings:

Layer 1 Specify

Layer 2 Specify

150

Calibration file $=$

\section{Ch\#}

1\&2 REFL

$1 \& 2$ REFL

$1 \& 2$ REFL

$1 \& 2$ REFL

$1 \& 2$ REFL

$1 \& 2$ REFL

$1 \& 2$ REFL

1\&2 REFL

$1 \& 2$ REFL

1\&2 REFL

$1 \& 2$ REFL

110

0

0

$\begin{array}{lll}\text { Scan\# } & \mathbf{x}(\mathrm{ft}) & \mathbf{y}(\mathrm{ft}) \\ 1 & 550 & 550 \\ 1 & 551 & 551 \\ 1 & 552 & 552 \\ 1 & 553 & 553 \\ 1 & 554 & 554 \\ 1 & 555 & 555 \\ 1 & 556 & 556 \\ 1 & 557 & 557 \\ 1 & 558 & 558 \\ 1 & 559 & 559 \\ & 560 & 560\end{array}$

\begin{tabular}{|c|c|c|c|c|c|}
\hline File & $\mathrm{Ch} \#$ & & & $x(f t)$ & \\
\hline 1\&2 REFL & & 1 & 810 & & 810 \\
\hline 1\&2 REFL & & 1 & 811 & & 811 \\
\hline 1\&2 REFL & & 1 & 812 & & 812 \\
\hline 1\&2 REFL & & 1 & 813 & & 813 \\
\hline 1\&2 REFL & & 1 & 814 & & 814 \\
\hline 1\&2 REFL & & 1 & 815 & & 815 \\
\hline 1\&2 REFL & & 1 & 816 & & 816 \\
\hline 1\&2 REFL & & 1 & 817 & & 817 \\
\hline 1\&2 REFL & & 1 & 818 & & 818 \\
\hline 1\&2 REFL & & 1 & 819 & & 819 \\
\hline 1\&2 REFL & & 1 & 820 & & 820 \\
\hline
\end{tabular}

$\begin{array}{ll}1 & 3 \\ 2 & 3\end{array}$

Layer 1
0 Layer 1
0 Layer 1
0 Layer 1
0 Layer 1
0 Layer 1
0 Layer 1
0 Layer 1
0 Layer 1
0 Layer 1
0 Layer 1
0 Layer 1

$z$ (in)

\begin{tabular}{lr}
\multicolumn{2}{c}{ Amp } \\
0.415 & $2.00 E+04$ \\
0.415 & $1.98 E+04$ \\
0.415 & $1.98 E+04$ \\
0.415 & $1.97 E+04$ \\
0.415 & $1.96 E+04$ \\
0.415 & $1.94 E+04$ \\
0.415 & $1.93 E+04$ \\
0.415 & $1.91 E+04$ \\
0.415 & $1.89 E+04$ \\
0.415 & $1.88 E+04$ \\
0.415 & $1.87 E+04$
\end{tabular}

Layer 1

0 Layer 2

0 Layer 2

0 Layer 2

0 Layer 2

0 Layer 2

0 Layer 2

0 Layer 2

0 Layer 2

0 Layer 2

0 Layer 2

0 Layer 2

\begin{tabular}{cc} 
z(in) & \multicolumn{2}{c}{ Amp } \\
3.559 & $1.29 \mathrm{E}+04$ \\
3.559 & $1.28 \mathrm{E}+04$ \\
3.559 & $1.28 \mathrm{E}+04$ \\
3.559 & $1.28 \mathrm{E}+04$ \\
3.559 & $1.28 \mathrm{E}+04$ \\
3.559 & $1.28 \mathrm{E}+04$ \\
3.559 & $1.28 \mathrm{E}+04$ \\
3.559 & $1.28 \mathrm{E}+04$ \\
3.559 & $1.27 \mathrm{E}+04$ \\
3.559 & $1.28 \mathrm{E}+04$ \\
3.559 & $1.28 \mathrm{E}+04$
\end{tabular}




\begin{tabular}{|c|c|c|c|c|c|c|c|}
\hline $\operatorname{Dev}(f t)$ & Scan\# & $x(f t)$ & \% Scans Vel. Type & $v($ in/ns) & $t(n s)$ & $V(\mathrm{~m} / \mathrm{s})$ & $\varepsilon$ \\
\hline 0.03 & 550 & 550 & 100 Specify & 5.906 & -0.141 & $1.50 E+08$ & 4.00 \\
\hline 0.03 & 551 & 551 & 100 Specify & 5.906 & -0.141 & $1.50 \mathrm{E}+08$ & 4.00 \\
\hline 0.02 & 552 & 552 & 100 Specify & 5.906 & -0.141 & $1.50 E+08$ & 4.00 \\
\hline 0.02 & 553 & 553 & 100 Specify & 5.906 & -0.141 & $1.50 E+08$ & 4.00 \\
\hline 0.02 & 554 & 554 & 100 Specify & 5.906 & -0.141 & $1.50 \mathrm{E}+08$ & 4.00 \\
\hline 0.01 & 555 & 555 & 100 Specify & 5.906 & -0.141 & $1.50 \mathrm{E}+08$ & 4.00 \\
\hline 0.01 & 556 & 556 & 100 Specify & 5.906 & -0.141 & $1.50 E+08$ & 4.00 \\
\hline 0.01 & 557 & 557 & 100 Specify & 5.906 & -0.141 & $1.50 E+08$ & 4.00 \\
\hline 0.01 & 558 & 558 & 100 Specify & 5.906 & -0.141 & $1.50 \mathrm{E}+08$ & 4.00 \\
\hline 0.01 & 559 & 559 & 100 Specify & 5.906 & -0.141 & $1.50 E+08$ & 4.00 \\
\hline 0.01 & 560 & 560 & 100 Specify & 5.906 & -0.141 & $1.50 E+08$ & 4.00 \\
\hline
\end{tabular}

\begin{tabular}{|c|c|c|c|c|c|c|c|}
\hline $\operatorname{Dev}(\mathrm{ft})$ & Scan\# & $x(f t)$ & \% Scans Vel. Type & $v($ in/ns) & $t(n s)$ & $\mathrm{V}(\mathrm{m} / \mathrm{s})$ & $\varepsilon$ \\
\hline 0.01 & 810 & 810 & 100 Specify & 4.331 & 1.578 & $1.10 E+08$ & 7.44 \\
\hline 0.01 & 811 & 811 & 100 Specify & 4.331 & 1.578 & $1.10 E+08$ & 7.44 \\
\hline 0.02 & 812 & 812 & 100 Specify & 4.331 & 1.578 & $1.10 E+08$ & 7.44 \\
\hline 0.02 & 813 & 813 & 100 Specify & 4.331 & 1.578 & $1.10 E+08$ & 7.44 \\
\hline 0.02 & 814 & 814 & 100 Specify & 4.331 & 1.578 & $1.10 E+08$ & 7.44 \\
\hline 0.02 & 815 & 815 & 100 Specify & 4.331 & 1.578 & $1.10 E+08$ & 7.44 \\
\hline 0.03 & 816 & 816 & 100 Specify & 4.331 & 1.578 & $1.10 \mathrm{E}+08$ & 7.44 \\
\hline 0.03 & 817 & 817 & 100 Specify & 4.331 & 1.578 & $1.10 E+08$ & 7.44 \\
\hline 0.03 & 818 & 818 & 100 Specify & 4.331 & 1.578 & $1.10 E+08$ & 7.44 \\
\hline 0.03 & 819 & 819 & 100 Specify & 4.331 & 1.578 & $1.10 E+08$ & 7.44 \\
\hline 0.03 & 820 & 820 & 100 Specify & 4.331 & 1.578 & $1.10 E+08$ & 7.44 \\
\hline
\end{tabular}


WARNING: Modification of this ASCll file outside of RADAN may

Version $=5$

cause unpredictable behavior when this file is reloaded

Data Filename $=1 \& 2$ PERP.DZT into RADAN.

Layer threshold distance $=32.807999 \mathrm{ft}$

Number of layers $=2$

Amplitude Units $=$ Data Units

Last Pick Settings:

$\begin{array}{llllll}\text { Layer 1 } & \text { Core Data } & 150 & 0 & 1 & 3 \\ \text { Layer } 2 & \text { Core Data } & 110 & 0 & 2 & 3\end{array}$

Calibration file $=$

\begin{tabular}{|c|c|c|c|c|c|c|c|c|c|}
\hline File & Ch\# & \multicolumn{2}{|c|}{ Scan\# } & $x(f t)$ & $y(f t)$ & Layer 1 & $z$ (in) & Amp & $\operatorname{Dev}(f t)$ \\
\hline \multicolumn{2}{|l|}{$1 \& 2$ THICK } & 1 & 475 & & 475 & 0 Layer 1 & 2.91 & $1.30 \mathrm{E}+04$ & 0.02 \\
\hline \multicolumn{2}{|l|}{$1 \& 2 \mathrm{THICK}$} & 1 & 476 & & 476 & 0 Layer 1 & 2.91 & $1.31 E+04$ & 0.03 \\
\hline \multicolumn{2}{|l|}{$1 \& 2$ THICK } & 1 & 477 & & 477 & 0 Layer 1 & 2.91 & $1.31 \mathrm{E}+04$ & 0.03 \\
\hline \multicolumn{2}{|l|}{$1 \& 2 \mathrm{THICK}$} & 1 & 478 & & 478 & 0 Layer 1 & 2.91 & $1.31 \mathrm{E}+04$ & 0.04 \\
\hline \multicolumn{2}{|l|}{$1 \& 2 \mathrm{THICK}$} & 1 & 479 & & 479 & 0 Layer 1 & 2.91 & $1.32 E+04$ & 0.05 \\
\hline \multicolumn{2}{|l|}{$1 \& 2$ THICK } & 1 & 480 & & 480 & 0 Layer 1 & 2.91 & $1.32 E+04$ & 0.05 \\
\hline \multicolumn{2}{|l|}{$1 \& 2$ THICK } & 1 & 481 & & 481 & 0 Layer 1 & 2.91 & $1.32 E+04$ & 0.06 \\
\hline \multicolumn{2}{|l|}{$1 \& 2 \mathrm{THICK}$} & 1 & 482 & & 482 & 0 Layer 1 & 2.839 & $1.32 E+04$ & 0.06 \\
\hline \multicolumn{2}{|l|}{$1 \& 2 \mathrm{THICK}$} & 1 & 483 & & 483 & 0 Layer 1 & 2.839 & 1.33E+04 & 0.05 \\
\hline \multicolumn{2}{|l|}{$1 \& 2 \mathrm{THICK}$} & 1 & 484 & & 484 & 0 Layer 1 & 2.839 & $1.33 E+04$ & 0.05 \\
\hline \multicolumn{2}{|l|}{$1 \& 2 \mathrm{THICK}$} & 1 & 485 & & 485 & 0 Layer 1 & 2,839 & $1.34 E+04$ & 0.05 \\
\hline & $\mathrm{Ch} \#$ & \multicolumn{2}{|c|}{ Scan\# } & $x(f t)$ & $y(f t)$ & Layer 1 & $z$ (in) & Amp & $\operatorname{Dev}(f t)$ \\
\hline \multicolumn{2}{|c|}{$1 \& 2$ THICK } & 1 & 835 & & 835 & 0 Layer 2 & 2.911 & 1.30E+04 & 0.05 \\
\hline \multirow{2}{*}{\multicolumn{2}{|c|}{$\begin{array}{l}1 \& 2 \text { THICK } \\
1 \& 2 \text { THICK }\end{array}$}} & 1 & 836 & & 836 & 0 Layer 2 & 2.985 & 1.30E+04 & 0.03 \\
\hline & & 1 & 837 & & 837 & 0 Layer 2 & 2.985 & 1.30E+04 & 0.03 \\
\hline \multicolumn{2}{|l|}{$1 \& 2$ THICK } & 1 & 838 & & 838 & 0 Layer 2 & 2.985 & $1.30 E+04$ & 0.03 \\
\hline \multicolumn{2}{|l|}{$1 \& 2$ THICK } & 1 & 839 & & 839 & 0 Layer 2 & 2.985 & $1.29 E+04$ & 0.03 \\
\hline \multicolumn{2}{|l|}{$1 \& 2 \mathrm{THICK}$} & 1 & 840 & & 840 & 0 Layer 2 & 2.985 & $1.29 E+04$ & 0.03 \\
\hline \multicolumn{2}{|l|}{$1 \& 2 \mathrm{THICK}$} & 1 & 841 & & 841 & 0 Layer 2 & 2.985 & $1.29 E+04$ & 0.02 \\
\hline \multicolumn{2}{|l|}{$1 \& 2 \mathrm{THICK}$} & 1 & 842 & & 842 & 0 Layer 2 & 2.985 & 1.28E+04 & 0.02 \\
\hline \multicolumn{2}{|l|}{$1 \& 2$ THICK } & 1 & 843 & & 843 & 0 Layer 2 & 2.985 & 1.27E+04 & 0.02 \\
\hline \multicolumn{2}{|l|}{$1 \& 2$ THICK } & 1 & 844 & & 844 & 0 Layer 2 & 2.985 & 1.28E+04 & 0.02 \\
\hline \multicolumn{2}{|l|}{$1 \& 2 \mathrm{THICK}$} & 1 & 845 & & 845 & 0 Layer 2 & 2.985 & $1.28 \mathrm{E}+04$ & 0.02 \\
\hline
\end{tabular}




\begin{tabular}{|c|c|c|c|c|c|}
\hline can\# & Vel. Type & $v($ in/ns $)$ & $t(n s)$ & $V(\mathrm{~m} / \mathrm{s})$ & $\boldsymbol{\varepsilon}$ \\
\hline 475 & Core Data & $3.60 \mathrm{E}+00$ & 1.617 & $9.14 \mathrm{E}+07$ & 10.78 \\
\hline 476 & Core Data & $3.60 \mathrm{E}+00$ & 1.617 & $9.14 \mathrm{E}+07$ & 10.78 \\
\hline 477 & Core Data & $3.60 \mathrm{E}+00$ & 1.617 & $9.14 \mathrm{E}+07$ & 10.78 \\
\hline 478 & Core Data & $3.60 \mathrm{E}+00$ & 1.617 & $9.14 E+07$ & 10.78 \\
\hline 479 & Core Data & $3.60 \mathrm{E}+00$ & 1.617 & $9.14 \mathrm{E}+07$ & 10.78 \\
\hline 480 & Core Data & $3.60 \mathrm{E}+00$ & 1.617 & $9.14 \mathrm{E}+07$ & 10.78 \\
\hline 481 & Core Data & $3.60 \mathrm{E}+00$ & 1.617 & $9.14 \mathrm{E}+07$ & 10.78 \\
\hline 482 & Core Data & $3.60 \mathrm{E}+00$ & 1.578 & $9.14 \mathrm{E}+07$ & 10.78 \\
\hline 483 & Core Data & $3.60 \mathrm{E}+00$ & 1.578 & $9.14 \mathrm{E}+07$ & 10.78 \\
\hline 484 & Core Data & $3.60 \mathrm{E}+00$ & 1.578 & $9.14 \mathrm{E}+07$ & 10.78 \\
\hline 485 & Core Data & $3.60 \mathrm{E}+00$ & 1.578 & $9.14 \mathrm{E}+07$ & 10.78 \\
\hline \# & Vel. Type & $v($ in/ns $)$ & $t$ (ns) & $V(\mathrm{~m} / \mathrm{s})$ & $\boldsymbol{\varepsilon}$ \\
\hline 835 & Core Data & $3.78 \mathrm{E}+00$ & 1.539 & $9.61 \mathrm{E}+07$ & 9.75 \\
\hline 836 & Core Data & $3.78 \mathrm{E}+00$ & 1.578 & $9.61 \mathrm{E}+07$ & 9.75 \\
\hline 837 & Core Data & $3.78 \mathrm{E}+00$ & 1.578 & $9.61 \mathrm{E}+07$ & 9.75 \\
\hline 838 & Core Data & $3.78 \mathrm{E}+00$ & 1.578 & $9.61 \mathrm{E}+07$ & 9.75 \\
\hline 839 & Core Data & $3.78 \mathrm{E}+00$ & 1.578 & $9.61 \mathrm{E}+07$ & 9.75 \\
\hline 840 & Core Data & $3.78 \mathrm{E}+00$ & 1.578 & $9.61 \mathrm{E}+07$ & 9.75 \\
\hline 841 & Core Data & $3.78 \mathrm{E}+00$ & 1.578 & $9.61 \mathrm{E}+07$ & 9.75 \\
\hline 842 & Core Data & $3.78 \mathrm{E}+00$ & 1.578 & $9.61 \mathrm{E}+07$ & 9.75 \\
\hline 843 & Core Data & $3.78 E+00$ & 1.578 & $9.61 \mathrm{E}+07$ & 9.75 \\
\hline 844 & Core Data & $3.78 E+00$ & 1.578 & $9.61 \mathrm{E}+07$ & 9.75 \\
\hline 845 & Core Date & $3.78 \mathrm{E}+00$ & 1.578 & $9.61 \mathrm{E}+07$ & 9.75 \\
\hline
\end{tabular}


WARNING: Modification of this ASCIl file outside of RADAN may cause

Version $=5$

unpredictable behavior when this file is reloaded into RADAN.

Data Filename $=3 \& 4$ PERP.DZT

Layer threshold distance $=32.807999 \mathrm{ft}$

Number of layers $=2$

Amplitude Units $=$ Data Units

Last Pick Settings:

$\begin{array}{llllll}\text { Layer } 1 & \text { Core Data } & 150 & 0 & 1 & 3 \\ \text { Layer } 2 & \text { Core Data } & 110 & 0 & 2 & 3\end{array}$

Calibration file $=$

\begin{tabular}{|c|c|c|c|c|c|c|c|c|}
\hline File & Ch\# & & $x(f t)$ & $y(f t)$ & Layer 1 & $z$ (in) & Amp & $\operatorname{Dev}(f t)$ \\
\hline $3 \& 4$ THICK & & 1 & 345 & 345 & 0 Layer 1 & 3.191 & $1.12 E+04$ & $-6.54 E+33$ \\
\hline $3 \& 4$ THICK & & 1 & 346 & 346 & 0 Layer 1 & 3.126 & $1.12 E+04$ & $-6.54 E+33$ \\
\hline $3 \& 4$ THICK & & 1 & 347 & 347 & 0 Layer 1 & 3.126 & 1.12E+04 & $-6.54 E+33$ \\
\hline $3 \& 4$ THICK & & 1 & 348 & 348 & 0 Layer 1 & 3.126 & $1.13 E+04$ & $-6.54 E+33$ \\
\hline $3 \& 4$ THICK & & 1 & 349 & 349 & 0 Layer 1 & 3.126 & $1.13 E+04$ & $-6.54 E+33$ \\
\hline $3 \& 4$ THICK & & 1 & 350 & 350 & 0 Layer 1 & 3.126 & $1.15 E+04$ & $-6.54 E+33$ \\
\hline $3 \& 4$ THICK & & 1 & 351 & 351 & 0 Layer 1 & 3.126 & $1.14 E+04$ & $-6.54 E+33$ \\
\hline $3 \& 4$ THICK & & 1 & 352 & 352 & 0 Layer 1 & 3.126 & 1.16E+04 & $-6.54 E+33$ \\
\hline $3 \& 4$ THICK & & 1 & 353 & 353 & 0 Layer 1 & 3.126 & 1.17E+04 & $-6.54 E+33$ \\
\hline $3 \& 4$ THICK & & 1 & 354 & 354 & 0 Layer 1 & 3.126 & $1.18 E+04$ & $-6.54 E+33$ \\
\hline $3 \& 4$ THICK & & 1 & 355 & 355 & 0 Layer 1 & 3.126 & 1.17E+04 & $-6.54 E+33$ \\
\hline
\end{tabular}

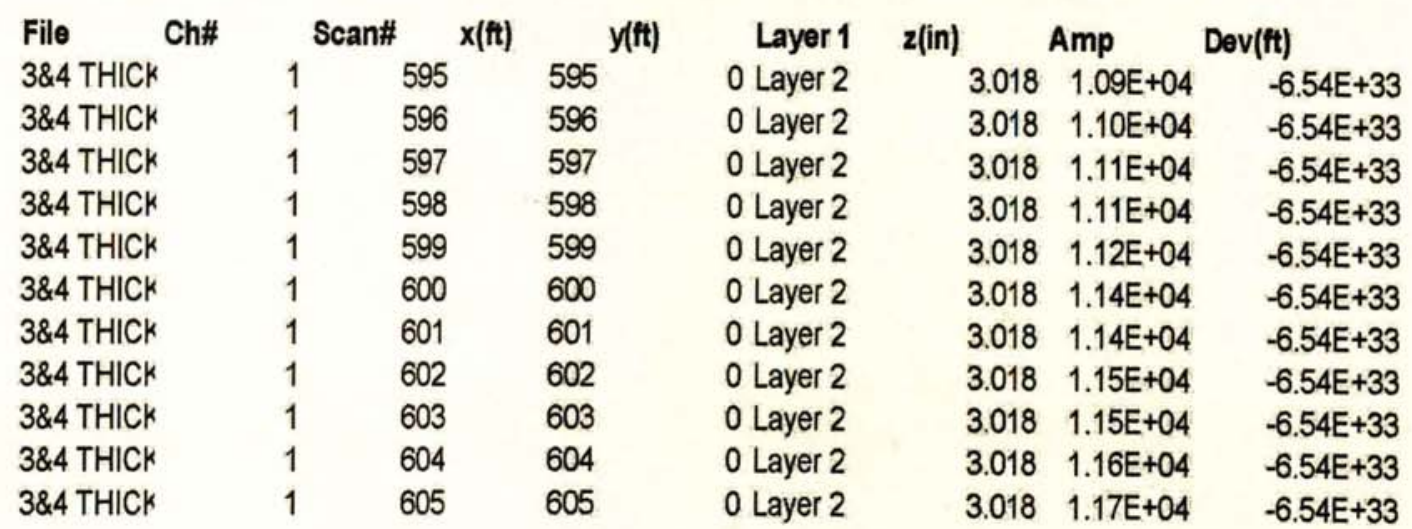




\begin{tabular}{|c|c|c|c|c|c|}
\hline :an\# & Vel. Type & $v($ in/ns $)$ & $t(n s)$ & $V(m / s)$ & $\varepsilon$ \\
\hline 345 & Core Data & 3.307 & 1.93 & $8.40 \mathrm{E}+07$ & 12.76 \\
\hline 346 & Core Data & 3.307 & 1.891 & $8.40 \mathrm{E}+07$ & 12.76 \\
\hline 347 & Core Data & 3.307 & 1.891 & $8.40 \mathrm{E}+07$ & 12.76 \\
\hline 348 & Core Data & 3.307 & 1.891 & $8.40 \mathrm{E}+07$ & 12.76 \\
\hline 349 & Core Data & 3.307 & 1.891 & $8.40 \mathrm{E}+07$ & 12.76 \\
\hline 350 & Core Data & 3.307 & 1.891 & $8.40 E+07$ & 12.76 \\
\hline 351 & Core Data & 3.307 & 1.891 & $8.40 E+07$ & 12.76 \\
\hline 352 & Core Data & 3.307 & 1.891 & $8.40 E+07$ & 12.76 \\
\hline 353 & Core Data & 3.307 & 1.891 & $8.40 E+07$ & 12.76 \\
\hline 35 & Data & 3.307 & 1.891 & $8.40 E+07$ & 12.76 \\
\hline 35 & Core Data & 3.307 & 1.891 & $8.40 E+07$ & 12.76 \\
\hline
\end{tabular}

\begin{tabular}{rrrrrr} 
Scan\# $\begin{array}{rrrl}\text { Vel. Type } \\
\text { 595 (in/ns) }\end{array}$ & $\mathbf{t}(\mathbf{n s})$ & \multicolumn{2}{c}{$\mathbf{V}(\mathbf{m} / \mathbf{s})$} & $\varepsilon$ & \\
596 Core Data & 3.331 & 1.813 & $8.46 \mathrm{E}+07$ & 12.57 \\
597 Core Data & 3.331 & 1.813 & $8.46 \mathrm{E}+07$ & 12.57 \\
598 Core Data & 3.331 & 1.813 & $8.46 \mathrm{E}+07$ & 12.57 \\
599 Core Data & 3.331 & 1.813 & $8.46 \mathrm{E}+07$ & 12.57 \\
600 Core Data & 3.331 & 1.813 & $8.46 \mathrm{E}+07$ & 12.57 \\
601 Core Data & 3.331 & 1.813 & $8.46 \mathrm{E}+07$ & 12.57 \\
602 Core Data & 3.331 & 1.813 & $8.46 \mathrm{E}+07$ & 12.57 \\
603 Core Data & 3.331 & 1.813 & $8.46 \mathrm{E}+07$ & 12.57 \\
604 Core Data & 3.331 & 1.813 & $8.46 \mathrm{E}+07$ & 12.57 \\
605 Core Data & 3.331 & 1.813 & $8.46 \mathrm{E}+07$ & 12.57 \\
& & & & 12.57
\end{tabular}


WARNING: Modification of this ASCII file outside of RADAN may cause

Version $=5$

unpredictable behavior when this file is reloaded into RADAN.

Data Filename $=5 \& 6$ PERP.DZT

Layer threshold distance $=32.807999 \mathrm{ft}$

Number of layers $=2$

Amplitude Units $=$ Data Units

Last Pick Settings:

Layer 1 Vel. Analys 150

Layer 2 Vel. Analys 110

$150 \quad 0$

Calibration file $=$

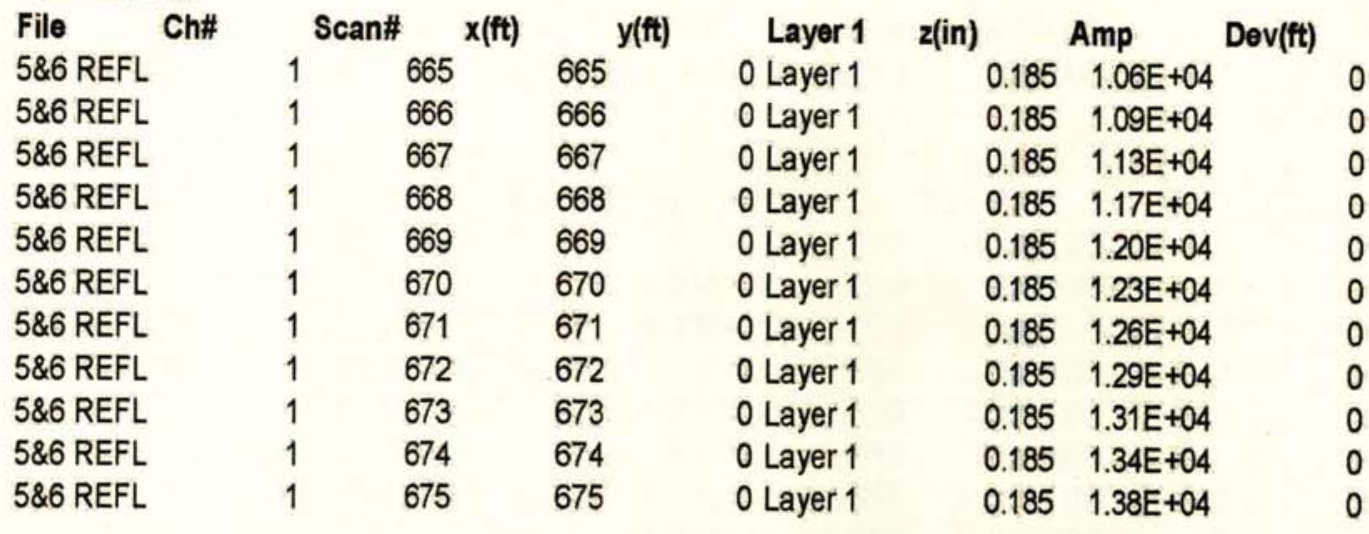

\begin{tabular}{llllllll} 
File & Ch\# & \multicolumn{1}{c}{ Scan\# } & $\mathbf{x}$ (ft) & y(ft) & Layer 1 & z(in) & \multicolumn{2}{c}{ Amp } & \multicolumn{1}{c}{ Dev(ft) } \\
5\&6 REFL & 1 & 535 & 535 & O Layer 2 & 3.999 & $1.25 E+04$ & 0.06 \\
5\&6 REFL & 1 & 536 & 536 & O Layer 2 & 3.999 & $1.25 E+04$ & 0.06 \\
5\&6 REFL & 1 & 537 & 537 & O Layer 2 & 3.999 & $1.24 E+04$ & 0.05 \\
5\&6 REFL & 1 & 538 & 538 & O Layer 2 & 3.999 & $1.25 E+04$ & 0.05 \\
5\&6 REFL & 1 & 539 & 539 & O Layer 2 & 3.999 & $1.25 E+04$ & 0.05 \\
5\&6 REFL & 1 & 540 & 540 & O Layer 2 & 3.999 & $1.24 E+04$ & 0.05 \\
5\&6 REFL & 1 & 541 & 541 & O Layer 2 & 3.999 & $1.24 E+04$ & 0.05 \\
5\&6 REFL & 1 & 542 & 542 & O Layer 2 & 4.083 & $1.22 E+04$ & 0.04 \\
5\&6 REFL & 1 & 543 & 543 & O Layer 2 & 4.083 & $1.23 E+04$ & 0.04 \\
5\&6 REFL & 1 & 544 & 544 & O Layer 2 & 4.083 & $1.22 E+04$ & 0.04 \\
5\&6 REFL & 1 & 545 & 545 & O Layer 2 & 4.114 & $1.22 E+04$ & 0.07
\end{tabular}




\begin{tabular}{|c|c|c|c|c|c|c|}
\hline Scan\# & $\%$ Scans & Vel. Type & $v($ in/ns $)$ & $t(n s)$ & $V(m / s)$ & $\varepsilon$ \\
\hline 665 & 63.64 & Vel. Analys & 5.906 & -0.063 & $1.50 \mathrm{E}+08$ & 4.00 \\
\hline 666 & 66.67 & Vel. Analys & 5.906 & -0.063 & $1.50 E+08$ & 4.00 \\
\hline 667 & 69.7 & Vel. Analys & 5.906 & -0.063 & $1.50 E+08$ & 4.00 \\
\hline 668 & 72.73 & Vel. Analys & 5.906 & -0.063 & $1.50 E+08$ & 4.00 \\
\hline 669 & 75.76 & Vel. Analys & 5.906 & -0.063 & $1.50 \mathrm{E}+08$ & 4.00 \\
\hline 670 & 78.79 & Vel. Analys & 5.906 & -0.063 & $1.50 E+08$ & 4.00 \\
\hline 671 & 81.82 & Vel. Analys & 5.906 & -0.063 & $1.50 \mathrm{E}+08$ & 4.00 \\
\hline 672 & 84.85 & Vel. Analys & 5.906 & -0.063 & $1.50 \mathrm{E}+08$ & 4.00 \\
\hline 673 & 87.88 & Vel. Analys & 5.906 & -0.063 & $1.50 \mathrm{E}+08$ & 4.00 \\
\hline 674 & 90.9 & Vel. Analys & 5.906 & -0.063 & $1.50 E+08$ & 4.00 \\
\hline 675 & 93.94 & Vel. Analys & 5.906 & -0.063 & $1.50 E+08$ & 4.00 \\
\hline
\end{tabular}

\begin{tabular}{|c|c|c|c|c|c|}
\hline Scan\# & \% Scans Vel. Type & $v($ in/ns) & $t(n s)$ & $V(\mathrm{~m} / \mathrm{s})$ & $\varepsilon$ \\
\hline 535 & 81.82 Vel. Analys & 4.331 & 1.813 & $1.10 \mathrm{E}+08$ & 7.44 \\
\hline 536 & 78.79 Vel. Analys & 4.331 & 1.813 & 1.10E+08 & 7.44 \\
\hline 537 & 75.76 Vel. Analys & 4.331 & 1.813 & $1.10 \mathrm{E}+08$ & 7.44 \\
\hline 538 & $72.73 \mathrm{Vel}$. Analys & 4.331 & 1.813 & $1.10 \mathrm{E}+08$ & 7.44 \\
\hline 539 & $69.7 \mathrm{Vel}$. Analys & 4.331 & 1.813 & $1.10 \mathrm{E}+08$ & 7.44 \\
\hline 540 & $66.67 \mathrm{Vel}$. Analys & 4.331 & 1.813 & $1.10 \mathrm{E}+08$ & 7.44 \\
\hline 541 & 63.64 Vel. Analys & 4.331 & 1.813 & 1.10E+08 & 7.44 \\
\hline 542 & $60.61 \mathrm{Vel}$. Analys & 4.331 & 1.852 & 1.10E+08 & 7.44 \\
\hline 543 & $57.58 \mathrm{Vel}$. Analys & 4.331 & 1.852 & 1.10E+08 & 7.44 \\
\hline 544 & 54.55 Vel. Analys & 4.331 & 1.852 & 1.10E+08 & 7.44 \\
\hline 545 & 51.52 Vel. Analys & 4.331 & 1.852 & $1.10 \mathrm{E}+08$ & 7.44 \\
\hline
\end{tabular}




\section{APPENDIX C}

Appendix $\mathrm{C}$ contains the MATLAB programs used to calculate the dielectric constant values for each of the surveys, along with the thin bed, GPR wavelet, and TDR analysis programs. 


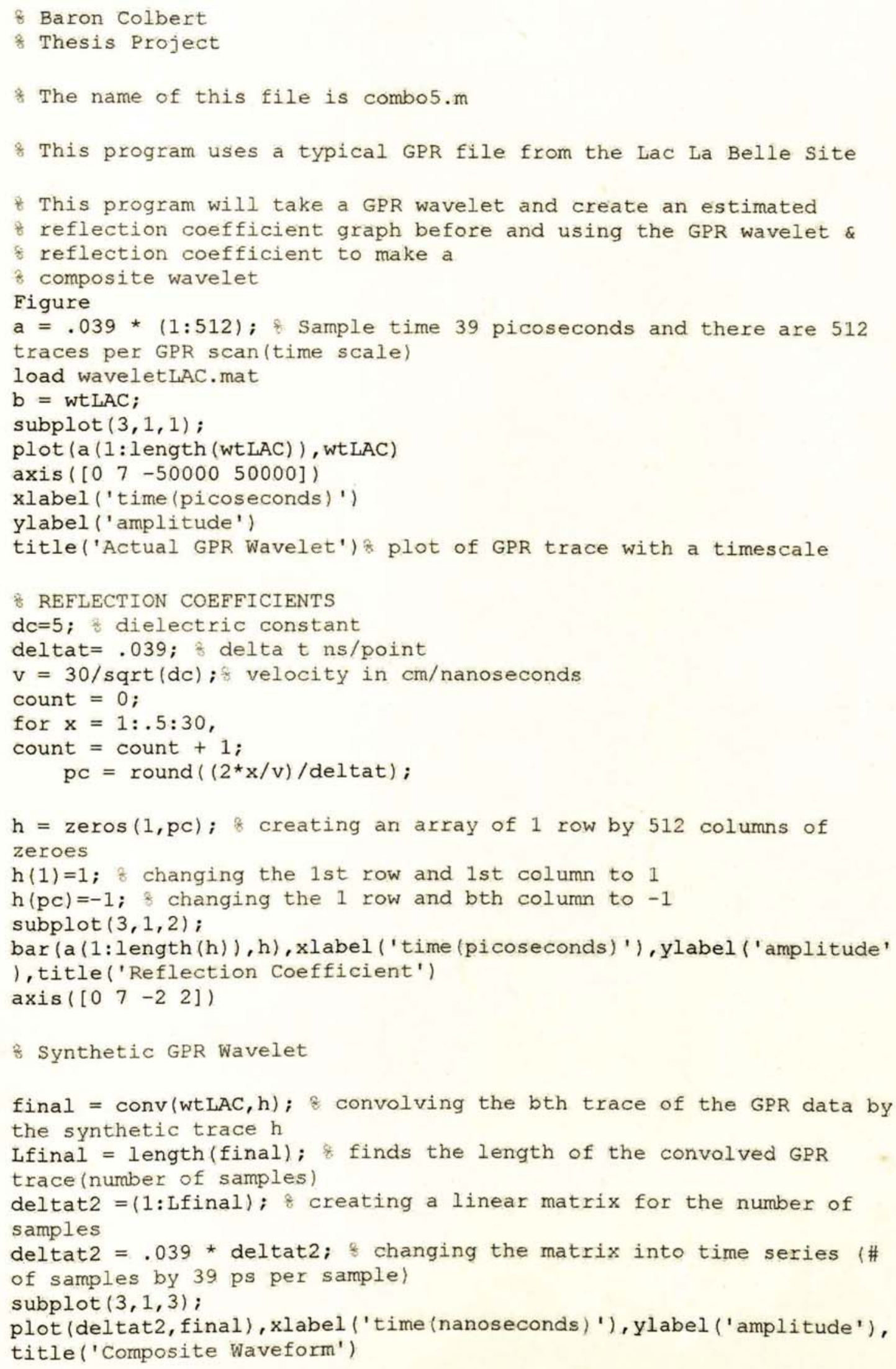


axis ([ $\left.\left[\begin{array}{llll}0 & 7 & -50000 & 50000\end{array}\right]\right)$

text $(.5,-30000$, 'thickness in $\mathrm{cm}=$ ')

text $(2.2,-30000$, num $2 \operatorname{str}(x))$

pause (.5)

end 
궁 Baron Colbert

* Thesis Project

* The name of this file is tdrdata.m

$$
\begin{aligned}
& t=1 ; \\
& t 2=1 ; \\
& t 3=1 ; \\
& t 4=1 ;
\end{aligned}
$$

load print32. mat

disp('choose coodinates for viewing')

disp ('to end press zero')

plot (print33 $(:, 2)$ ), xlabel ('data

number'), ylabel ('voltage'), title('TDR Plot of Data')

while $t==1$

$\mathrm{y} 1$ = input ('input start value for $\mathrm{x}$ : ')

y2 = input ('input end value for $\mathrm{x}$ : ')

$x 1=\left[y 1: y^{2}\right]^{\prime} ;$

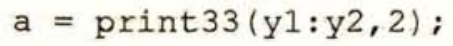

plot (x1,a), xlabel ('data number'), ylabel('voltage'), title('TDR Plot of Data')

$t=$ input('satisfied press 0 if not press 1:

end

disp('minimum voltage is')

plotmin $=\min (a) ;$

disp('maximum voltage is')

time $=.01 . \star \times 1 ;$

tdrtime $=$ time./7.61;

realt $=$ tdrtime $\cdot{ }^{*} 10^{\wedge}-9 ;$

voltchange $=a-$ plotmin $;$ 




end

taureal $=\operatorname{realt}\left(\mathrm{y}^{2}: \mathrm{y}^{2}+\left(1-\mathrm{y}^{2}\right)\right)$

$C=$ taureal. $/ 50 ;$

close

flipvolt $=$-voltchange $+-\min (-$ voltchange);

flip68 = -volt $68+$ flipvolt $(1,1) ;$

disp('choose y coodinate to place data at above zero') 


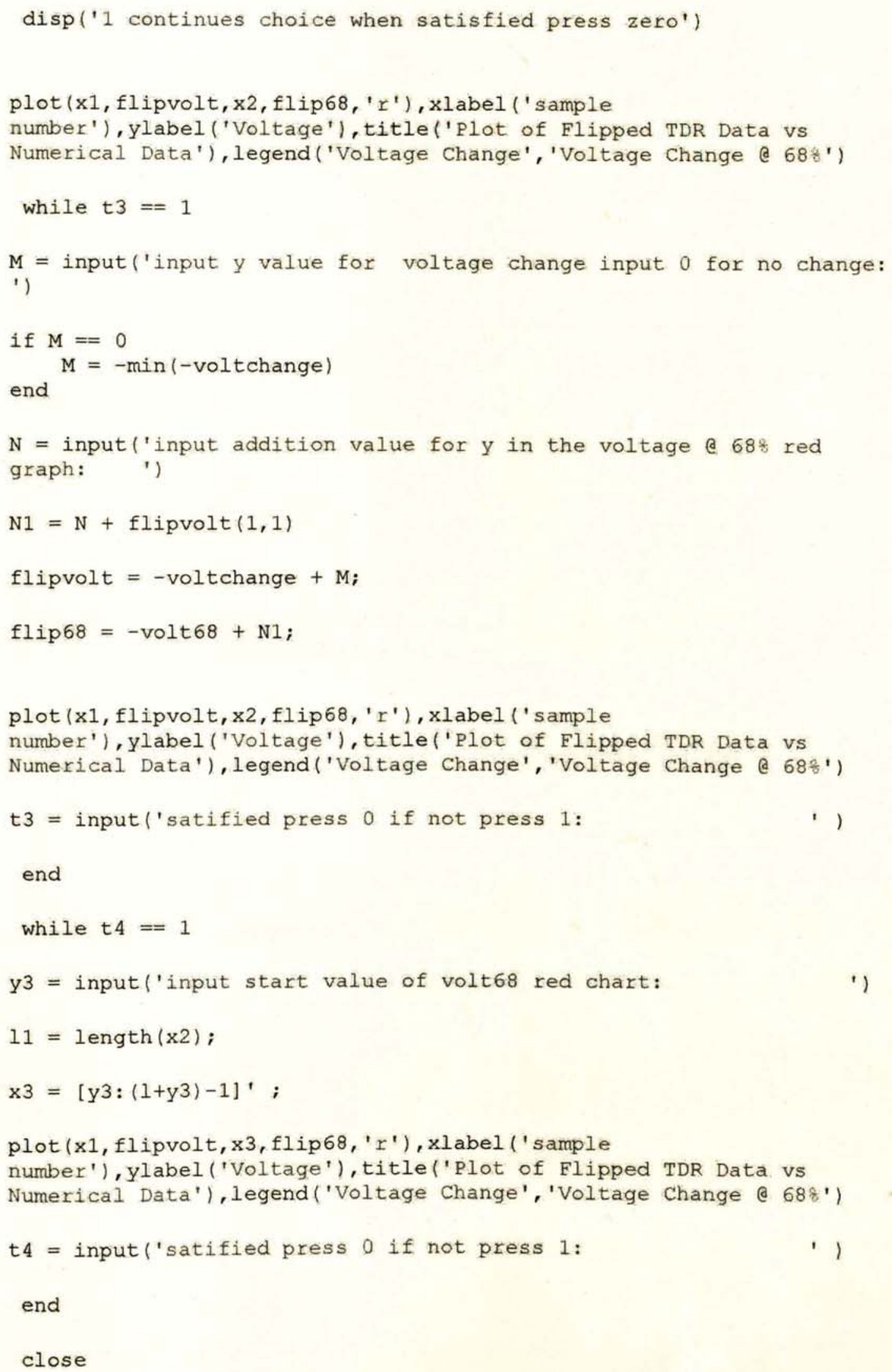




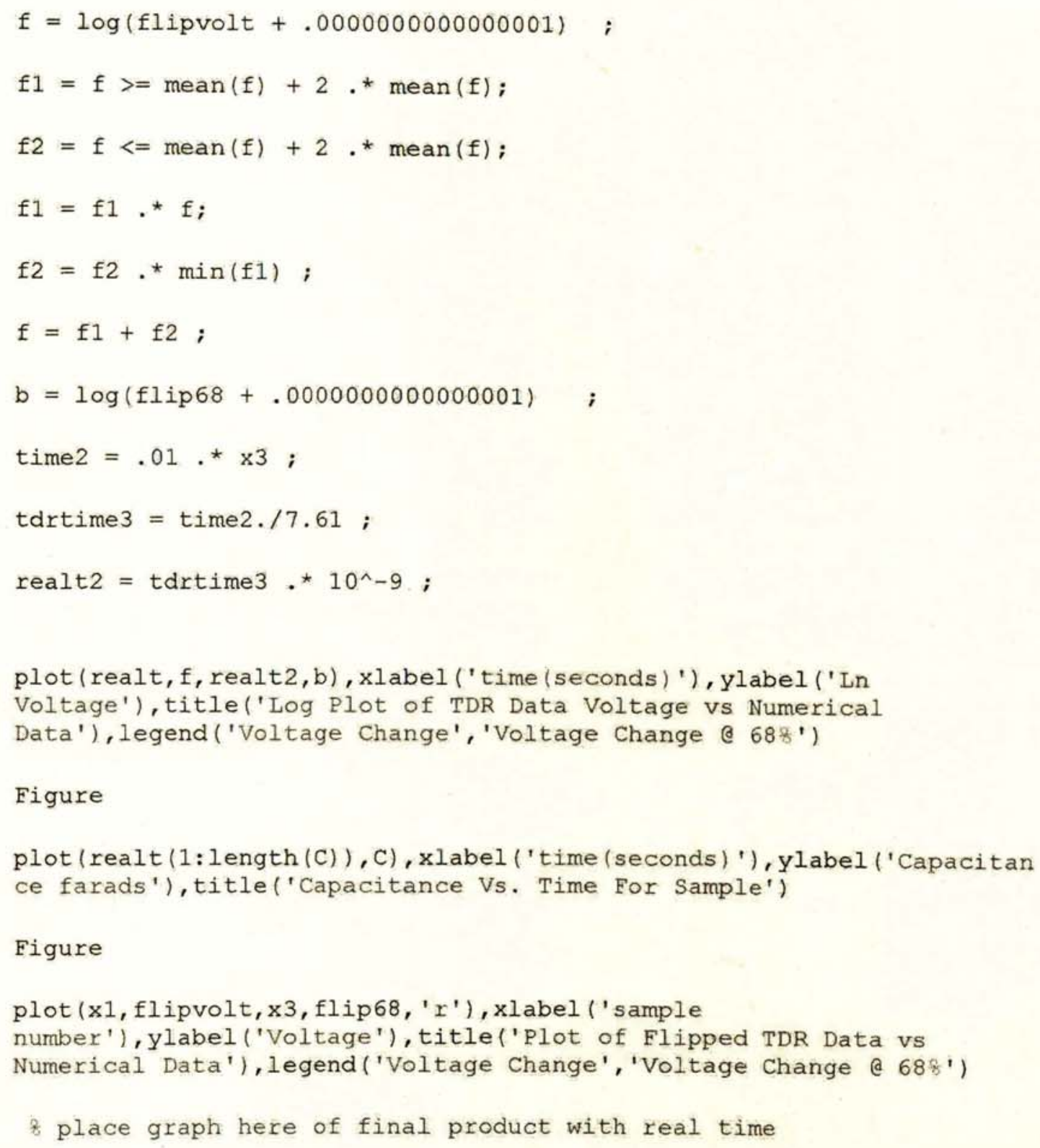









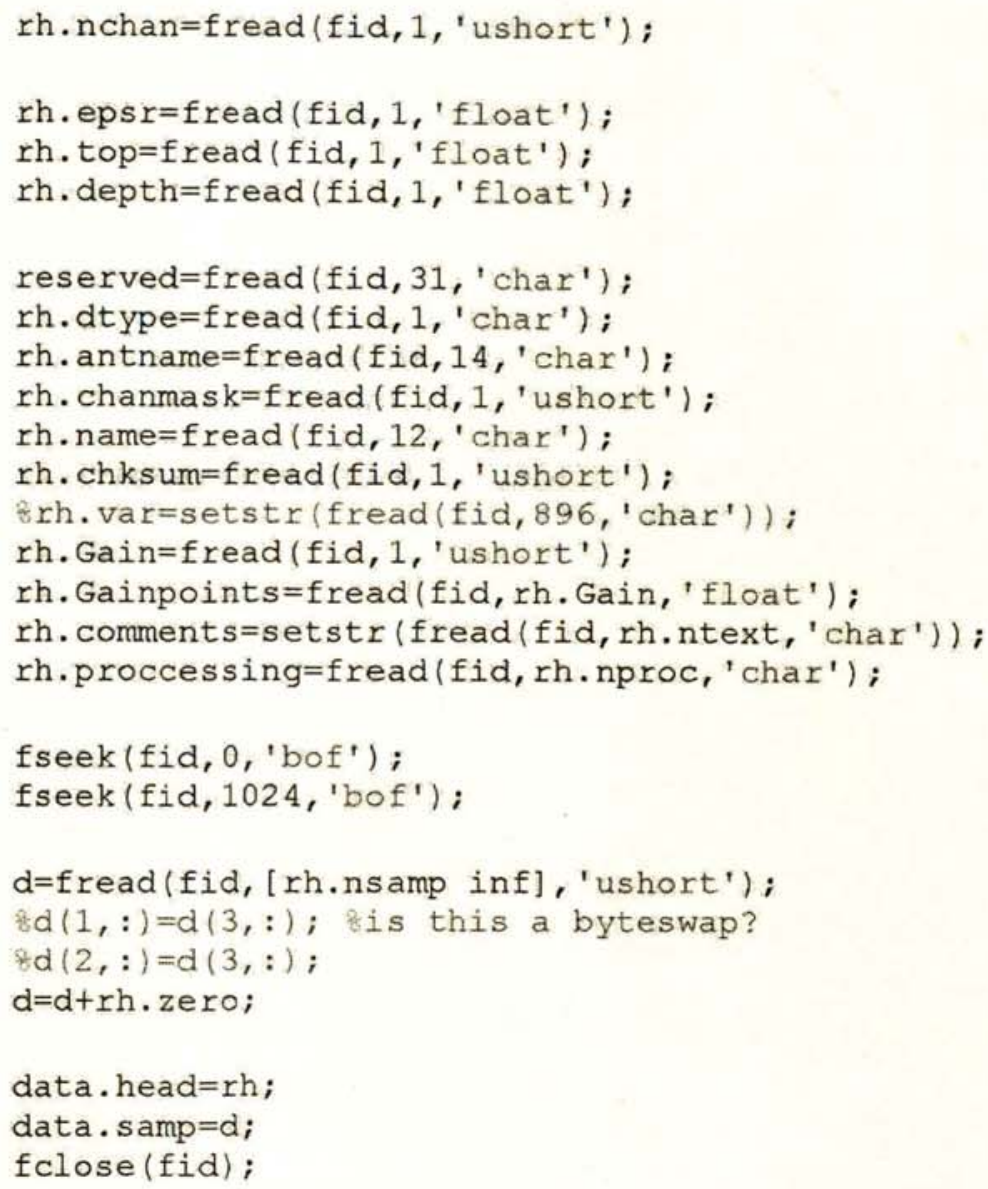




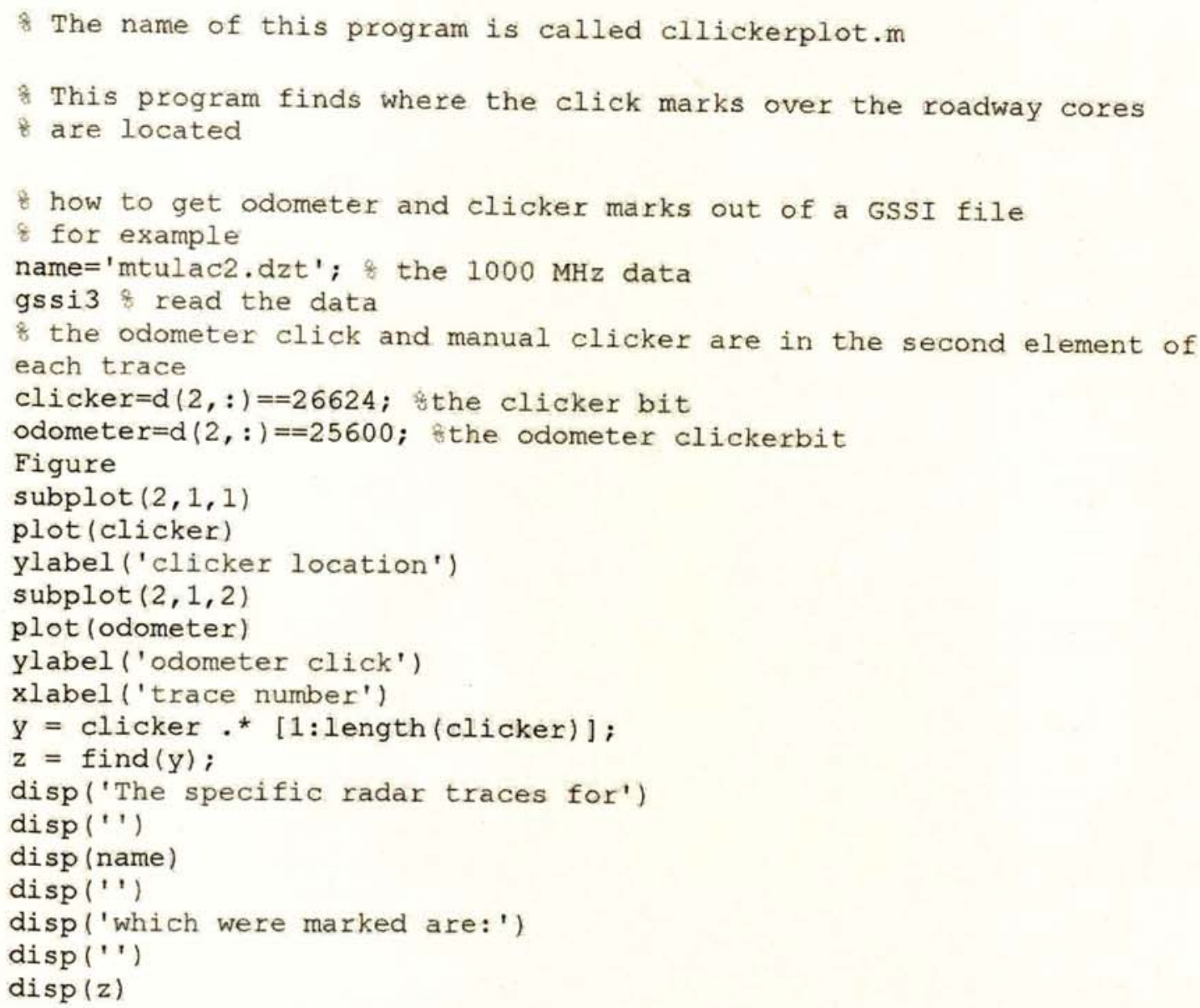




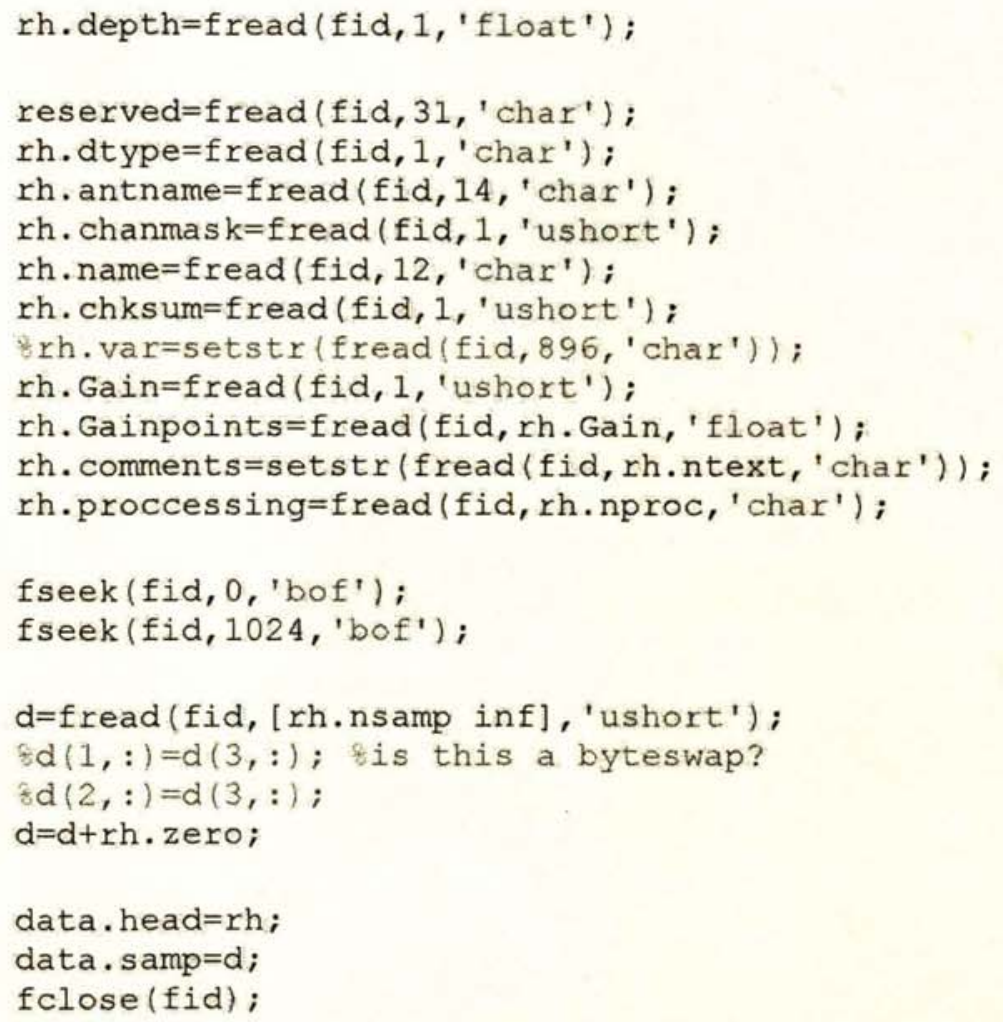

whos d

$\mathrm{a}=$ input ('input number of traces per scan: ')

$\mathrm{b}=$ input ('input number of scans: ')

lay1 = input('do you want one layer? input 1 for yes 2 for no: ')

if $\operatorname{lay} 1==1$

\& Picking Points from AGC Image

$\mathrm{u}=[1: \mathrm{b}]$ ';

$\mathrm{n}=1$;

$\mathrm{m}=1$;

imagesc (d)

starty = input ('where should autopicker start y coord: close all

for $t=1: b$; 


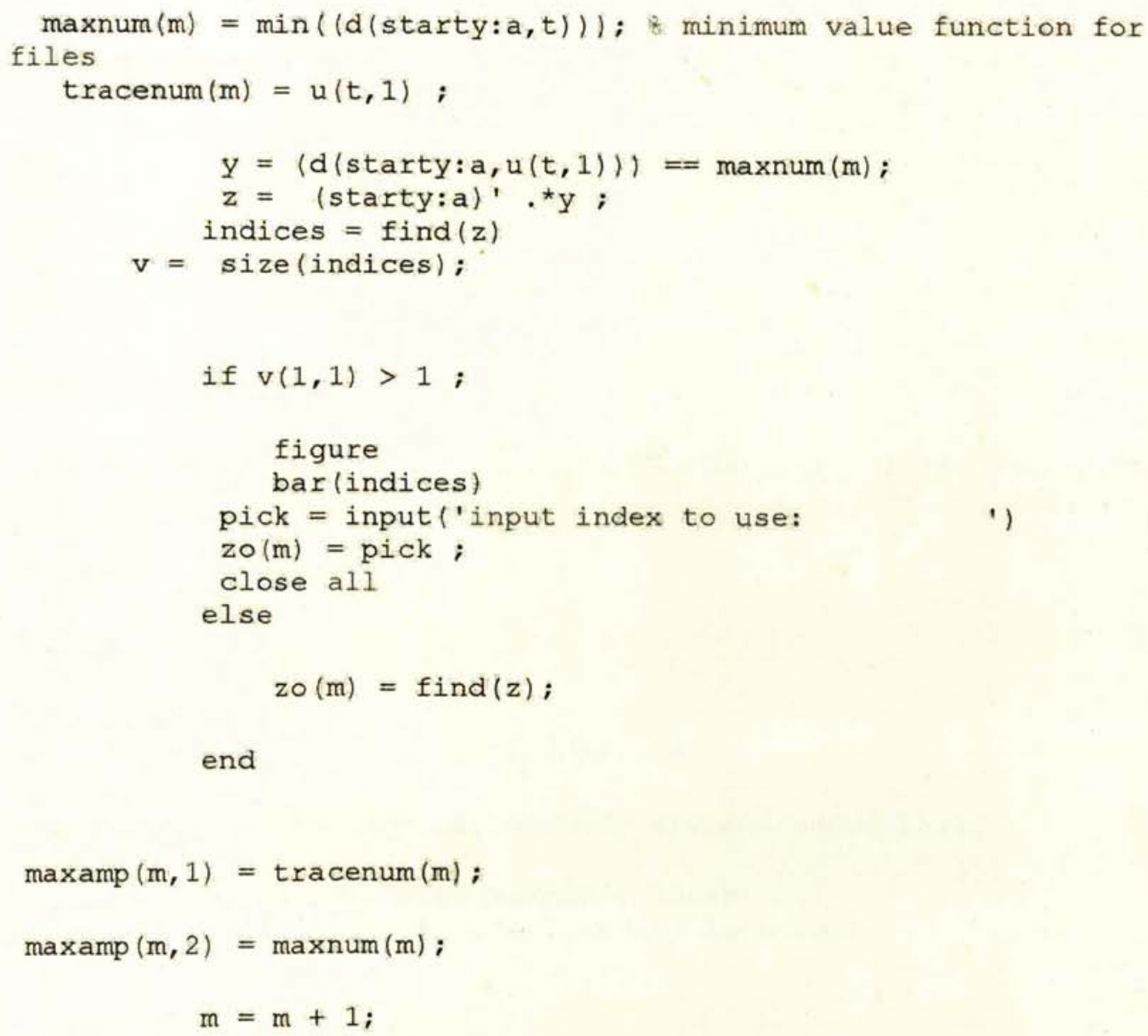

end 


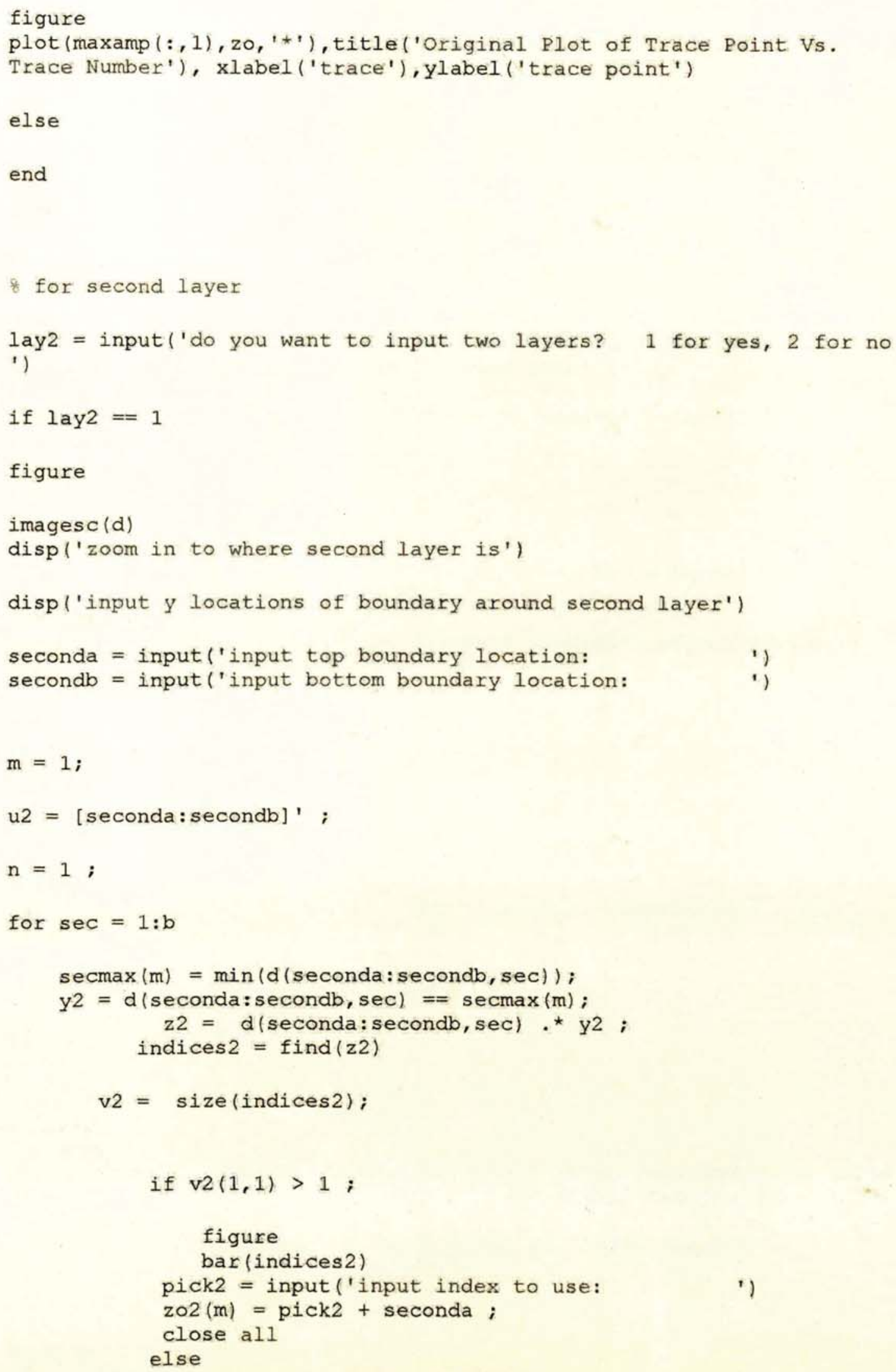




$$
z \circ 2(m)=\text { find }(z 2)+\text { seconda; }
$$

end

$$
\mathrm{m}=\mathrm{m}+1
$$

end






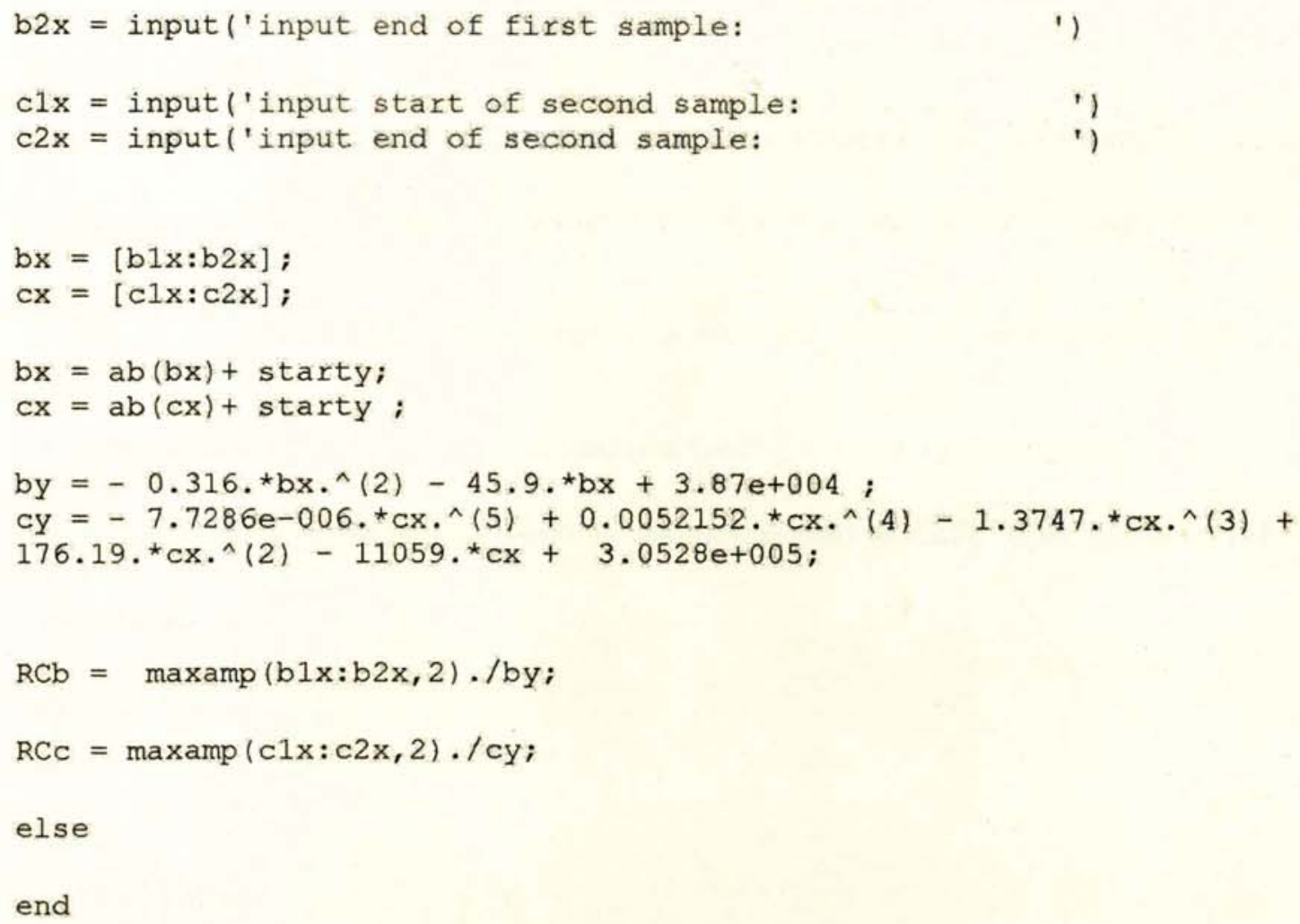

end 


\section{APPENDIX D}

Appendix D contains the dielectric constant values of the TDR samples, $\mathrm{C}_{\text {theory }}$ is capacitance calculated from a parallel plate capacitor assuming an air dielectric $\varepsilon=$

$1, C_{\text {theory }}=\frac{A \varepsilon}{d}$ where $\mathrm{C}$ is capacitance, $\mathrm{A}$ is plate area, and $\mathrm{d}$ is sample thickness.

TDR capacitance is the value of capacitance taken from the TDR and $\varepsilon$ using $C /$

$\mathrm{C}_{\text {theory }}$ is dielectric constant calculated by taking the ratio of TDR capacitance vs. the $\mathrm{C}_{\text {theory value. }}$ 


\begin{tabular}{|c|c|c|c|}
\hline PAVEMENT SAMPLE & $\varepsilon$ using ClCtheory & $\begin{array}{c}\frac{\varepsilon \text { using TDR }}{\text { air dielectric values }} \\
\end{array}$ & $\begin{array}{l}\text { Air Dielectric Check } \\
\text { CTDR }_{\text {air }} / \text { Ctheoretical }\end{array}$ \\
\hline US 127 MASON $3 C$ & 4.15 & 10.17 & 0.41 \\
\hline US 127 MASON B2 & 2.35 & 1.28 & 1.83 \\
\hline US 127 MASONA & 16.36 & 3.77 & 4.34 \\
\hline US $131 E$ & 10.42 & 3.52 & 2.96 \\
\hline US 127 MASONE & 5.86 & 2.21 & 2.65 \\
\hline US 127 MASONE & 2.82 & 1.06 & 2.65 \\
\hline US 12 Mich Ave D & 8.91 & 3.51 & 2.54 \\
\hline US 12 Mich Ave A & 5.57 & 1.33 & 4.18 \\
\hline US 12 Mich Ave B & 5.33 & 3.35 & 1.59 \\
\hline US 12 Mich Ave F & 4.52 & 1.16 & 3.89 \\
\hline US 12 Mich Ave C & 1.43 & 0.76 & 1.89 \\
\hline US 12 Mich Ave E & 4.92 & 2.48 & 1.98 \\
\hline US 131 BG Rapids A & 4.99 & 1.68 & 2.97 \\
\hline US 131 BG Rapids B & 5.17 & 1.37 & 3.78 \\
\hline US 131 BG Rapids C & 5.31 & 1.90 & 2.80 \\
\hline US 131 BG Rapids D & 5.47 & 2.38 & 2.30 \\
\hline US 127 MASONE & 5.04 & 1.59 & 3.17 \\
\hline M84 Saginaw $3 B$ & 51.28 & 10.55 & 4.86 \\
\hline 1 & 1.50 & 2.49 & 0.62 \\
\hline 2 & 1.81 & 2.78 & 0.62 \\
\hline 3 & 1.32 & 1.74 & 0.62 \\
\hline 4 & 1.95 & 2.38 & 0.62 \\
\hline 5 & 1.70 & 2.20 & 0.62 \\
\hline 6 & 1.16 & 1.50 & 0.62 \\
\hline 7 & 1.83 & 2.95 & 0.62 \\
\hline
\end{tabular}




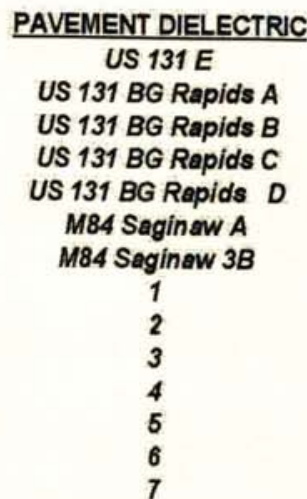

US 127 MASON $3 C$ US 127 MASON B2 US 127 MASONA US 127 MASONE US 127 MASONE US 127 MASONE US 12 Mioh Ave D US 12 Mich Ave E US 12 Mich Ave B US 12 Mich Ave C US 12 Mich Ave F US 12 Mioh Ave A

Air Dielectric Sample US 127 MASON 3C US 127 MASON B2 US 127 MASON A US 127 MASONE US 127 MASONE US 127 MASONE US 12 Mioh Ave D US 12 Mich Ave E US 12 Mioh Ave B US 12 Mioh Ave C US 12 Mich Ave F US 12 Mioh Ave A US $131 \mathrm{E}$

US 131 BG Rapids A US 131 BG Rapids A US 131BG Rapids B US 131 BG Rapids C US 131 BG Rapids D M84 Saginaw 3B M84 Saginaw A Samples 1-7
slope
$8.93 \mathrm{E}+09$
$9.23 E+09$
$7.80 \mathrm{E}+09$
$9.04 \mathrm{E}+09$
$5.65 \mathrm{E}+09$
1.15E+10
$1.37 \mathrm{E}+10$
$9.19 \mathrm{E}+09$
$5.38 \mathrm{E}+09$
$5.01 \mathrm{E}+09$
$6.26 \mathrm{E}+09$
$5.80 \mathrm{E}+09$
$5.75 \mathrm{E}+09$
$7.28 \mathrm{E}+09$
$1.04 \mathrm{E}+10$
1. $18 \mathrm{E}+10$
$8.55 \mathrm{E}+09$
$1.11 \mathrm{E}+10$
$6.89 \mathrm{E}+09$
$1.83 \mathrm{E}+10$
$8.52 \mathrm{E}+09$
8.13E+09
$8.29 \mathrm{E}+09$
1.26E+10
$9.96 \mathrm{E}+09$
$8.14 E+09$

Sample Thiokness

$2.9 \mathrm{~cm}$

$3.5 \mathrm{~cm}$

$3.5 \mathrm{~cm}$

$3.5 \mathrm{~cm}$

$3.5 \mathrm{~cm}$

$3.0 \mathrm{~cm}$

$3.5 \mathrm{~cm}$

$4.0 \mathrm{~cm}$

$4.0 \mathrm{~cm}$

$4.0 \mathrm{~cm}$

$3.5 \mathrm{~cm}$

$3.0 \mathrm{~cm}$

$4.0 \mathrm{~cm}$

$4.0 \mathrm{~cm}$

$4.0 \mathrm{~cm}$

$3.0 \mathrm{~cm}$

$4.0 \mathrm{~cm}$

$3.5 \mathrm{~cm}$

$9.5 \mathrm{~cm}$

$7.5 \mathrm{~cm}$

$1.0 \mathrm{~cm}$
TDR Capacitance

1.12E-10

$1.08 \mathrm{E}-10$

1.28E-10

1.11E-10

1.77E-10

8.68E-11

7.28E-11

1.09E-10

1.86E-10

2.00E-10

1.60E-10

1.72E-10

$1.74 E-10$

$1.37 \mathrm{E}-10$

9.62E-11

8.44E-11

1.17E-10

9.02E-11

1.45E-10

5.46E-11

1.17E-10

1.23E-10

1.21E-10

7.93E-11

1.00E-10

1.23E-10

slope

$7.83 \mathrm{E}+\infty 9$

$6.96 \mathrm{E}+09$

$7.61 \mathrm{E}+09$

$1.11 \mathrm{E}+10$

$1.14 E+10$

$1.03 E+10$

$5.02 E+08$

$1.47 \mathrm{E}+10$

1.27E+10

$1.18 \mathrm{E}+10$

$1.21 \mathrm{E}+10$

$7.49 \mathrm{E}+09$

$1.40 \mathrm{E}+10$

$9.23 E+09$

$1.65 \mathrm{E}+10$

$5.47 \mathrm{E}+09$

1. $23 \mathrm{E}+10$

$8.91 \mathrm{E}+09$

2.37E+08

$1.71 \mathrm{E}+08$

4.51E+09
Theoretioal Capacitance

3.59E-12

5.21E-12

3.91E-12

4.47E-12

5.69E-12

2.00E-12

1.65E-12

2.77E-11

2.57E-11

2.20E-11

2.04E-11

2.16E-11

2.15E-11

2.69E-11

6.26E-12

$6.26 \mathrm{E}-12$

$5.21 \mathrm{E}-12$

3.91E-12

$5.69 \mathrm{E}-12$

$5.69 \mathrm{E}-12$

4.47E-12

4.47E-12

$3.91 \mathrm{E}-12$

4.47E-12

$3.91 \mathrm{E}-12$

$4.81 \mathrm{E}-12$

IDR Air Capacitance Value 1.28E-10

1.44E-10

1.31E-10

9.02E-11

8.79E-11

9.67E-11

3.98E-11

$6.78 \mathrm{E}-11$

7.86E-11

8.49E-11

8.24E-11

1.34E-10

7.15E-11

$1.08 \mathrm{E}-10$

6.07E-11

1.83E-10

8.13E-11

1.12E-10

8.44E-11

1.17E-10

2.22E-10 


\section{APPENDIX E}

\section{Thin Bed Considerations}

The thin roadway layers present at the Lac La Belle and M-26 sites hampered determining the dielectric constant at these sites, therefore I attempted to determine whether the roadway layer was so thin that the reflection from the top and bottom merged, thus making the determination of reflection amplitude inaccurate. This problem is known as the "thin bed problem" in Widess(1973). According to Widess (1973), a thin bed is defined as a bed whose thickness is less than $\lambda_{b} / 8$, where $\lambda_{b}$ of a GPR wavelet is the dominant wavelength within the roadway. A sample calculation for the determination of thin pavement layers according to Widess is as follows using the GPR wavelengths, GPR velocity within pavement and in air. For this GPR study the wavelength in air is $\lambda_{b}=\frac{c}{\text { frequency }}=\frac{3 * 10^{8} \frac{\mathrm{m}}{\mathrm{s}}}{1 * 10^{9} \mathrm{hz}}=29.98 \mathrm{~cm}$. Therefore a thin bed is characterized as any pavement less than about $29.98 \mathrm{~cm} / 8=3.75 \mathrm{~cm}$. Using this definition and comparing the pavement thicknesses with those shown in Appendix A, core locations 2,3,5,7,8, \& 11 at the M-26 site as well as the Lac La Belle site would qualify as being thin beds since the pavement cores were less than about $3.75 \mathrm{~cm}$. To address this thin bed problem I used metal plate calibration files from the GSSI along with GPR pavement surface amplitudes to find dielectric constant values at these sites. MATLAB was used to automatically determine at what pavement thickness a thin bed would be encountered. This program was implemented using actual GPR waveforms from the M-26 and Lac La Belle sites to determine the roadway thicknesses that would allow reflections from the top and 
bottom of the layer to be visible. The computation consists of creating an impulse response of a thin layer separated by the two way travel time of the layer. This impulse response is convolved with an actual wavelet taken from a radar trace. The result of Combo5.m shows the composite waveform which will reveal whether or not the top and bottom of the layer can be resolved. The wavelets for the Lac La Belle, M-26, and Five Mile Point Road sites are given in Figures 1 to 3 shown below.



Figure 1: GPR wavelet of trace 540 taken from the Lac La Belle Site 




Figure 2: GPR wavelet of trace 540 taken from the M-26 Twin Lakes site 


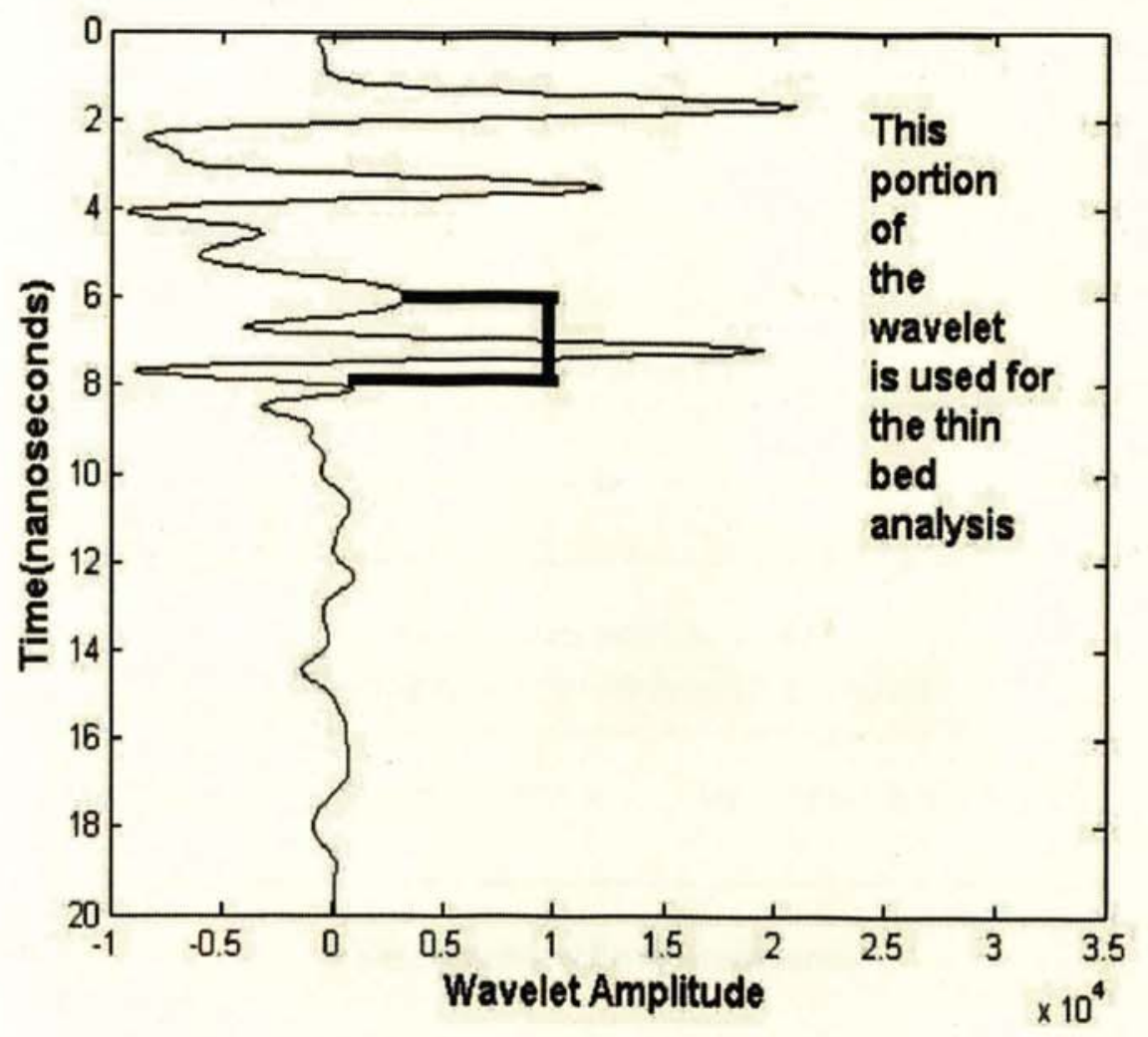

Figure 3: GPR wavelet of trace 362 taken from the Five Mile Point Road site

Figures 1 to 3 show the sample wavelet taken from each of the sites, the impulse response, and the composite waveforms at each site. Following Widess' example, I created synthetic radargrams using actual radar wavelets from field data. Using the sample rate of the Radan Roadway Software of 39 nanoseconds/sample, the use of actual radar wavelets recorded from each site, and the pavement velocities of nearly $1 / 3$ the speed of light within the pavement, thin bed criterion could be established for each site. Thus, the results from this thin bed analysis program show that the minimum thickness one needs to distinguish a pavement layer from the GPR trace is approximately seven centimeters or $2 \frac{1}{2}$ inches as shown from Figure 4 to 6 . 
Actual GPR Wavelet within Pavement for Lac La Belle GPR TRACE
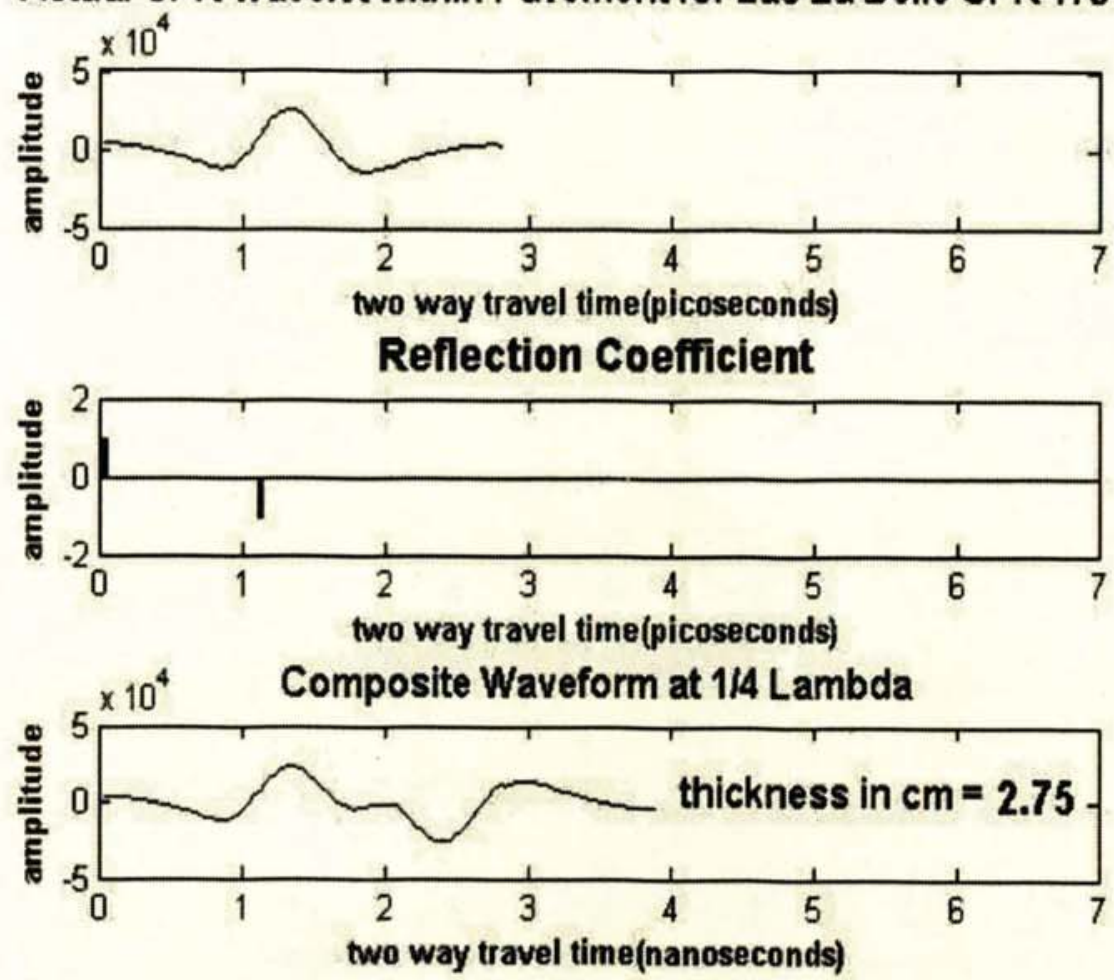

Figure 4: Composite Wavelet Chart showing the minimum distance where two waveforms are completely separated in time for the Lac La Belle site 

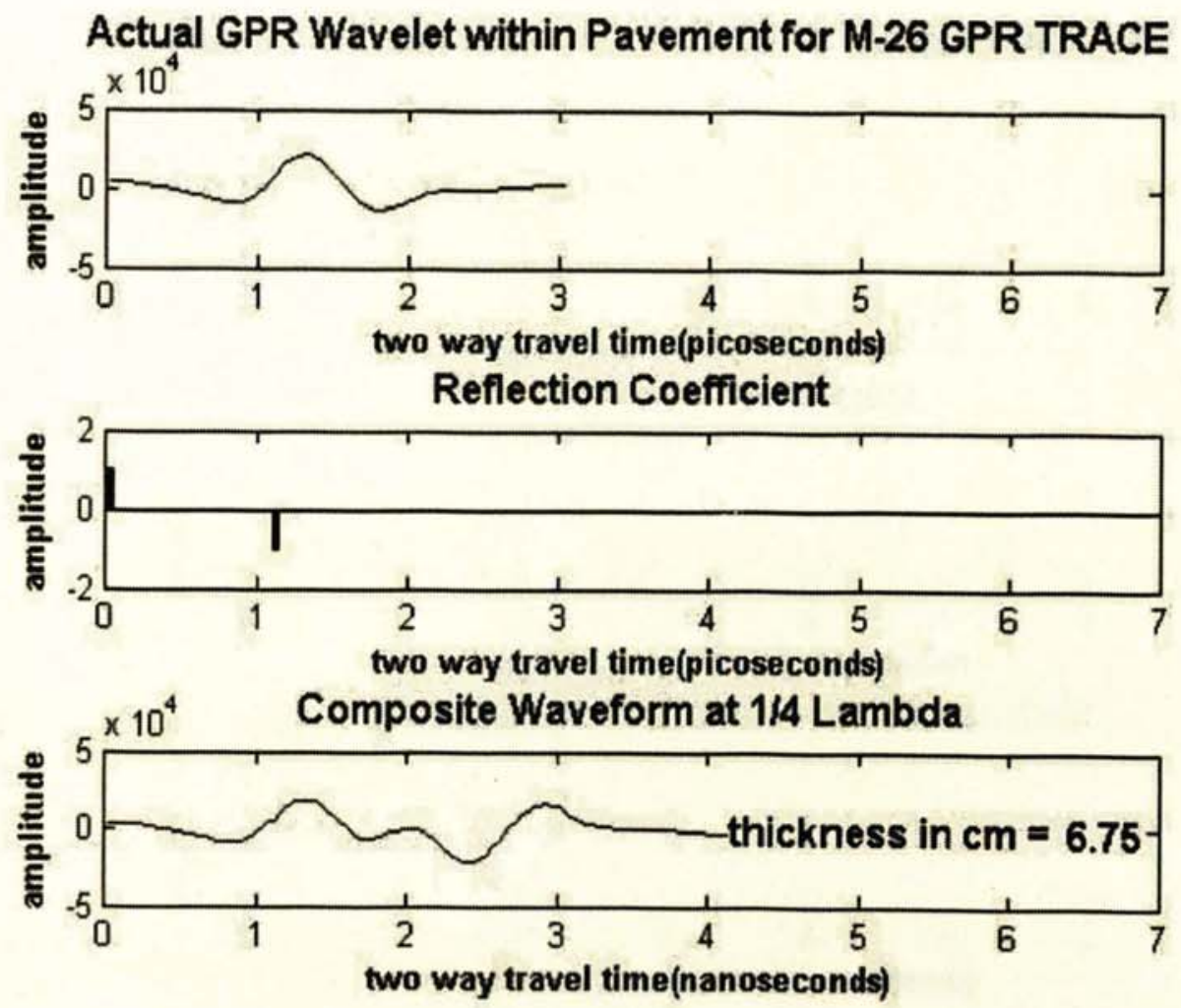

Figure 5: Composite Wavelet Chart showing the minimum distance where two waveforms are completely separated for the M-26/Twin Lakes site 


\section{Actual GPR Wavelet within Pavement for Lac La Belle GPR TRACE}
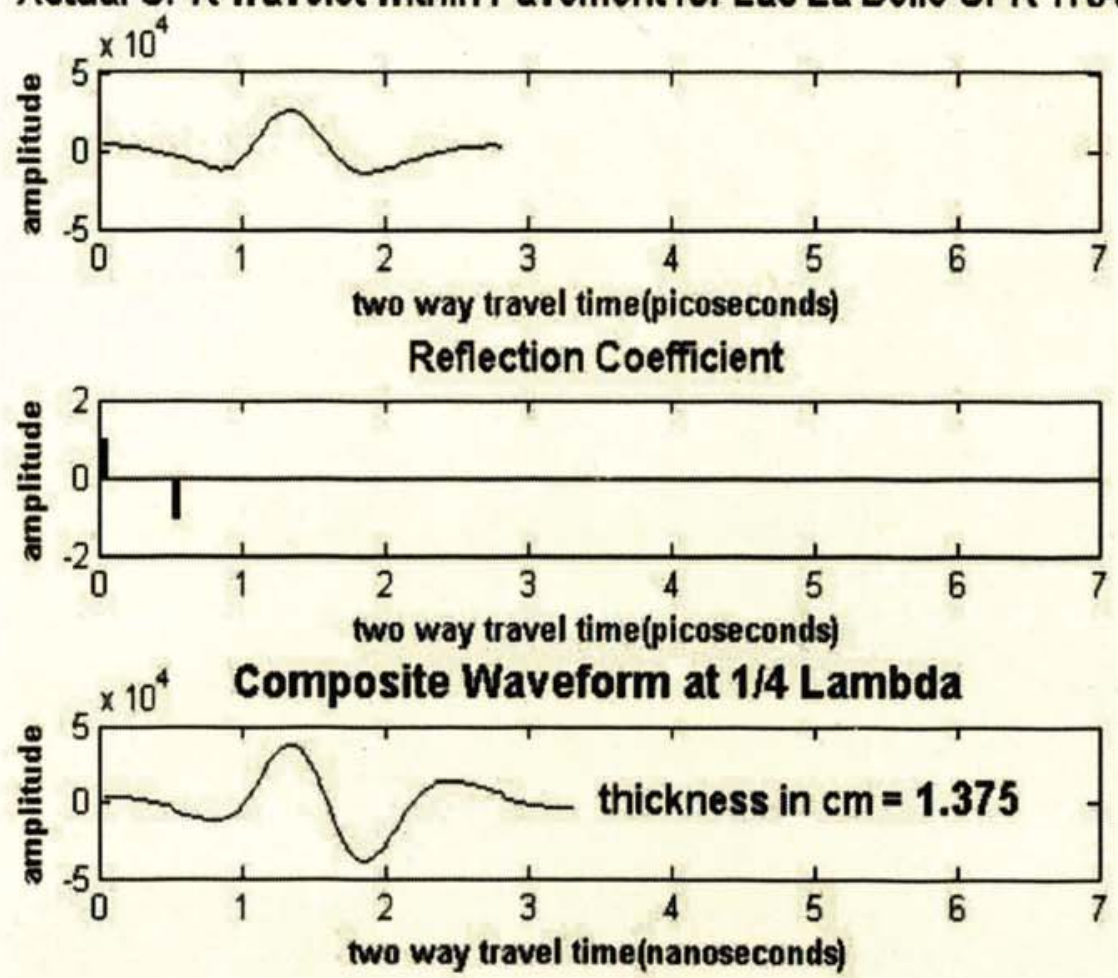

Figure 6: Composite Wavelet Chart encompassing the entire upper and lower pavement interfaces for greater resolution at the Lac La Belle site.

Thus, the M-26 and the Lac La Belle Road sites would marginally qualify as sites that may have thin bed considerations due to their thickness measurement being less than $\lambda / 8$ or $\frac{\lambda=c / 1 * 10^{9}}{8}=3.75 \mathrm{~cm}$. Also the fact the reflections from the top and bottom of the layer are beginning to merge indicates that the bed is "very thin". To overcome this problem the steps taken in the analysis section as suggested in the Widess (1975) study the entire bed encompassing both upper and lower interfaces may have to be considered together in order to greatly increase the resolving power for the GPR trace. 